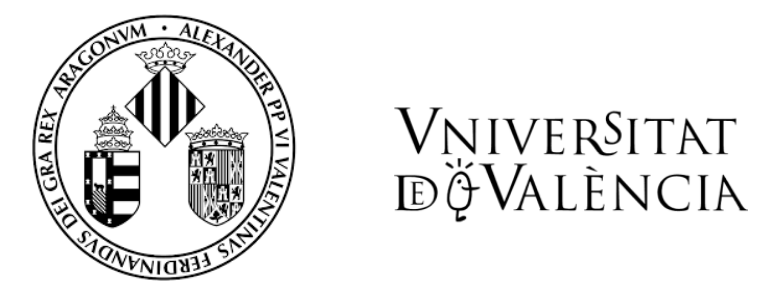

\title{
El Documento de Voluntades Anticipadas. \\ Comparativa de la legislación actual en el marco de la Unión Europea
}

\author{
Tesis Doctoral
}

María Elena Porcar Rodado

Licenciada en Medicina y Cirugía. Especialista en Medicina Intensiva

Directora y tutora: Dra. Marina Gisbert Grifo

Departament de Medicina Preventiva i Salut Pública, Ciències de 1'Alimentació, Toxicologia i Medicina Legal. Programa: Medicina Legal i Salut Pública

Facultat de Medicina i Odontologia

Universitat de València 



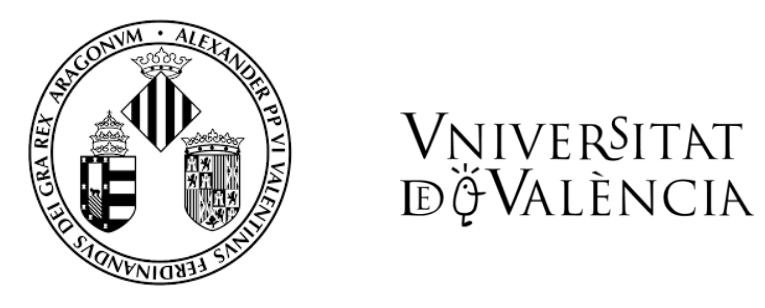

\title{
El Documento de Voluntades Anticipadas. \\ Comparativa de la legislación actual en el marco de la Unión Europea
}

\author{
Tesis Doctoral
}

María Elena Porcar Rodado

Licenciada en Medicina y Cirugía. Especialista en Medicina Intensiva

Directora y tutora: Dra. Marina Gisbert Grifo

Departament de Medicina Preventiva i Salut Pública, Ciències de 1'Alimentació, Toxicologia i Medicina Legal. Programa: Medicina Legal i Salut Pública

Facultat de Medicina i Odontologia

Universitat de València 
Departament de Medicina Preventiva i Salut Pública, Ciències de 1'Alimentació, Toxicologia i Medicina Legal. Facultat de Medicina i Odontologia.

Universitat de València

Programa: Medicina Legal i Salut Pública

El Documento de Voluntades Anticipadas. Comparativa de la legislación actual en el marco de la Unión Europea

María Elena Porcar Rodado

Licenciada en Medicina y Cirugía. Especialista en Medicina Intensiva

Directora y tutora:

Dra. Marina Gisbert Grifo 


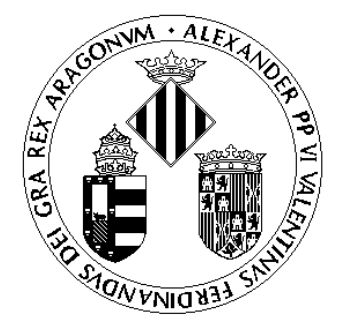

Unitat docent de Medicina Legal

Facultat de Medicina i Odontologia

Av. Blasco Ibañez 13, 46010 València

963864165

VNIVERSITAT Q̈̈ IN VLĖNCIA

Marina S. Gisbert Grifo, Profesora Titular de Medicina Legal de la Facultat de Medicina i Odontologia de la Universitat de València

CERTIFICA que la presente Tesis Doctoral titulada: "EI Documento de Voluntades Anticipadas. Comparativa de la legislación actual en el marco de la Unión Europea" ha sido realizada bajo mi dirección por Dña. Maria Elena Porcar Rodado y en ella se reflejan fielmente los datos y resultados obtenidos.

Una vez redactada, ha sido revisada y la encuentro conforme para que sea presentada ante la Comisión que se designe para aspirar al título de Doctor, autorizando por ello su defensa.

Y para que así conste, en cumplimiento de las disposiciones vigentes, extiendo el presente certificado en Valencia a 15 de junio de dos mil quince.

Fdo.: M. Gisbert 

A mis padres y a mi hermano, a mis hijas Marina y Làia, y por supuesto, a David. 



\section{Agradecimientos}

A mi directora y amiga, Marina Gisbert, porque sin ella este trabajo no estaría finalizado. Por ser sincera y por no aceptar mi juicio cuando estuve dispuesta a no continuar. Por saber encontrar la palabra justa y por hacerlo en el momento adecuado. Por la disposición y la disponibilidad. Y por tantos momentos.

A David, mi marido y compañero. Has sido el motor. Gracias por no dejar que cediera. Gracias por creer que esto es bueno para los dos. Gracias por las ideas, el entusiasmo por el trabajo y la dedicación. Gracias por llegar hasta donde yo no podía cuando intentaba llevar adelante este trabajo. Gracias.

A Manuel y Teo, mis padres, por enseñarme que el trabajo y la dedicación son el camino. Si estoy aquí es porque ellos lo han hecho posible. Gracias por traerme hasta aquí.

A Joan, mi hermano, por no dudar nunca de que esto "estaba hecho", o al menos de que lo haría.

A Marina y Làia, mis hijas. No entendieron muy bien qué hacia su mamá, pero sabían que era importante. Gracias por vuestro cariño y ternura.

A mis compañeros por su paciencia, y a mis amigas y amigos, y a Flori también, por sus palabras y gestos, que han supuesto un gran apoyo en este proceso. Gracias a todos. 



\section{Resumen}

Con la publicación de la Ley 41/2002, de 14 de noviembre, básica reguladora de la autonomía del paciente y de derechos y obligaciones en materia de información y documentación clínica, se da valor legal vinculante a las Voluntades Anticipadas en España.

Mediante la recogida y estudio de la legislación en materia de derechos del paciente en los distintos países de la Unión Europea, se establece una comparativa actualizada de las distintas características que la legislación de cada país otorga a las Voluntades Anticipadas, en caso de que exista.

De los 28 países que forman parte de la Unión Europea, solo 15 han desarrollado legislación específica en materia de Voluntades Anticipadas, y le otorgan carácter vinculante el $86 \%$ si se utiliza la formulación escrita. Solo 7 países exigen formalización del Documento de Voluntades Anticipadas ante notario, testigos o ante representantes de la Administración. La designación de representante en materia de salud se contempla en 11 de los países, aunque 6 legislaciones solicitan su designación en un documento específico. Solo en 3 países se prevé la existencia de un registro de Voluntades Anticipadas, mientras que en otros se promueve su inclusión en la historia clínica del paciente. Solo en 5 países se exige la revisión periódica del Documento, que pierde validez pasado este periodo de vigencia. Todas las legislaciones prevén modificaciones y la revocación de las Voluntades Anticipadas, mientras que prohiben el seguimiento de actuaciones que van en contra de la ley. El contenido de las Voluntades Anticipadas suele ser de rechazo a medidas de soporte y limitación de tratamiento, aunque las solicitudes de tratamiento específico se contemplan como orientativas.

La legislación sobre Voluntades Anticipadas existente en los países de la Unión Europea es muy diversa, con múltiples connotaciones específicas en cada país. Sería deseable una legislación más homogénea, divulgada y aplicada de acuerdo a la sociedad actual. 



\section{Resum}

Amb la publicació de la Llei 41/2002, de 14 de novembre, bàsica reguladora de l'autonomia del pacient i de drets i obligacions en matèria d'informació i documentació clínica, es dóna valor legal vinculant a les Voluntats Anticipades a Espanya.

Mitjançant la recollida i l'estudi de la legislació en matèria de drets del pacient en els diferents països de la Unió Europea, s'estableix una comparativa actualitzada de les diferents característiques que la legislació de cada país atorga a les Voluntats Anticipades, en cas que existeixi.

Dels 28 països que formen part de la Unió Europea, només 15 han desenvolupat legislació específica en matèria de Voluntats Anticipades, i li atorguen caràcter vinculant el $86 \%$ si s'utilitza la formulació escrita. Només 7 països exigeixen formalització del Document de Voluntats Anticipades davant de notari, testimonis o davant de representants de l'Administració. La designació de representant en matèria de salut es contempla en 11 dels països, encara que 6 legislacions sol-liciten la seva designació en un document específic. Només en 3 països es preveu l'existència d'un registre de Voluntats Anticipades, mentre que en altres es promou la seva inclusió en la història clínica del pacient. Només en 5 països s'exigeix la revisió periòdica del Document, que perd validesa passat aquest període de vigència. Totes les legislacions preveuen modificacions i la revocació de les Voluntats Anticipades, mentre que prohibeixen el seguiment d'actuacions que son contràries a la llei. El contingut de les Voluntats Anticipades sol ser de rebuig a mesures de suport i limitació de tractament, tot i que les sol-licituds de tractament específic es contemplen com orientatives.

La legislació sobre Voluntats Anticipades existent en els països de la Unió Europea és molt diversa, amb múltiples connotacions específiques a cada país. Seria desitjable una legislació més homogènia, divulgada i aplicada d'acord a la societat actual. 



\begin{abstract}
Advance Directives have had legal value in Spain since the publication of Act 41/2002, of $14^{\text {th }}$ November, which regulates patient's autonomy rights and obligations concerning clinical information and records.
\end{abstract}

By collecting and studying the legislation on patients' rights in the European Union countries we have made an updated comparison of the different features that each country grants to Advance Directives.

Only 15 out of the 28 European Union Countries have developed specific rules about advance directives which makes them legally binding in the $86 \%$ of cases, with the condition that they be written. A formal Advance Directive signed before a notary, a civil officer or a witnesses, is required in only 7 countries. The designation of a patient's representative for health matters is regulated in 11 of the countries, although a document for this particular purpose is only required in 6 of them. An Advance Directives Register is contemplated in 3 countries, whilst its inclusion in the patient's clinical records is promoted in others. A regular revision of an Advance Directive document, necessary to maintain its validity, is required in five countries. All the them provide for amendments and revocation of Advance Directives, as they forbid actions against the law. Rejection of usually supportive measures and treatment limitation are the main content of Advance Directives, although specific treatment applications are seen as a guidance.

There seem to be considerable differences in the laws concerning Advance Directives among the European Union Countries. A more homogeneous legislation, publicised and applied within the wider social consensus, would be desirable. 



\section{Índice general}

\section{Introducción}

1.1. Introducción a las Voluntades Anticipadas 3

1.2. Los derechos del paciente 6

1.2.1. El modelo de beneficencia. Desde la antigua Grecia hasta nuestros días 6

1.2.2. El modelo de Autonomía 9

1.3. Principios generales de Bioética. El principio de Autonomía 11

1.3.1. Autonomía 14

1.3.2. No maleficencia 15

1.3.3. Beneficencia 15

1.3.4. Justicia 16

1.4. Las Voluntades Anticipadas 17

1.5. Las Voluntades Anticipadas en la historia reciente 22

1.6. Las Voluntades Anticipadas en Europa 25

1.7. Las Voluntades Anticipadas en España. Legislación actual 32

2. Objetivos y plan de trabajo 43

2.1. Objetivos 45

2.1.1. Objetivo principal 45

2.1.2. Objetivos secundarios 45

2.2. Plan de trabajo 46 
3. Material y método

3.1. Material 49

3.1.1. Normativa española en materia de Voluntades Anticipadas $\quad 49$

3.1.2. Normativa del Consejo de Europa en materia de derechos del paciente y Voluntades Anticipadas

3.1.3. Normativa del resto de países de la Unión Europea en materia de derechos del paciente y Voluntades Anticipadas

3.2. Método

3.2.1. Recogida de la legislación sobre Voluntades Anticipadas

y Documento de Voluntades Anticipadas vigente en el Estado español

3.2.2. Análisis y extracción de las principales características del

Documento de Voluntades Anticipadas e Instrucciones Previas según la legislación española 56

3.2.3. Tabla comparativa 58

3.2.4. Legislación europea 60

3.2.5. Análisis 60

\section{Resultados}

4.1. El Convenio de Oviedo

4.2. Legislación específica sobre Voluntades Anticipadas

4.3. Legislación vinculante 68

4.4. Formulación escrita 68

4.5. Formalización 69

4.6. Designación de representante 71

4.7. El registro de Voluntades Anticipadas 72

4.8. Acceso al Documento de Voluntades Anticipadas 72

4.9. Revisiones periódicas 
4.10. Modificaciones de las Voluntades Anticipadas 74

4.11. Revocación de las Voluntades Anticipadas $\quad 74$

4.12. Características del contenido 75

5. Discusión 95

5.1. El Convenio de Oviedo. Legislación en materia de Voluntades Anticipadas 98

5.2. Legislación vinculante 104

5.3. Formato escrito. Validez de las Voluntades Anticipadas

expresadas de forma oral 106

5.4. Formalización 107

5.5. Designación de representante 110

5.6. El registro de Voluntades Anticipadas y el acceso al Documento de Voluntades Anticipadas 117

5.7. Revisiones periódicas del Documento de Voluntades Anticipadas 120

5.8. Modificaciones y revocación del Documento de Voluntades

Anticipadas 121

5.9. El contenido de las Voluntades Anticipadas 123

5.10. Países sin legislación en materia de Voluntades Anticipadas 126

5.11. Consideraciones prácticas 127

5.12. Consideraciones finales 130

6. Conclusiones 133

6.1. Conclusiones 135

6.2. Puntos de reflexión y mejora de la legislación vigente 136

7. Referencias bibliográficas 139 
A. Ley 41/2002, de 14 de noviembre, básica reguladora de la autonomía del paciente y de derechos y obligaciones en materia de información y documentación clínica

B. Convenio de Oviedo. Convention for the Protection of Human

Rights and Dignity of the Human Being with regard to the Application of Biology and Medicine: Convention on Human Rights and Biomedicine

C. Recommendation CM/Rec(2009)11 of the Committee of Ministers to member states on principles concerning continuing powers of attorney and advance directives for incapacity

D. Resolution 1859 (2012). Council of Europe. Protecting human rights and dignity by taking into account previously expressed wishes of patients

E. Recommendation 1993 (2012). Council of Europe. Protecting human rights and dignity by taking into account previously expressed wishes of patients 


\section{Nomenclatura}

\begin{tabular}{ll} 
ADMÓN: & Administración \\
BOA: & Boletín Oficial de Aragón \\
BOC: & Boletín Oficial de Canarias \\
BOC: & Boletín Oficial de Cantabria \\
BOCM: & Boletín Oficial de la Comunidad de Madrid \\
BOCyL: & Boletín Oficial de Castilla y León \\
BOE: & Boletín Oficial del Estado \\
BOIB: & Boletín Oficial de las Islas Baleares \\
BOJA: & Boletín Oficial de la Junta de Andalucía \\
BON: & Boletín Oficial de Navarra \\
BOPV: & Boletín Oficial del País Vasco \\
BOR: & Boletín Oficial de La Rioja \\
DOCM: & Boletín Oficial de la Comunidad de Madrid \\
DOCV: & Diario Oficial de la Comunidad Valenciana \\
DOE: & Diario Oficial de Extremadura \\
DOGC: & Diario Oficial de la Generalitat Catalana \\
CCAA: & Comunidades Autónomas \\
CO: & Convenio de Oviedo \\
DVA: & Documento de Voluntades Anticipadas \\
HC: & Historia clínica \\
NUMS: & Números \\
\hline
\end{tabular}


TTO: $\quad$ Tratamiento

UE: Unión Europea

VA: Voluntades Anticipadas 


\section{Índice de figuras}

Figura 1. Representación de los países con legislación vinculante (números absolutos)

Figura 2. Representación de los países con legislación vinculante (porcentaje) 68

Figura 3. Número de países que solicitan formato escrito 69

Figura 4. Modo de formalización 70

Figura 5. Designación de representante 71

Figura 6. Países con registro de DVA 72

Figura 7. Características de contenido 76 



\section{Índice de tablas}

Tabla 1. Leyes que regulan las VA en las CCAA 36

Tabla 2. Características de las VA y el DVA según la legislación española $\quad 59$

Tabla 3. Países de la UE y ratificación del Convenio de Oviedo 63

Tabla 4. Países con legislación específica sobre VA 64

Tabla 5. Países con legislación específica en VA, año de publicación y año de ratificación del $\mathrm{CO} \quad 65$

Tabla 6. Países sin legislación específica en VA firmantes del CO 66

Tabla 7. Países de la UE, años de publicación de legislación específica de VA y ratificación del CO 67

Tabla 8. Distribución según las necesidades de revisión del DVA 74

Tabla 9. Características de las VA y DVA en Alemania 79

Tabla 10. Características de las VA y DVA en Austria 80

Tabla 11. Características de las VA y DVA en Bélgica 81

Tabla 12. Características de las VA y DVA en Dinamarca 82

Tabla 13. Características de las VA y DVA en Eslovenia 83

Tabla 14. Características de las VA y DVA en España 84

Tabla 15. Características de las VA y DVA en Estonia 85

Tabla 16. Características de las VA y DVA en Finlandia 86

Tabla 17. Características de las VA y DVA en Francia 87

Tabla 18. Características de las VA y DVA en Hungría 88

Tabla 19. Características de las VA y DVA en Letonia 89 
Tabla 20. Características de las VA y DVA en Luxemburgo 90

Tabla 21. Características de las VA y DVA en Países Bajos 91

Tabla 22. Características de las VA y DVA en Portugal 92

Tabla 23. Características de las VA y DVA en Reino Unido 93 
Capítulo 1

Introducción 



\subsection{Introducción a las Voluntades Anticipadas.}

Durante siglos la práctica habitual de la Medicina se ha basado en la idea de que, contra la enfermedad y la muerte todo valía y que por ello, se debía hacer todo lo posible para mantener al enfermo con vida. Esto justificaba que las actuaciones médicas se centraran únicamente en luchar contra la enfermedad y con este fin, cualquier actuación estaba legitimada. Era hasta cierto punto bien visto y bien entendido que se ocultara información al paciente, e incluso se le administraran tratamientos en contra de su voluntad, puesto que se aceptaba que, asociada a la enfermedad física, existía una merma en la capacidad moral, lo que ponía al paciente en una situación de incompetencia, de indefensión y sin libertad de decisión, sometido al paternalismo médico ${ }^{1}$.

La relación entre médico y enfermo se ha modificado a lo largo de la historia, pero es en el último tercio del siglo XX cuando se han producido los cambios más importantes. Tanto es así que muchos autores, entre ellos Diego Gracia, afirman que "la relación entre el médico y sus pacientes se ha modificado más en el último tercio del siglo XX que en los 20 siglos anteriores"2.

Esta relación, marcada principalmente por el paternalismo absoluto en favor del principio de beneficencia, ha dado paso a un modelo de relación en el que el principio de autonomía marca la pauta a seguir, un principio que se ha de garantizar en todo momento, puesto que es el paciente el que tiene la potestad para tomar las decisiones oportunas sobre su situación de salud o enfermedad y sobre aquellas intervenciones o tratamientos que desea o no recibir.

En paralelo al avance sociocultural se ha producido un desarrollo técnico y tecnológico que ha favorecido, junto con diversos factores, el aumento de la 
esperanza de vida, lo que a su vez motiva que sean no pocas las personas que tengan que enfrentarse a situaciones de enfermedad (tanto aguda como crónica), que en determinados momentos va a limitar su autonomía o, al menos, su estado de enfermedad va a interferir lo suficiente como para que no puedan comunicarse y así poder expresar su voluntad. Son estas situaciones las que pretende cubrir, de alguna manera, el Documento de Voluntades Anticipadas.

Este documento trata de recoger de forma explícita la voluntad del paciente en relación a medidas de soporte y/o tratamiento sobre las que consiente o no, llegada la situación en que no pudiera expresarse. También permite designar un representante que, en el caso de no existir indicaciones claras y ajustadas a la situación real, sería el encargado de trasladar la opinión del paciente sobre los problemas que se planteen.

En la línea de lo expresado por Diego Gracia $^{2}$ son destacables distintas iniciativas a nivel internacional que tratan de poner en valor la autonomía del paciente y que se han venido produciendo en los últimos 60 años. La más importante en el entorno europeo surge a finales de los años 90, del Consejo de Europa, con la apertura a la firma, en Oviedo, del Convenio para la Protección de los Derechos Humanos y la Dignidad del Ser Humano en relación a la Aplicación de la Biología y la Medicina: Convenio de los Derechos Humanos y Biomedicina $^{3}$, (de ahora en adelante denominado Convenio de Oviedo, como es popularmente conocido) que supone el primer marco jurídicamente vinculante para el reconocimiento de la autonomía del paciente y, de forma especial, de las Voluntades Anticipadas.

El desarrollo normativo que han sufrido las Voluntades Anticipadas en los distintos países de la Unión Europea presenta amplias diferencias tanto en su 
forma como en su contenido. Así pues, la existencia de un marco legislativo común amparado por el Consejo de Europa, no ha supuesto un obstáculo para que cada país se comporte de forma diferente frente a este concepto. Estas diferencias normativas pueden obedecer a diferentes factores destacando probablemente los culturales y religiosos ${ }^{4}$, entre otros.

Es esta variabilidad la que genera una situación heterogénea difícil de plasmar. La presente Tesis Doctoral tratará de establecer una visión, ajustada a la realidad y actualizada, de la situación que viven las Voluntades Anticipadas y la normativa legal existente, en el entorno geográfico y social de la Unión Europea.

Pero antes debemos situar las Voluntades Anticipadas en su contexto (histórico, social y normativo), lo que obliga a un barrido histórico que ha de ser necesariamente breve y a destacar ciertos hechos que conducen a la situación actual. Todo esto lo vamos a hacer a través de los siguientes apartados:

- Los derechos del paciente.

- Principios generales de Bioética. El principio de Autonomía.

- El Documento de Voluntades Anticipadas.

- El Documento de Voluntades Anticipadas en la historia reciente.

- Las Voluntades Anticipadas en Europa.

- Las Voluntades Anticipadas en España. Legislación actual. 


\subsection{Los derechos del paciente.}

La naturaleza de la relación médico-paciente y la práctica médica, desde la medicina hipócratica hasta el siglo XIX, se basan en un modelo ético estable cuyo principio fundamental ha sido la beneficencia. Los cambios sociales sobrevenidos en el último siglo pueden valorarse de forma destacada en el cambio de la tradición médica, ya que se da paso a un modelo en el cual debe predominar el respeto a la autonomía del paciente. De esta forma el derecho a la autodeterminación del paciente, informada y razonada, pasa en poco tiempo de no tener valor a ser legalmente reconocida.

\subsubsection{El modelo de Beneficencia. Desde la antigua Grecia hasta nuestros días.}

La relación-médico paciente basada en el principio de beneficencia podemos encontrarla ya en textos de tradición hipocrática. El propio juramento hipocrático en sus primeras versiones aboga por intervenciones (dietéticas) en beneficio del paciente, siguiendo el criterio del propio médico ${ }^{5}$. De la misma manera, el juramento hipocrático en su forma clásica hace referencia a la clase médica como un grupo de individuos de conocimiento elevado con entrenamiento especializado, determinados a mantener su práctica dentro de un conjunto seleccionado, obligados por el propio juramento a instruir solo a aquellos que hayan adoptado la ley médica ${ }^{1,6}$.

Por otra parte, el lenguaje y los términos que utiliza el juramento hipocrático hacen pensar que el médico tiene un conocimiento superior que le otorga la capacidad de diagnosticar y tratar la enfermedad de otros, evitando provocar 
daños, eliminando el mal y promoviendo el bien. Según estas premisas establecidas en el juramento, el médico está obligado, según su criterio personal, a promover el beneficio de otros. Así históricamente la profesión médica ha actuado en base a su propio juicio, de la forma que ha creído más oportuna y más beneficiosa para sus pacientes, con independencia de la opinión del enfermo, que según la misma tradición hipocrática debía ponerse en manos de los médicos y obedecer a sus dictados, sin plantear dudas?

Podemos encontrar con frecuencia en la bibliografía, referencias a como los códigos éticos clásicos de la profesión médica son muy similares a manuales de etiqueta $^{8}$, en los que se instruye a los profesionales médicos en formas y maneras de comportamiento, así como también en el lenguaje que deben utilizar y como realizar ejercicio de autoridad sobre los pacientes que a su vez, según estos códigos, deben ser obedientes. Dados los escasos resultados de los tratamientos aplicables en épocas anteriores, era de máxima importancia la percepción que el paciente tenía del profesional, ya que era esta la que hacía crecer el respeto y la reputación del profesional ${ }^{7}$.

En la concepción clásica la confianza del paciente era tan importante que se animaba a sostener lo que actualmente denominamos paternalismo médico. Dado que el paciente, por el mero hecho de estar enfermo, no tiene capacidad para tomar decisiones complejas, ha de confiar en que será el médico el que con su sabiduría y rectitud elegirá el mejor tratamiento posible ${ }^{9}$. Se entendía que había que evitar cualquier información que pudiera impactar de forma negativa en el paciente, hasta el punto de mentir si era considerado necesario ${ }^{7}$.

Este modelo se mantiene prácticamente estable hasta la Ilustración, pero con la llegada del siglo XVIII y el creciente interés por la razón humana y el progreso, se abrirán nuevas corrientes de discusión. 
Surgirán autores que valorarán de forma diferente la relación entre médico y paciente ${ }^{7}$, como John Gregory y Benjamin Rush, maestro y pupilo, claramente influenciados por los filósofos de la época. Son, probablemente, los máximos exponentes de esta nueva línea de médicos ilustrados que abogan por la verdad en la relación con los pacientes, aunque no buscando la autonomía del enfermo sino ahondando en la beneficencia. Pensaban que aumentando el conocimiento de su situación, el paciente "ilustrado" mejoraría de su enfermedad. Pero a pesar de todo ello, seguían manteniendo que los pacientes debían someterse a la autoridad inflexible del médico, el cual mostrando su sabiduría lograría mejorar el pronóstico del paciente ${ }^{7}$, y en ningún momento plantean la opción de solicitar siquiera la opinión del propio paciente.

No obstante, este modelo sería ampliamente superado por el propuesto por un coetáneo suyo, el médico británico Thomas Percival que, posicionado lejos de las ideas de sus compañeros, defendió la etiqueta médica y el comportamiento caballeroso, cuestionando la capacidad del paciente para razonar y entender la situación ${ }^{6}$ y estimando que el médico podía ofrecer su criterio mas allá de lo estrictamente médico. Abogó por la beneficencia afirmando que "un médico no miente si el objetivo es dar esperanza"7.

De esta manera es como la tradición hipocrática sobrevive hasta bien entrado el siglo XX. Se produce en este punto una evolución diferente en el viejo y en el nuevo continente. Mientras en Europa el modelo paternalista pervive con más facilidad, en Estados Unidos se inicia un cambio progresivo. A pesar de todo, el avance de la Medicina y su complejidad creciente hacen que la población general siga dependiendo de la clase médica que, ahora sí, va a estar mejor formada y más especializada, gracias principalmente al nacimiento y proliferación de las escuelas y facultades de Medicina, desde finales del siglo XIX. 


\subsubsection{El modelo de Autonomía.}

El verdadero cambio de modelo arranca con el siglo XX y son diversos los factores que lo favorecen. La creación de instituciones sanitarias favorece la profesionalización de la Medicina, apareciendo consultorios médicos donde es el paciente el que acude a ver al médico y no al revés, como se había venido produciendo durante siglos. Esta situación se ve favorecida a su vez por la aparición de nuevos medios de diagnóstico complementarios, que presentan abultado tamaño y transporte imposible, lo que obliga, en cierta forma, a que sea el paciente el que se desplace hasta la consulta del doctor. Como consecuencia el médico deja de visitar el domicilio de sus pacientes, lo que en la práctica supone una pérdida de intimidad en la relación.

El creciente avance tecnológico facilita el avance científico y una mejora de los resultados de las técnicas diagnóstico-terapeúticas. El acento se traslada desde la impresión subjetiva que tiene el paciente del profesional hacia la calidad científica, siendo el resultado un valor a exigir. Como consecuencia, el paciente se vuelve mas demandante, tanto de atención como de resultados, lo que generó en cierto modo la aparición de una escalada de demandas por mala praxis. Es en este momento cuando aparece el consentimiento informado, tal y como ha llegado hasta nuestro días.

Es cierto que existen casos de demandas contra profesionales por actuar sin consentimiento ya en el siglo XVIII. Un ejemplo conocido es el caso de Slater contra Baker y Stapleton, que data de 1767, donde se falló contra los cirujanos por fracturar un callo mal consolidado e implantar una prótesis, sin informar previamente al paciente ${ }^{10}$. Pero es en la segunda década del siglo XX cuando se produce el que será probablemente el mas famoso de los casos judiciales que 
invocan el consentimiento informado, el caso Schoendorff vs Society of New York Hospitals ${ }^{11}$ donde el Juez Cardozo pasó a la historia de los derechos de los pacientes al emitir, en 1914, el siguiente dictamen: "Todo ser humano de edad adulta y en su sano juicio tiene derecho a determinar lo que se hará con su propio cuerpo; y un cirujano que realiza una operación sin el consentimiento de su paciente comete un asalto del que es responsable de los daños. Esto es cierto, excepto en casos de emergencia en que el paciente está inconsciente y donde es necesario operar antes de poder obtener el consentimiento"12. A pesar de que esta sentencia da valor legal a la autodeterminación del paciente, habrá de pasar medio siglo más para que este concepto dé el salto al campo de la ética.

Otro hecho relevante se produce cuando se detectan prácticas como la experimentación con humanos llevada a cabo durante la Segunda Guerra Mundial por parte de Alemania y Estados Unidos de América. Surge la necesidad de luchar contra las atrocidades cometidas, y así nacen distintas actuaciones que darían lugar al Código de Nuremberg ${ }^{13}$ y a la Declaración de Helsinki ${ }^{14}$, iniciativas que recogen la necesidad de obtener el consentimiento voluntario del sujeto para participar en estudios humanos. Ante la evidente falta de control, inicialmente se abogó por la autorregulación del sector sanitario y científico, pero continuaron saliendo a la luz experimentos, como el de Tuskegee o los desvelados por Beecher ${ }^{15}$, donde la ausencia de consentimiento previo por parte del sujeto de estudio era la norma.

El conocimiento público de estos y otros casos hace que se inicie una aproximación al problema de la toma de decisiones desde otros puntos de vista y que, contextualizado por la lucha por lo derechos civiles, el derecho a la autodeterminación expresado como consentimiento informado inicie su andadura ${ }^{6}$. 


\subsection{Principios generales de la Bioética: El principio de} Autonomía.

A los cambios sociales sufridos a lo largo del siglo XX hay que sumar la aparición de una nueva disciplina hacia mediados de los años 70: la Bioética.

Es en 1974, y nuevamente en Estados Unidos de América, cuando nace la Bioética, término acuñado por el oncólogo holandés Van Rensselaer Potter en 1970, en su artículo titulado: "Bioethics, the science of survival"16. Este nuevo término se define según la "Encyclopedia of Bioethics" de 1995, como "el estudio sistemático de la conducta humana en el campo de las ciencias biológicas y la atención a la salud, en la medida en que esta conducta se examine a la luz de valores y principios morales" ${ }^{17}$, siendo estos principios y valores válidos para todos los individuos, buscando el respeto a la persona.

En ese mismo año, 1974, se crea la Comisión Nacional para la Protección de los Sujetos Humanos de Investigación Biomédica y del Comportamiento, con el fin de tratar de identificar los principios básicos aplicables en caso de investigación con humanos, en cualquiera de sus formas. Esta comisión culminaría su experiencia en 1978 con la redacción del "Informe Belmont" y su posterior publicación, en 1979. En este informe se establecen por primera vez los principios éticos básicos:

“...se refiere a aquellos juicios generales que sirven como justificación básica para las muchas prescripciones y evaluaciones éticas particulares de las acciones humanas. Tres principios básicos, entre los generalmente aceptados en nuestra tradición cultural, son particularmente relevantes para 
la ética de la investigación con humanos; ellos son: respeto por las personas, beneficio y justicia"18.

A pesar de que el Informe Belmont hace referencia únicamente a la experimentación clínica con humanos, en la exposición que se hace de los tres principios éticos existen connotaciones que, por su trascendencia en relación a las Voluntades Anticipadas, son merecedoras de ser destacadas en este punto:

\section{- RESPETO POR LAS PERSONAS.}

Este respeto incorpora, al menos, dos convicciones éticas; la primera: que los individuos deben ser tratados como agentes autónomos; la segunda: que las personas con autonomía disminuida tienen derecho a protección. El principio del respeto por las personas se divide entonces en dos requerimientos morales separados: el de reconocer la autonomía y el de proteger a quienes la tienen disminuida.

\section{- BENEFICENCIA.}

Las personas son tratadas éticamente no sólo respetando sus condiciones y protegiéndolas de daño, sino también haciendo esfuerzos para asegurar su bienestar. Tal tratamiento cae bajo el principio de "beneficencia" (...). Se han formulado dos reglas generales como expresiones complementarias de acciones de beneficencia en este sentido: no hacer daño y aumentar los beneficios y disminuir los posibles daños lo más que sea posible. 
- JUSTICIA.

¿Quién debiera recibir los beneficios de la investigación y quién soportar sus cargas? Esto es una cuestión de justicia en el sentido de "equidad en la distribución" o "lo que se merece". (...). Otra manera de concebir el principio de justicia es que los iguales deben ser igualmente tratados. (...) Hay varias formulaciones ampliamente aceptadas de formas justas para distribuir las cargas y los beneficios. Cada formulación menciona alguna propiedad relevante sobre cuya base se debieran distribuir las cargas y los beneficios. Estas formulaciones son:

- a cada persona una porción igual

- a cada persona de acuerdo a su necesidad individual

- a cada persona de acuerdo al esfuerzo individual

- a cada persona de acuerdo a su contribución a la sociedad

- a cada persona de acuerdo al mérito.

Durante el desarrollo del Informe Belmont se establecen unas aplicaciones de los principios generales anteriormente relacionados que se estiman requerimientos para el desarrollo de la investigación y son:

a. Consentimiento informado, que a su vez contiene tres elementos: información, comprensión y voluntariedad.

b. Valoración de riesgos y beneficios.

c. Selección de los sujetos: "del mismo modo que el principio del respeto por las personas se expresa en la exigencia del consentimiento $\mathrm{y}$ el principio de beneficencia en la valoración de riesgos $\mathrm{y}$ beneficios, el principio de justicia da lugar a la exigencia moral de que hay procedimientos y resultados justos en la selección de los sujetos de investigación" 
Pero como ya se ha referido anteriormente, el Informe Belmont solo hace referencia a las cuestiones éticas que se pueden derivar del desarrollo de trabajos de investigación con sujetos humanos, a pesar de lo cual, es destacable la valoración que hace del principio de autonomía en forma de "respeto por las personas", que sin estar identificado como el principio más importante, si se encuentra situado en primer lugar.

Prácticamente a la vez que el Informe Belmont se publica el libro Principles of Biomedical Ethics, cuyos autores, Tom L. Beauchamp y James F. Childress, son considerados los padres de la "ética principialista". Estos autores, ya desde su primera edición, defienden la existencia de cuatro principios fundamentales en los que se basa la ética médica actual: autonomía, no maleficencia, beneficencia y justicia. Beauchamp y Childress nos ofrecen una visión donde, si bien no existe jerarquización sobre los cuatro principios, si se considera que el principio de autonomía debe predominar sobre el resto, en la medida de lo posible ${ }^{19}$.

\subsubsection{Autonomía.}

Entendida como el "respeto a actuar libremente, según un plan autoescogido"20. Según los autores citados, una acción es autónoma si se lleva a cabo de forma intencionada, comprendida y sin otras influencias. Así, ofrecen unas directrices para tratar de forma autónoma a las personas:

- Decir la verdad.

- Respetar la privacidad.

- Preservar la confidencialidad.

- Solicitar consentimiento para las intervenciones.

- Si se solicita, prestar ayuda para la toma de decisiones. 


\subsubsection{No maleficencia.}

Entendida como la "obligación de no hacer daño", de no lesionar los intereses de la persona, de no generar daño ni dolor, discapacidad ni muerte ${ }^{20}$. Podemos encontrar corrientes de pensamiento que estiman qué la beneficencia y la no maleficencia son el mismo principio. Según Beauchamp y Childress la obligación de no hacer daño es totalmente diferente de la obligación de ayudar o promover bienestar. Las premisas referidas al principio de no maleficiencia son:

- No matar.

- No causar dolor mi sufrimiento.

- No causar discapacidad.

- No ofender.

- No privar a otros de lo que aprecian en la vida.

\subsubsection{Beneficencia.}

La beneficencia consiste en actuar buscando el bien y en prevenir y eliminar el daño. Frente a la inacción de la no-maleficencia, la beneficencia implica actuación. Según Beauchamp y Childress, existe la beneficencia positiva, que implica la obtención de beneficios y la utilidad y que refleja el balance entre beneficios y daños. Por eso, antes de aplicar una actuación o tratamiento sobre un paciente, se requiere valorar o aplicar las siguientes premisas:

- Proteger y defender los derechos de los demás.

- Evitar condiciones que produzcan daños a los demás.

- Ayudar a las personas con discapacidad.

- Rescatar a las personas en peligro. 


\subsubsection{Justicia.}

Es el tratamiento equitativo y apropiado, a la luz de lo qué es debido a una persona, y una distribución equitativa de las cargas, según el esquema referido anteriormente en el Informe Belmont. Así según este principio la sociedad tiene la obligación de proteger la igualdad de oportunidades de todos sus miembros ${ }^{21}$ y facilitarles el acceso a los cuidados de la salud.

Así es como los principios de la Bioética han llegado a nuestros días. Con escasos cambios formales pero si con muchas teorías de reformulación y propuestas de utilización en caso de conflicto. Beauchamp y Childress adoptan la nomenclatura propuesta inicialmente por David Ross y establecen que los principios son muy generales (su campo de aplicación es muy amplio y su contenido muy abstracto), prima facie vinculantes (vinculan siempre a menos que otra obligación moral concurrente tenga más peso en las circunstancias particulares del caso) e independientes (ningún principio está contenido en otro $)^{22}$. Es por esto que en casos determinados y particulares los principios pueden entrar en conflicto y alterar su relación.

Mas cerca, Diego Gracia considera que los cuatro principios no tienen el mismo rango, por tener distinta fundamentación ${ }^{23,24}$. La no-maleficencia y la justicia se diferencian de la autonomía y de la beneficencia en que obligan con independencia de la opinión y voluntad de las personas pero, tal diferencia no es jerárquica sino que es procedimental, lo que significa que tienen igual fuerza normativa, y que solo tienen diferente rango cuando los principios entran en conflicto. 
Todo ello permite plantear la existencia de una "ética de mínimos" (principios de no maleficencia y justicia), que además representan los principios de carácter público y una "ética de máximos" (principios de autonomía y beneficencia), que son los principios de carácter privado ${ }^{22}$. Así, en caso de entrar en conflicto, Gracia propone la deliberación moral como procedimiento para el análisis de la situación y determinación de que principio debe prevalecer en función de la situación particular a la que nos estamos enfrentando ${ }^{24}$. Esta deliberación es la que nos llevara a determinar los posibles cursos de acción.

El avance de la Bioética tiene sus paralelismos en el Derecho. Es también a partir del último cuarto del siglo XX cuando se empieza a legislar a favor de la autonomía del paciente como derecho fundamental.

\subsection{Las Voluntades Anticipadas.}

En la actualidad existe en la práctica clínica amplio consenso en que debe prevalecer el respeto por la autonomía del individuo y que los profesionales médicos deben trasladar la decisión última al paciente. En principio esto no debe suponer ningún problema en circunstancias normales y lleva consigo que, tras la exposición de los hechos, las ventajas, los inconvenientes y las alternativas, el paciente debe ser capaz de tomar una decisión sobre una intervención propuesta, en base a sus principios y forma de vida previa.

Pero, ¿qué ocurre si el paciente no tiene capacidad para tomar esta decisión? En estas circunstancias podríamos encontrarnos en dos escenarios claramente diferenciados. Por una parte, el paciente que no ha sido capaz anteriormente, como sería el caso de los niños o de personas que se desarrollan con un retraso 
cognitivo limitante y, por otra, el caso de aquellas personas que pierden dicha capacidad, bien sea de forma lenta y progresiva, o bien sea de forma brusca. La diferencia entre ambos escenarios es importante a la hora de tomar decisiones. En el primer caso, dado que no ha existido posibilidad de autonomía previa solo puede primar el principio de beneficencia, ya que debemos buscar el "mejor interés" para el sujeto. De esta forma debemos buscar objetivos generales, como la ausencia de dolor, el confort y la recuperación funcional de los aspectos físicos y psíquicos del paciente. En el segundo caso, nos encontraríamos ante una incapacidad sobrevenida, situación en la que deberíamos de tratar de reconstruir lo que el paciente hubiese querido para sí mismo, dando prioridad al principio de autonomía ${ }^{25}$.

Las Voluntades Anticipadas son en sí mismas la expresión máxima del principio de autonomía ${ }^{26}$. Constituyen una declaración mediante la cual una persona que tiene capacidad mental suficiente, expone de forma libre e informada las instrucciones que se deben tener en cuenta respecto a la atención sanitaria que desea recibir en caso de enfermedad y de no poder expresar su voluntad.

Ciertamente y según lo define la Ley 41/2002, de 14 de noviembre, básica reguladora de la autonomía del paciente y de derechos y obligaciones en materia de información y documentación clínica publicada en el BOE con fecha 15 de noviembre de $2002^{27}$ (Apéndice A), el Documento de Voluntades Anticipadas o Instrucciones Previas "es aquel en el que, una persona mayor de edad, capaz y libre, manifiesta anticipadamente su voluntad, con el objeto de que esta se cumpla en el momento en que llegue a situaciones en cuyas circunstancias no sea capaz de expresarla personalmente, sobre los cuidados y el tratamiento de su salud o, una vez llegado el fallecimiento, sobre el destino de su cuerpo o de los órganos del mismo. El otorgante del documento puede designar, además, un representante para que, llegado el caso, sirva como interlocutor suyo con el 
médico o el equipo sanitario para procurar el cumplimiento de las instrucciones" 27 .

De esta forma, el Documento de Voluntades Anticipadas, no solo recoge las disposiciones que una persona pueda hacer con respecto a su situación de enfermedad previendo no poder expresar su voluntad, sino que además permite designar un representante, que será el encargado de tomar decisiones en su nombre, de manifestar su voluntad y dar su consentimiento sobre posibles intervenciones o diferentes actitudes que se puedan tomar en relación a una supuesta situación de incapacidad sobrevenida; todo ello en base a los deseos expresados por el otorgante con anterioridad, respetando su voluntad, sus valores, su estilo de vida, tratando de hacer un juicio por sustitución, en la medida que sea posible. Las designación de representante es la parte mas novedosa y podría justificar en sí misma el documento ${ }^{28}$. El Documento de Voluntades Anticipadas también permite establecer el destino del cuerpo y de los órganos, tras el fallecimiento.

En los casos en los que la pérdida de capacidad se produce de forma progresiva, como sería el caso de las demencias, las Voluntades Anticipadas podrían suponer una guía de los cuidados personales que se desea recibir, lo cual puede facilitar la atención y el tratamiento. También pueden recoger límites o umbrales de tolerancia a ciertas situaciones por las que no se quiera pasar, así como la historia de valores personales y objetivos vitales que puedan servir como orientación y ayuden a interpretar la voluntad del otorgante ${ }^{29}$. En algunas legislaciones, como la finlandesa y en alguna de las emitidas por las Comunidades Autónomas españolas, se sugiere la inclusión de estilos de vida y gustos personales que, en caso de enfermedades de larga evolución, como sería la demencia, pueden ayudar a respetar el estilo y la forma de vida del enfermo. 
Si bien el Documento de Voluntades Anticipadas en su definición tiene implícito la existencia de un formato escrito, las Voluntades Anticipadas también podrían expresarse de forma oral, sin necesidad de estar recogidas en un documento físico determinado ${ }^{30}$. No obstante, esta formulación podría generar problemas en el momento de su aplicación ${ }^{1}$. Por ello se recomienda dejar constancia de alguna forma, por ejemplo, como anotación en la historia clínica del enfermo.

Por tanto, y teóricamente, bien sea por escrito o bien sea de forma oral, las Voluntades Anticipadas permiten un amplio abanico de posibilidades, ya que se puede solicitar la aplicación de todas las medidas de actuación posibles, poner ciertos límites a las mismas o rechazarlas totalmente ${ }^{31}$. Esta situación, en principio, es valorada de forma muy positiva por todos los sectores implicados, dado que facilita la toma de decisiones respetando el principio de autonomía y supone un canal de comunicación importante entre médico y paciente, ahondando en la mejora de esta relación ${ }^{31}$.

No obstante, también se han levantado voces en su contra por parte de profesionales que afirman que los pacientes prefieren no hablar de muerte y discapacidad, y que es difícil tomar decisiones adecuadas en previsión de situaciones futuras ya que, no suelen poder predecir bien sus deseos, puesto que las opiniones son cambiantes ${ }^{32}$. De la misma forma se afirma también que un representante no siempre es un interlocutor válido para los intereses del paciente ${ }^{33,34}$, puesto que puede verse influenciado por sus propias opiniones. Así pues, las Voluntades Anticipadas no están exentas de polémica ${ }^{35}$.

Volviendo a su aspecto formal, la Ley 41/2002 es la legislación estatal que enmarca las 17 variantes legislativas que, dada la estructura política de nuestro Estado, se han generado en torno a esta materia. Esto sería de otro modo si a la estructura de nuestro sistema se la dotará de acuerdos de fondo reales, que 
permitieran establecer normas comunes sobre conceptos técnicos y legales, entendiendo como tales para el caso que nos ocupa, el respeto a la autonomía y su defensa en situaciones de incompetencia ${ }^{36}$.

Tan llamativa es la diversidad de las concepciones legislativas en nuestro país que podemos encontrar hasta seis denominaciones diferentes para lo que, en la ley estatal, se denomina Instrucciones Previas:

- "Instrucciones Previas" es utilizada en Asturias, Castilla y León, Galicia, La Rioja, Madrid y Murcia.

- "Voluntades Anticipadas" es utilizada en Aragón, Baleares, Castilla La Mancha, Cataluña, Comunidad Valenciana, Navarra y País Vasco.

- "Manifestaciones Anticipadas de Voluntad" en Canarias.

- "Voluntades Previas" en Cantabria.

- “Expresión Anticipada de Voluntades” en Extremadura.

- "Voluntades Vitales Anticipadas" en Andalucía.

Si bien la denominación que recoge la Ley 41/2002 es la de Instrucciones Previas, previo al desarrollo del presente trabajo he optado por el término "Voluntades Anticipadas". El motivo es doble. Por una parte el trabajo ha sido desarrollado en la Comunidad Valenciana, donde la Ley 1/2003, de 16 de enero, de derechos e información al paciente de la Comunidad Valenciana ${ }^{37}$, utiliza la nomenclatura "Voluntades Anticipadas" y "Documento de Voluntades Anticipadas". A su vez, es la denominación adoptada por un mayor número de 
Comunidades Autónomas, como puede verse referido anteriormente. Es por esto que de ahora en adelante, y como venía haciendo, me referiré a las Instrucciones Previas como Voluntades Anticipadas.

\subsection{Las Voluntades Anticipadas en la historia reciente.}

El Documento de Voluntades Anticipadas surge de la necesidad de dar respuesta a situaciones de conflicto, en las que se plantea la disyuntiva entre mantener o retirar medidas de soporte, o iniciar intervenciones y procedimientos en pacientes que no tienen la capacidad de manifestar su voluntad.

Es a finales de la década de los 60 cuando se formula lo que sería el primer borrador de un Documento de Voluntades Anticipadas, lo que se llamo en ese momento, y en muchas ocasiones con posterioridad, Testamento Vital. Louis Kutner, abogado de profesión y activista de una asociación Pro-derecho a una muerte digna, crea un documento, similar a un testamento convencional, en el que el otorgante podía dejar constancia de las instrucciones sobre el tratamiento, las intervenciones médicas, así como los cuidados, que deseaba recibir en los últimos días de su vida. Este documento debía ser cumplimentado mientras el paciente era considerado competente.

La formulación del Testamento Vital quería dar respuesta a tres problemas principales. En primer lugar, liberar a la familia de la presión que genera tener que tomar decisiones en nombre del paciente, puesto que quedaba recogido de forma clara y evidente cuál era su opinión o voluntad con respecto a la situación que estaban viviendo. Por otra parte, respetando la voluntad de no prolongar los 
últimos días de vida del paciente, también se libera la familia de tener que pagar altos honorarios por los servicios sanitarios recibidos, dada la estructura sanitaria existente en Estados Unidos, país donde se inician estos movimientos. En tercer lugar permitía al sujeto formar parte del proceso de toma de decisiones, respetando así su autonomía ${ }^{26}$. Este concepto, relativamente nuevo en el contexto social existente, era cada vez más demandado. Además, la introducción del testamento vital en la relación médico-paciente, podía ayudar a establecer una nueva línea de educación socio-sanitaria y los profesionales podrían ver que, una huida hacia adelante, entendida como el mantenimiento de la vida a toda costa utilizando las nuevas tecnologías a su alcance, no tenía porqué ser la mejor opción, ni la voluntad del paciente.

No obstante, este documento era de carácter privado, por lo qué tenía limitaciones muy importantes. La primera, fácil entender, era su baja difusión y escaso conocimiento por la sociedad en general, situación que lamentablemente poco ha cambiado a día de hoy. Por otra parte se daba una circunstancia curiosa: el documento de carácter únicamente privado, como ya se ha comentado, perdía validez en el momento en el que el otorgante se entendía como incapaz. Esto era, por tanto, una contradicción. El documento estaba destinado a manifestar la voluntad del paciente en el momento que no fuera capaz de expresarla pero era justo en este momento cuando perdía validez jurídica. A pesar de ser útil para conocer los deseos del paciente no aportaba un marco legal suficiente para los profesionales, lo cual generaba dudas a la hora de su aplicación. No obstante, sí supuso una nueva vía e inició un nuevo camino hacia legislaciones posteriores.

En la década siguiente, numerosas iniciativas arrancan en Estados Unidos para legislar sobre las Voluntades Anticipadas. A raíz de casos específicos como el de Karen Ann Kinlan ${ }^{38}$, aparecen estatutos y reglamentos en los diferentes estados para intentar dar forma a un documento que pudiera dar cobertura legal a la hora 
de tomar decisiones con respecto al mantenimiento o limitación de medidas extraordinarias. Surgen así normativas como la Natural Death Act, en California $^{39}$. A pesar de sus limitaciones supone un paso importante en la formalización del Documento de Voluntades Anticipadas. Problemas como un lenguaje vago en su redacción o definir conceptos como "enfermedad terminal" podían generar enfrentamientos a la hora de establecer sus límites. Es por esto, probablemente, que surgen más movimientos en favor de que las Voluntades Anticipadas recojan de alguna manera la figura del representante, conocido en el lenguaje sajón, como "durable powers of attorney" o "continuing powers of attorney". La aparición del representante supone la salvación del principal escollo de las Voluntades Anticipadas, puesto que la presencia de un interlocutor válido en el momento de la aparición de la enfermedad aporta un juicio ajustado a la situación real. No obstante, son muchas las personas que abogan por una situación mixta, es decir, que el Documento de Voluntades Anticipadas recoja instrucciones más o menos precisas, junto con la designación de un representante. De esta manera el representante puede interpretar de forma más sólida la voluntad del paciente y se pueden salvar situaciones no recogidas específicamente en el Documento de Voluntades Anticipadas.

Poco o nada cambia la situación en los siguientes 30 años, con la salvedad de que un movimiento que inicialmente es local, se extiende de forma más o menos rápida por Estados Unidos, dando el salto a Europa y al resto del mundo en la década de los años 90. No obstante, son pocos los países europeos que legislan en este sentido antes de iniciado el siglo XXI. Las razones para este retraso son varias pero probablemente un menor avance tecnológico y una visión global más paternalista de la medicina sean las principales. 


\subsection{Las Voluntades Anticipadas en Europa.}

El interés creciente observado en Estados Unidos por los derechos del paciente, durante los años sesenta, se desarrolla de forma más lenta en Europa. Los motivos que pueden dar lugar a esta situación son varios. El desarrollo tecnológico experimentado en el ámbito médico llega a Europa tras años de aplicación en el nuevo continente. Por otra parte, una visión sociocultural diferente, donde el concepto de familia y los valores religiosos tienen más peso a la hora de enfrentar el final de la vida, hacen que el interés por la autonomía al final de la vida sea, en cierta manera, menor. $Y$ es que es mayoritariamente aceptado que van a ser los familiares más cercanos y allegados los que van a tomar las riendas en estas circunstancias ${ }^{40}$. Tampoco es menos cierto que el paternalismo médico es una forma de relación médico-paciente mucho más arraigada en el continente europeo. Esta situación empezará a modificarse a mediados de la década de los 80 .

Es concretamente hacia finales de 1986 cuando se alzan las primeras voces desde la Organización para la Cooperación y Desarrollo Económico (OCDE) y el Consejo de Europa, solicitando la realización de una convención abierta a estados no miembros que pusiera de manifiesto los derechos de los pacientes, que podían verse sensiblemente afectados por el desarrollo de las ciencias biomédicas ${ }^{41}$. Más de una década de conferencias, estudios y ponencias harán falta para que desde el seno del Consejo de Europa finalmente se abra a la firma y ratificación, en abril de 1997, lo que se gestó como un tratado sobre Bioética y que finalmente daría en llamarse: Convention for the Protection of Human Rights and Dignity of the Human Being with regard to the Application of Biology and Medicine: Convention on Human Rights and Biomedicine ${ }^{2}$, que se tradujo en España como "Convenio para la Protección de los Derechos 
Humanos y la Dignidad del Ser Humano con respeto a la aplicación de la Biología y la Medicina: Convenio sobre Derechos Humanos y Biomedicina", conocido como Convenio de Oviedo (Apéndice B). Se trata de un documento de aplicación internacional de la mayor relevancia, equiparado a la Declaración Universal de los Derechos Humanos y considerado entre los cinco más importantes ${ }^{41}$ a nivel mundial.

La apertura a la firma de este tratado para los estados miembros del Consejo de Europa $^{42}$ y otros países invitados ${ }^{43}$ tanto europeos como del resto del planeta, supone un hito histórico para la sociedad moderna así como una manifestación clara y evidente de la voluntad de legislar a favor de los derechos humanos. El documento desarrolla como puntos clave la protección de la dignidad y la identidad del ser humano y la garantía del respeto a su integridad y otros derechos y libertades fundamentales relacionados con la aplicación de la biología a la medicina. Es el primer instrumento internacional con carácter jurídico vinculante para los países que lo ratifican. Es además, un marco común que cada país ha de ajustar a su propia jurisdicción ${ }^{44}$.

El Convenio resalta claramente la importancia del consentimiento y, por ello, le dedica el segundo capítulo (artículos 5 al 9). El consentimiento, como expresión del principio de autonomía, queda recogido de la siguiente manera:

Artículo 5. Regla general.

- Una intervención en el ámbito de la sanidad sólo podrá efectuarse después de que la persona afectada haya dado su libre e informado consentimiento.

- Dicha persona deberá recibir previamente una información adecuada acerca de la finalidad y la naturaleza de la intervención, así como sobre sus riesgos y consecuencias. 
- En cualquier momento la persona afectada podrá retirar libremente su consentimiento.

En los artículos posteriores, el Convenio da forma y consistencia al consentimiento de las personas que no son capaces de consentir bien por minoría de edad o bien por incapacidad mental ${ }^{45}$. Únicamente excluye de la obligatoriedad de la obtención del consentimiento aquellas situaciones que podamos identificar como emergencias, cuando la obtención del consentimiento pueda suponer una pérdida del beneficio que la técnica puede aportar ${ }^{46}$.

El capítulo II finaliza con el artículo 9, objeto de este estudio. Este artículo supone, como ya he comentado, un hito histórico en relación al principio de autonomía y el consentimiento informado y se manifiesta en los siguientes términos:

\section{Artículo 9: Deseos expresados anteriormente.}

Serán tomados en consideración los deseos expresados anteriormente con respecto a una intervención médica por un paciente que, en el momento de la intervención, no se encuentre en situación de expresar su voluntad.

Este artículo supone el punto de partida para una serie de iniciativas legisladoras que van a ir surgiendo en toda Europa. Pero además, dado que se trata de un convenio, supone en sí mismo, un marco legal, de obligatorio cumplimiento para aquellos países firmantes que posteriormente lo ratifiquen.

En el acto de apertura a la firma del Convenio sobre los Derechos Humanos y Biomedicina, diecinueve países se adhieren al mismo, encontrándose entre ellos 
España. Posteriormente hasta un total de 35 países lo han hecho, siendo el último Albania, en marzo de 2011. Si bien la mayoría de países han ratificado este Convenio, seis de ellos entre los que se encuentran Suecia, Italia y Polonia aún no lo han hecho. Otros países destacados, como Alemania y Reino Unido, no han iniciado los trámites para la firma del mismo ${ }^{47}$.

De cualquier forma, son múltiples las iniciativas que, de forma lenta pero constante, se han ido desarrollando en el entorno europeo en favor de legislar sobre los derechos del paciente al final de la vida.

Con anterioridad a la firma del Convenio de Derechos Humanos y Bioética, ya algunos países publicaron modificaciones en las leyes referentes a los derechos del paciente, que establecían la necesidad de tener en cuenta las voluntades expresadas con anterioridad. Así por ejemplo, el Gran Consejo de Estado de Ginebra (Suiza), aprueba una modificación en su ley referente a la "relación entre profesionales de la salud y los pacientes" vigente desde 1987, que contempla la necesidad de valorar y respetar las opiniones del paciente antes de que se produzca la pérdida de capacidad ${ }^{48}$.

Por otra parte, en 1998, Dinamarca da salida a su Ley sobre derechos de los pacientes que en su artículo 17 da validez legal a la posibilidad de establecer Voluntades Anticipadas ${ }^{49}$.

Con posterioridad a la firma del Convenio de Oviedo, concretamente cinco años después, España sería uno de los primeros países en reconocer de forma explícita la validez de las Voluntades Anticipadas, con la publicación de la Ley 41/2002 sobre la Autonomía y Derechos del Paciente, y concretamente, el artículo 11 llamado "Instrucciones previas". 
Tras la firma del Convenio de Derechos Humanos y Bioética, no son pocos los países europeos que inician su camino promoviendo legislaciones sobre los derechos del paciente, teniendo como referencia el principio de autonomía y no son pocos los que recogen en su redacción la necesidad de tener en cuenta "los deseos expresados con anterioridad" en relación a los cuidados y técnicas médicas que se pueden aplicar en el final de la vida. A pesar de todo, este proceso será largo y aún a fecha de hoy restan países que ni siquiera han iniciado esta andadura ${ }^{3}$.

En cualquier caso, desde el Consejo de Europa se han promovido nuevas iniciativas que instan a los países a seguir profundizando en esta reformas.

Previo a la toma de decisiones y emisión de nueva legislación, el Consejo de Europa encarga la realización de un estudio sobre la situación de las Voluntades Anticipadas en el entorno europeo. Con este motivo se emite un informe en 2008, que muestra la amplia variabilidad en la legislación sobre esta materia en los estados miembros ${ }^{50}$, mostrando que existían de forma genérica tres grupos en los que se podrían catalogar la situación con respecto a la legislación sobre Voluntades Anticipadas. Un primer grupo con una minoría franca donde se encontraban incluidos Reino Unido y España habían desarrollado legislación en materia de Voluntades Anticipadas. Los autores de este informe establecía un segundo grupo de países, entre lo que se encontraba Francia, que no tenían legislación vigente en materia de Voluntades Anticipadas pero se había establecido medidas para su desarrollo. Por último, se daba un tercer grupo, el más numeroso, que englobaba a países en los que no existía legislación en este sentido ni se tenía previsto que a corto plazo fueran a tenerla.

Ante este panorama el Consejo de Europa decide en Consejo de Ministros, el 9 de Diciembre de 2009, en su $1073^{\mathrm{a}}$ reunión, y con amplio consenso, la 
aprobación de "Recommendation CM/Rec(2009)11 of the Committee of Ministers to member states on principles concerning continuing powers of attorney and advance directives for incapacity" (Apéndice C), por la que se trata de promover la autodeterminación de adultos capaces en previsión de su futura incapacidad bien sea mediante Voluntades Anticipadas o bien mediante la determinación de un representante ${ }^{51}$, instando a los gobiernos de los estados miembros a legislar en esta dirección.

Esta recomendación se divide en tres partes principales. La primera dedicada al ámbito de aplicación, la segunda a la designación de representante y la tercera a las Voluntades Anticipadas, propiamente dichas.

\section{A. Parte I. Ámbito de aplicación:}

A.1 De acuerdo con el principio 1 los países deben promover la autodeterminación de las personas en el supuesto de futura incapacidad, mediante la designación de representante y mediante las Voluntades Anticipadas.

\section{B. Parte II. Designación de representante:}

B.1 De acuerdo con el principio 3, los estados deben valorar si el representante puede cubrir diferentes aspectos como los económicos, financieros, de salud y bienestar, asuntos personales o precisar si alguno de ellos debe ser excluido.

B.2 De acuerdo con los principios 4 y 5 se determina quién puede ser representante y en que circunstancias y señala que la designación del representante debe hacerse por escrito. 
B.3 El resto de la Parte II, establece directrices para la designación del representante, modo de formalización y garantías para la buena representación.

\section{Parte III. Voluntades Anticipadas}

C.1 El principio 14 hace referencia al contenido y dice que "las Voluntades Anticipadas pueden referirse a la salud, el bienestar y otros aspectos personales, a cuestiones económicas y financieras y a la elección de un representante"

C.2 El principio 15 hace referencia al efecto y dice que "los estados deben decidir en qué medida las Voluntades Anticipadas pueden tener efecto vinculante. Las Voluntades Anticipadas que no tengan efecto vinculante deben ser tratadas como declaraciones de deseos que se deben respetar". Así mismo "los estados deberían abordar las situaciones que se planteen en el cambio sustancial de circunstancias"

C. 3 El principio 16 hace referencia a la forma y dice que "los estados deben considerar si las Voluntades Anticipadas deben constar por escrito para tener valor legal". De la misma manera "deben considerar otras provisiones y mecanismos que sean requeridos para asegurar la validez y efectividad de dichas Voluntades Anticipadas".

C.4 El principio 17 dice que "las directivas anticipadas deben ser revocables en cualquier momento y sin ninguna formalización". 
Este no es el último intento que se ha realizado desde el Consejo de Europa para impulsar la legislación en materia de Voluntades Anticipadas. El 25 de enero de 2012, liderado por el Comité de Asuntos Sociales, Salud y Desarrollo Sostenible, en la voz del español Jordi Xucla i Costa, se adoptó en sede parlamentaria la Resolución 1859 (2012) y la posterior Recomendación 1993 (2012), que llevan por título "Protecting human rights and dignity by taking into account previously expressed wishes of patients" (Apéndice D y E). En ella se insta desde el Comité de Ministros en sede parlamentaria a que los Estados miembros se adhieran al Convenio de Derechos Humanos y Biomedicina (Convenio de Oviedo) y a la Recomendación CM/Rec (2009)1 y, de la misma manera, implementen las medidas necesarias para su desarrollo y faciliten la monitorización de su evolución ${ }^{52}$.

\subsection{Las Voluntades Anticipadas en España. Legislación actual.}

El camino que se ha seguido para llegar a la situación actual ha sido largo, lento y no exento de dificultades. Muchos son los años que se han necesitado para desarrollar el marco legislativo actual, sin faltar por ello la controversia.

La primera referencia que podemos encontrar en la legislación española en relación a la autonomía del paciente se encuentra en la Constitución española de $1978^{53}$. En concreto en el Título I (De los derechos y deberes fundamentales) podemos leer en el artículo 43,:

1.- Se reconoce el derecho a la protección de la salud. 
2.- Compete a los poderes públicos organizar y tutelar la salud pública a través de medidas preventivas y de las prestaciones y servicios necesarios. La ley establecerá los derechos y deberes de todos al respecto.

Posteriormente la Ley General de Sanidad de $1986^{54}$ desarrolla los derechos del paciente. En ella no encontramos referencia alguna a la posibilidad de plasmar Voluntades Anticipadas pero sí recoge de forma explícita el derecho a la autonomía del paciente, vehiculizado a través del derecho a la información, al consentimiento previo y al consentimiento por representación. Así lo podemos encontrar recogido en el artículo 10.6.b:

(El paciente tiene derecho) a la libre elección entre las opciones que le presente el responsable médico de su caso, siendo preciso el previo consentimiento por escrito del usuario para la realización de cualquier intervención, excepto (...) cuando no esté capacitado para tomar decisiones, en cuyo caso, el derecho corresponderá a sus familiares o personas a él allegadas.

Como ya he comentado es la primera referencia explícita que encontramos en la legislación española sobre el consentimiento por representación $\mathrm{y}$, probablemente por esto, como todos los principios, es demasiado ambigua. No establece qué criterios se han de seguir para designar al representante (familiar o allegado) ni qué tipo decisiones pueden tomar ${ }^{55}$.

Once años después y tras un largo proceso de gestación, España se adhiere al Convenio de Oviedo ${ }^{3}$, como país miembro del Consejo de Europa y anfitrión, en el acto de apertura a la firma para el resto de países miembros y no miembros, el día 4 de abril de 1997. La ratificación de dicho tratado se lleva a cabo dos años y 
medio después, el día 1 de septiembre de 1999, entrando en vigor el 1 de enero del año 2000.

Dos años más se hace esperar la Ley 41/2002, de 14 de noviembre, básica reguladora de la autonomía del paciente y derechos y obligaciones en materia de información y documentación clínica ${ }^{27}$. Esta ley surge como instrumento para dar cabida a diferentes iniciativas que se habían ido produciendo a lo largo del territorio español desde diferentes Comunidades Autónomas, encabezadas por la de Cataluña ${ }^{56}$, que incluso se adelanta a la ley estatal.

Aún así España, dentro del marco del Consejo de Europa, es de los primeros países en publicar una legislación moderna sobre de los derechos del paciente y que recoge con especial interés las Voluntades Anticipadas. En 2008, Andorno y colaboradores sitúan a España dentro del grupo de países con una "situación legal fuerte para las Voluntades Anticipadas" (Strong Legal Status of Advance Directives) $)^{57}$.

Parece importante destacar los aspectos más novedosos de esta Ley. En el capítulo dedicado a "el respeto a la autonomía del paciente "y en particular en el artículo 11, Instrucciones previas, podemos leer:

1. Por el documento de instrucciones previas, una persona mayor de edad, capaz y libre, manifiesta anticipadamente su voluntad, con objeto de que esta se cumpla en el momento en que llegue a situaciones en cuyas circunstancias no sea capaz de expresarlos personalmente, sobre los cuidados y el tratamiento de su salud o, una vez llegado el fallecimiento, sobre el destino de su cuerpo o de los órganos del mismo. El otorgante del documento puede designar, además, un representante para que, llegado el 
caso, sirva como interlocutor suyo con el médico o el equipo sanitario para procurar el cumplimiento de las instrucciones previas.

2. Cada servicio de salud regulará el procedimiento adecuado para que, llegado el caso, se garantice el cumplimiento de las instrucciones previas de cada persona, que deberán constar siempre por escrito.

3. No serán aplicadas las instrucciones previas contrarias al ordenamiento jurídico, a la «lex artis», ni las que no se correspondan con el supuesto de hecho que el interesado haya previsto en el momento de manifestarlas. En la historia clínica del paciente quedará constancia razonada de las anotaciones relacionadas con estas previsiones.

4. Las instrucciones previas podrán revocarse libremente en cualquier momento dejando constancia por escrito.

5. Con el fin de asegurar la eficacia en todo el territorio nacional de las instrucciones previas manifestadas por los pacientes y formalizadas de acuerdo con lo dispuesto en la legislación de las respectivas Comunidades Autónomas, se creará en el Ministerio de Sanidad y Consumo el Registro nacional de instrucciones previas que se regirá por las normas que reglamentariamente se determinen, previo acuerdo del Consejo Interterritorial del Sistema Nacional de Salud.

Esta norma condiciona las relaciones entre los usuarios y los profesionales de la salud y desarrolla cuestiones que se trataron de forma somera en la Ley General de Sanidad. Esta ley introduce aspectos novedosos con referencia explícita al 
derecho de autonomía recogido en el consentimiento informado y el tema que nos ocupa, las Voluntades Anticipadas.

El desarrollo legislativo posterior que han realizado las diferentes Comunidades Autónomas de esta ley ha dibujado de forma más ajustada el modo y formalización de las Voluntades Anticipadas en el territorio español, eso si, con un amplio catálogo de material legal, que se recoge en la siguiente tabla (ver tabla 1).

Tabla 1. Leyes que regulan las Voluntades Anticipadas en las CCAA

\begin{tabular}{|c|c|}
\hline ANDALUCIA & $\begin{array}{l}\text { - Ley } 2 / 1998 \text {, de } 15 \text { de junio, de salud de Andalucía. BOE N } 185 \text {, de } \\
4 / 08 / 1998 \text {. } \\
\text { Ley } 5 / 2003 \text {, de } 9 \text { de octubre, de declaración de voluntad vital anticipada. } \\
\text { BOJA N } 210 \text { de } 31 / 10 / 2003 \text {. } \\
\text { Decreto } 238 / 2004 \text {, de } 18 \text { de mayo, regulador del Registro de voluntades } \\
\text { vitales anticipadas de Andalucía. BOJA N } 104 \text {, de } 28 / 05 / 2004 \text {. } \\
\text { - Ley } 2 / 2010 \text {, de } 8 \text { de abril, de Derechos y Garantías de la Dignidad de la } \\
\text { Persona en el Proceso de la Muerte. BOJA N } 88 \text {, de } 07 / 05 / 2010\end{array}$ \\
\hline ARAGÓN & $\begin{array}{l}\text { - Ley } 6 / 2002 \text {, de } 15 \text { de abril, de salud de Aragón. BOE No } 121 \text { de } \\
21 / 05 / 2002 \\
\text { Decreto } 100 / 2003 \text {, de } 6 \text { de mayo, que aprueba el Reglamento de } \\
\text { organización y funcionamiento del Registro de Voluntades Anticipadas. } \\
\text { BOA N } 64 \text {, de } 28 / 05 / 2003 \text {. } \\
\text { Ley } 8 / 2009 \text {, de } 22 \text { de diciembre por la que se modifica la Ley } 6 / 2002 \text {, de } \\
15 \text { de abril, de salud de Aragón, en lo relativo a Voluntades Anticipadas. } \\
\text { BOA N } 252 \text { de } 30 / 12 / 2010 \text {. }\end{array}$ \\
\hline ASTURIAS & $\begin{array}{l}\text { - Ley } 1 / 92 \text { de julio del Servicio de Salud del Principado de Asturias. BOE } \\
\mathrm{N}^{\mathrm{o}} 211 \text { de } 02 / 09 / 1992 .\end{array}$ \\
\hline BALEARES & $\begin{array}{l}\text { - Ley 5/2003, de } 4 \text { de abril, de salud de las Illes Balears. BOE No } 110 \text { de } \\
\text { 08/05/2003. } \\
\text { Ley } 1 / 2006 \text {, de } 3 \text { de marzo, de Voluntades Anticipadas. BOE No } 81 \text { de } \\
\text { 05/04/2006. } \\
\text { Decreto 58/2007, de } 27 \text { de abril, de ampliación de la Ley de Voluntades } \\
\text { Anticipadas y del Registro de Voluntades Anticipadas de las Illes } \\
\text { Balears. BOIB N } 70 \text { de } 10 / 05 / 2007 \text {. }\end{array}$ \\
\hline
\end{tabular}




\section{Tabla 1. Continuación}

\begin{tabular}{|c|c|}
\hline CANARIAS & $\begin{array}{l}\text { Ley } 11 / 1994 \text { de } 26 \text { de julio, de Ordenación sanitaria en Canarias. BOC } \\
\mathrm{N}^{\circ} 96 \text { de } 26 / 08 / 1994 \text {. } \\
\text { Orden de } 28 \text { de febrero de } 2005 \text {, por la que se aprueba la Carta de los } \\
\text { derechos y de los deberes de los pacientes y usuarios sanitarios y se } \\
\text { regula su difusión. BOC } \mathrm{N}^{\circ} 55 \text { de } 17 / 03 / 2005 \text {. } \\
\text { Decreto } 13 / 2006 \text {, de } 8 \text { de febrero, por el que se regulan las } \\
\text { manifestaciones anticipadas de voluntad en el ámbito sanitario y la } \\
\text { creación de su correspondiente Registro. BOC } \mathrm{N}^{\circ} 43 \text { de } 02 / 03 / 2006 \text {. }\end{array}$ \\
\hline CANTABRIA & $\begin{array}{l}\text { - Ley de Cantabria } 6 / 2001 \text {, de } 20 \text { de noviembre, de atención y protección a } \\
\text { las personas en situación de dependencia. BOC } \mathrm{N}^{\mathrm{o}} 230 \text { de } 28 / 11 / 2001 \text {. } \\
\text { Ley } 7 / 2002 \text {, de } 10 \text { de diciembre, de ordenación sanitaria de Cantabria. } \\
\text { BOE } \mathrm{N}^{\circ} 06 \text { de } 07 / 01 / 2003 \text {. } \\
\text { - Ley de Cantabria } 2 / 2007 \text { de } 27 \text { de marzo, de Derechos y Servicios } \\
\text { Sociales. BOC } \mathrm{N}^{\mathrm{o}} 66 \text { de } 03 / 04 / 2007 \text {. } \\
\text { Decreto } 139 / 2004 \text {, de } 5 \text { de diciembre, que crea y regula el Registro de } \\
\text { Voluntades Previas de Cantabria. BOC } \mathrm{N}^{\circ} 248 \text { de } 27 / 12 / 2004 \text {. } \\
\text { - Orden } 27 / 2005 \text {, de } 16 \text { de septiembre, por la que se establece el } \\
\text { documento tipo de Voluntades expresadas con carácter previo de } \\
\text { Cantabria. BOC } \mathrm{N}^{\mathrm{o}} 188 \text { de } 30 / 09 / 2005 \text {. } \\
\text { Orden } 28 / 2005 \text {, de } 16 \text { de septiembre, por la que se crea el fichero } \\
\text { automatizado de datos de carácter personal del registro de Voluntades } \\
\text { Previas de Cantabria. BOC } \mathrm{N}^{\circ} 188 \text { de } 30 / 09 / 2005 \text {. }\end{array}$ \\
\hline $\begin{array}{l}\text { CASTILLA } \\
\text { LA MANCHA }\end{array}$ & $\begin{array}{l}\text { - Ley } 8 / 2000 \text {, de } 30 \text { de noviembre, de Ordenación sanitaria. BOE } N^{\circ} 50 \text {, } \\
\text { de } 27 / 02 / 2001 \text {. } \\
\text { Ley } 6 / 2005 \text {, de } 7 \text { de julio, sobre la declaración de voluntades anticipadas } \\
\text { en materia de la propia salud. BOE } N^{\circ} 203 \text { de } 25 / 08 / 2005 \text {. } \\
\text { Decreto } 15 / 2006 \text {, de } 21 \text { de febrero, del Registro de Voluntades } \\
\text { Anticipadas de Castilla la Mancha. DOCM N } 42 \text { de } 24 / 02 / 2006 \text {. } \\
\text { Ley } 5 / 2010 \text {, de } 24 \text { de junio, sobre derechos y deberes en materia de salud } \\
\text { de Castilla la Mancha. BOE No } 248 \text { de } 13 / 10 / 2010 \text {. }\end{array}$ \\
\hline $\begin{array}{l}\text { CASTILLA } \\
\text { LEÓN }\end{array}$ & $\begin{array}{l}\text { - Ley } 1 / 1993 \text {, de } 6 \text { de abril, de Ordenación del Sistema Sanitario. BOE N } \\
124 \text { de } 25 / 05 / 1993 \\
\text { - Ley 8/2010, de } 30 \text { de agosto, de Ordenación del Sistema de Salud de } \\
\text { Castilla y León. BOE } N^{\circ} 235 \text {, de } 28 / 09 / 2010 \text {. } \\
\text { - Ley 8/2003, de } 8 \text { de abril, sobre derechos y deberes de las personas en } \\
\text { relación con la salud. BOE N } 103 \text { de } 30 / 04 / 2003 \text {. } \\
\text { Orden SBS/1325/2003, de } 3 \text { de septiembre, de publicación de las Cartas } \\
\text { de derechos y deberes de las Guías de información al usuario. BOCyL N } \\
205 \text { de } 22 / 10 / 2003 \text {. } \\
\text { Orden } 687 / 2006 \text {, de } 19 \text { de abril, por la que se procede a la creación de } \\
\text { ficheros automatizados con datos de carácter personal. BOCyL No } 84 \text { de } \\
\text { 03/05/2006. }\end{array}$ \\
\hline
\end{tabular}




\section{Tabla 1. Continuación.}

\begin{tabular}{|c|c|}
\hline CATALUÑA & $\begin{array}{l}\text { - Ley } 21 / 2000 \text {, de } 29 \text { de diciembre, sobre derechos de información } \\
\text { concernientes a la salud, a la autonomía del paciente y a la } \\
\text { documentación clínica. BOE } N^{\circ} 29 \text { de } 02 / 02 / 2001 \text {. } \\
\text { Decreto } 175 / 2002 \text {, de } 25 \text { de junio, que regula el Registro de Voluntades } \\
\text { Anticipadas. DOGC núm. } 3665 \text { de } 27 / 06 / 2002 \text {. }\end{array}$ \\
\hline $\begin{array}{l}\text { COMUNIDAD } \\
\text { VALENCIANA }\end{array}$ & $\begin{array}{l}\text { - Ley } 1 / 2003 \text {, de } 28 \text { de enero, de derechos e información al paciente de la } \\
\text { Comunidad Valenciana. BOE } \mathrm{N}^{\mathrm{o}} 48 \text { de } 28 / 01 / 2003 \text {. } \\
\text { Decreto } 168 / 2004 \text {, de } 10 \text { de septiembre, por el que regula el documento } \\
\text { de Voluntades Anticipadas y crea el Registro centralizado de Voluntades } \\
\text { Anticipadas de la Comunidad Valenciana. DOCV N } 4846 \text { de } \\
21 / 09 / 2004 \text {. } \\
\text { Orden de } 25 \text { de febrero de } 2005 \text {, de la Consellería de Sanidat, de } \\
\text { desarrollo del Decreto } 168 / 2004 \text {. DOCV N } 4966 \text { de } 15 / 03 / 2005 \text {. }\end{array}$ \\
\hline $\begin{array}{l}\text { EXTREMA- } \\
\text { DURA }\end{array}$ & $\begin{array}{l}\text { - Ley } 10 / 2001 \text {, de } 28 \text { de junio, de salud. BOE No } 177 \text { de } 25 / 07 / 2001 \text {. } \\
\text { Ley } 3 / 2005 \text {, de } 8 \text { de julio, de información sanitaria y autonomía del } \\
\text { paciente. BOE N } 82 \text { de } 16 / 07 / 2005 \\
\text { Decreto } 311 / 2007 \text {, de } 15 \text { de octubre } 2007 \text {, por el que se regula el } \\
\text { contenido, organización y funcionamiento del Registro de Expresión de } \\
\text { Voluntades de la Comunidad Autónoma de Extremadura y se crea el } \\
\text { Fichero Automatizado de datos de carácter personal del citado Registro. } \\
\text { DOE N } 121 \text { de } 18 / 10 / 2007 \text {. }\end{array}$ \\
\hline GALICIA & $\begin{array}{l}\text { - Ley } 3 / 2001 \text {, de } 28 \text { de mayo, reguladora del consentimiento informado y } \\
\text { de la historia clínica de los pacientes. BOE } N^{\circ} 158 \text { de } 03 / 07 / 2001 \text {. } \\
\text { Ley } 7 / 2003 \text {, de } 9 \text { de diciembre, de ordenación sanitaria de Galicia. DOG } \\
\mathrm{N}^{\mathrm{o}} 246 \text { de } 19 / 12 / 2003 \text {. } \\
\text { Ley3/2005, de } 7 \text { de marzo, de modificación de la Ley } 2 / 2001 \text {. BOE } \mathrm{N}^{\mathrm{o}} \\
93 \text { de } 19 / 04 / 2005 \text {. } \\
\text { Ley } 8 / 2008 \text {, de } 10 \text { de Julio, de salud de Galicia. BOE } \mathrm{N}^{\mathrm{o}} 202 \text {, de } \\
21 / 08 / 2008 \text {. }\end{array}$ \\
\hline LA RIOJA & $\begin{array}{l}\text { - Ley } 2 / 2002 \text {, de } 17 \text { de abril, de salud de La Rioja. BOE } N^{\circ} 106 \text {, de } \\
03 / 05 / 2002 \\
\text { - Ley } 9 / 2005 \text {, de } 30 \text { de septiembre, reguladora del documento de } \\
\text { Instrucciones Previas en el ámbito de la sanidad. BO N } 252 \text { de } \\
21 / 10 / 2005 \\
\text { - Decreto } 30 / 2006 \text {, de } 19 \text { de mayo por el que se regula el Registro de } \\
\text { Instrucciones Previas de la Rioja. BOR } N^{\circ} 69 \text { de } 25 / 05 / 2006 \text {. } \\
\text { Orden } 8 / 2006 \text {, de } 26 \text { de julio, de la Consejería de Salud, sobre la forma } \\
\text { de otorgar documento de instrucciones previas ante personal de la } \\
\text { administración. BOR } N^{\circ} 103 \text { de } 5 / 08 / 2006 \text {. }\end{array}$ \\
\hline
\end{tabular}




\section{Tabla 1. Continución}

\begin{tabular}{|c|c|}
\hline MADRID & $\begin{array}{l}\text { - Ley } 12 / 2001 \text {, de } 21 \text { de diciembre, de ordenación sanitaria de la } \\
\text { Comunidad de Madrid. BOE N } 55 \text { de } 05 / 03 / 2002 \text {. } \\
\text { Ley } 3 / 2005 \text {, de } 23 \text { de mayo, que regula el ejercicio del derecho a } \\
\text { formular instrucciones previas en el ámbito sanitario y crea el registro } \\
\text { correspondiente. BOCM } N^{\circ} 140 \text { de } 14 / 06 / 2005 \text {. } \\
\text { Decreto } 101 / 2006 \text {, de } 16 \text { de noviembre, del Consejo de Gobierno, por el } \\
\text { que se regula el Registro de Instrucciones Previas de la Comunidad de } \\
\text { Madrid. BOCM N } 283 \text { de } 28 / 11 / 2006 \text {. } \\
\text { Orden } 2191 / 2006 \text {, de } 18 \text { de diciembre, por la que se regula el Registro de } \\
\text { Instrucciones Previas de la Comunidad de Madrid y se establecen los } \\
\text { modelos oficiales de los documentos de solicitud de inscripción de las } \\
\text { Instrucciones Previas y de su revocación, modificación o sustitución. } \\
\text { BOCM } N^{\circ} 302 \text { de } 20 / 12 / 2006 \text {. }\end{array}$ \\
\hline MURCIA & $\begin{array}{l}\text { - Ley } 14 / 1994 \text {, de } 26 \text { de julio, de Salud de la Región de Murcia. BOE No } \\
243 \text { de } 11 / 10 / 1994 \text {. } \\
\text { Decreto } 80 / 2005 \text {, de } 8 \text { de julio, por el que se aprueba el reglamento de } \\
\text { instrucciones previas y su registro. BORM N } 164 \text { de } 19 / 07 / 2005 \text {. } \\
\text { Ley } 3 / 2009 \text {, de } 11 \text { de mayo de los derechos y deberes de los usuarios del } \\
\text { sistema sanitario de la Región de Murcia. BOE No } 34 \text { de 09/02/2011. }\end{array}$ \\
\hline NAVARRA & $\begin{array}{l}\text { Ley foral } 11 / 2002 \text {, de } 6 \text { de mayo, de derechos del paciente a las } \\
\text { Voluntades Anticipadas, a la información y a la documentación clínica. } \\
\text { BOE } N^{\circ} 153 \text {, de } 27 / 06 / 2002 \text {. } \\
\text { Decreto foral } 140 / 2003 \text {, de } 16 \text { de junio, que regula el Registro de } \\
\text { Voluntades Anticipadas. BON No } 81 \text { de } 30 / 06 / 2003 \text {. } \\
\text { - Ley foral } 29 / 2003 \text {, de } 4 \text { de abril por la que se modifica parcialmente la } \\
\text { Ley Foral } 11 / 2002 \text { de } 6 \text { de mayo sobre los derechos del paciente a las } \\
\text { Voluntades Anticipadas, a la información y a la documentación clínica. } \\
\text { BON No } 45 \text { de } 11 / 04 / 2003 \text {. } \\
\text { Ley Foral } 17 / 2010 \text {, de } 8 \text { de noviembre, de derechos y deberes de las } \\
\text { personas en materia de salud de la Comunidad Foral de Navarra. BOE } \\
\text { nN } 315 \text { de } 28 / 12 / 2010 \text {. }\end{array}$ \\
\hline PAÍS VASCO & $\begin{array}{l}\text { - Ley } 7 / 2002 \text {, de } 12 \text { de diciembre, de Voluntades Anticipadas en el ámbito } \\
\text { de la sanidad. BOE N } 291 \text { de } 03 / 12 / 2011 \text {. } \\
\text { Decreto } 270 / 2003 \text {, de } 4 \text { de noviembre, que crea y regula el Registro } \\
\text { vasco de Voluntades Anticipadas. BOPV No } 233 \text { de } 28 / 11 / 2003 \text {. } \\
\text { Orden de } 6 \text { de noviembre de } 2003 \text {, de la Consejería de Sanidad por la } \\
\text { que se crea el fichero de datos automatizados de datos de carácter } \\
\text { personal denominado 'Registro vasco de Voluntades Anticipadas' y se } \\
\text { añade a los gestionados por el Departamento de Sanidad. BOPV N } 250 \\
\text { de } 23 / 12 / 2003 \text {. }\end{array}$ \\
\hline
\end{tabular}


El objetivo más importante de esta nueva herramienta, la Ley $41 / 2002$, es mejorar la relación entre pacientes y profesionales sanitarios y facilitar la toma de decisiones, llegado el momento en el que el paciente no puede tomarlas por si mismo. Para ello las diferentes iniciativas legislativas contemplan el contenido y sus límites 38 :

A. Contenido:

A.1 Objetivos vitales y valores personales, que ayudan a la interpretación y orientan para la toma de decisiones.

A.2 Actuaciones médicas en general.

A.3 Medidas sobre la prolongación de la vida. Por un lado, medidas específicas que no deben iniciarse $\mathrm{y}$, por otro, control del dolor y sufrimiento.

A.4 Destino del cuerpo y los órganos.

B. Límites (Situaciones que limitan la aplicación de las Voluntades Anticipadas):

B.1 Lo que el paciente demanda va contra el ordenamiento jurídico.

B.2 No existen correspondencia entre lo demandado en las Voluntades Anticipadas y la situación clínica del paciente.

B.3 Lo que el paciente demanda va en contra de la práctica clínica adecuada.

B.4 Lo que el paciente demanda es contrario a la ética profesional.

Coucerio Vidal hace un análisis pormenorizado de estos límites ${ }^{38}$, argumentando con claridad que probablemente el único límite adecuado sería la no correspondencia de la situación clínica con el supuesto contemplado en el 
documento. El resto de límites los considera superfluos o simplemente improcedentes.

Las diferentes leyes desarrolladas por las Comunidades Autónomas, y en virtud de lo establecido por la Ley 41/2002, también contemplan la creación de registros autonómicos de Voluntades Anticipadas.

En relación a este último punto se publica, años después, el Real Decreto 124/2007, de 2 de febrero, por el que se regula el Registro nacional de instrucciones previas y el correspondiente fichero automatizado de datos de carácter personal ${ }^{58}$. En él se desarrolla la creación, estructura y jerarquización del registro automatizado de Instrucciones Previas. Este instrumento pone al alcance de todo el territorio español las Voluntades Anticipadas de cualquier paciente que las otorgue, con independencia de donde lo haga, y facilita que puedan ser consultadas por los profesionales que le están asistiendo.

Así pues la situación legislativa en el territorio español, a pesar de las diferencias recogidas en cada Comunidad Autónoma, sus limitaciones y las posible críticas que se le puedan hacer, es bastante clara. Pero ¿cómo es en el resto de Europa? ¿Cuál es la situación actual en materia de Voluntades Anticipadas en la Unión Europea? Intentando dar respuesta a estas preguntas desarrollo el presente trabajo. 

Capítulo 2

Objetivos y plan de trabajo 



\subsection{Objetivos.}

Los objetivos de la presente tesis doctoral son los siguientes:

\subsubsection{Objetivo Principal.}

Como objetivo principal se ha establecido el desarrollo de una comparación de la legislación vigente en los 28 países que forman la Unión Europea, en relación a las Voluntades Anticipadas y el Documento de Voluntades Anticipadas, que permita valorar en que punto legislativo se encuentra cada país.

2.1.2. Objetivos Secundarios.

Son objetivos secundarios del presente trabajo:

S.1 Establecer puntos de reflexión sobre la situación real de las Voluntades Anticipadas y el Documento de Voluntades Anticipadas.

S.2 Establecer posibles puntos de mejora en el marco legislativo vigente. 


\subsection{Plan de Trabajo.}

Fase I. Recogida y estudio de la legislación vigente en España sobre derechos del paciente, Voluntades Anticipadas y Documento de Voluntades Anticipadas.

Fase II. Realización de una tabla con las características principales de la legislación vigente en España que sirva de base para el análisis comparativo de la legislación del resto de países de la Unión Europea.

Fase III. Recogida de la legislación vigente en materia de derechos del paciente y Voluntades Anticipadas en el resto de los países que forman parte de la Unión Europea y de las recomendaciones en esta materia del Consejo de Europa.

Fase IV. Estudio comparativo de las características de la legislación de los países de la Unión Europea, sobre Voluntades Anticipadas y Documento de Voluntades Anticipadas.

Fase IV. Análisis de los puntos de mejora, para la homogeneización de las distintas normativas vigentes 
Capítulo 3

Material y método 



\subsection{Material}

Para la realización del presente trabajo se recopiló el siguiente material:

\subsubsection{Normativa española en materia de Voluntades Anticipadas.}

- Ley 41/2002, de 14 de noviembre, básica reguladora de la autonomía del paciente y de derechos y obligaciones en materia de información y documentación clínica.

- Real Decreto 124/2007, de 2 de febrero, por el que se regula el Registro nacional de instrucciones previas y el correspondiente fichero automatizado de datos de carácter personal.

3.1.2. Normativa del Consejo de Europa en materia de derechos del paciente y Voluntades Anticipadas.

- ETS no 164. Convention for the protection of the Human Rights and Dignity of the Human Being with regard to the Application of Biology and Medicine: Convention on Human Rights and Biomedicine.

- Recommendation $\mathrm{CM} / \operatorname{Rec}$ (2009)11 of the Committee of Ministers to members states on principles concerning continuing powers of attorney and advance directives for incapacity. 
- Resolution 1859 (2012) y Recommendation 1993 (2012) of the Parliamentary Assembly of the Council of Europe: Protecting human rights and dignity by taking into account previously expressed wishes of patients.

3.1.3. Normativa del resto de países de la Unión Europea en materia de derechos de los pacientes y Voluntades Anticipadas.

\section{- ALEMANIA:}

- Drittes Gesetz zur Änderung des Betreuungsrechts, 31 de Julio de 2009 (Tercera Ley de Modificación de la Tutela).

\section{- AUSTRIA:}

- Bundesgesetz über Patientenverfügungen, 8 de Mayo de 2006 (Ley Federal sobre las Voluntades Anticipadas).

- Allgemeines Bürgerliches Gesetzbuch (Modificación del art. 284f del Código Civil General por el que se regula la figura del representante).

\section{- BÉLGICA:}

- Loi relative aux droits du patient, 22 de agosto de 2002 (Ley de los derechos de los pacientes).

- Loi relative a l'euthanasie, de 28 de mayo de 2002 (Ley relativa a la Eutanasia). 
- BULGARIA:

- ЗАКОН ЗА ЗДРАВЕТО SG No. 70/10.08.2004 (Ley de Salud), de 10 de agosto de 2004, última modificación SG No. 1/3.01.2014.

\section{- CHIPRE:}

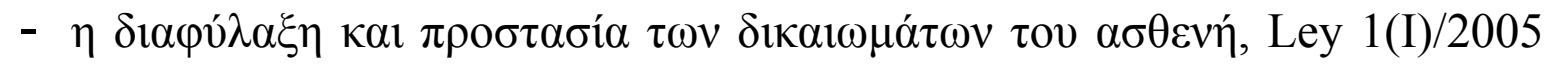
(La salvaguardia y protección de los derechos de los pacientes).

- CROACIA:

- Zakona o zaštiti prava pacijenata, de 24 de noviembre de 2004 (Ley de protección de los derechos de los pacientes).

- DINAMARCA:

- LOV nr 546 af 24/06/2005, última modificación LBK nr 1202 af 14/11/2014 (Ley de Salud).

- ESLOVAQUIA:

- Zákon 576/2004 Z.z. o zdravotnej starostlivosti (Ley de Cuidado de la Salud).

- ESLOVENIA:

- Zakona o pacientovih pravicah (ZPacP), 15/2008, de 2 de febrero de 2008 (Ley de derechos del paciente (PACPA)). 


\section{- ESTONIA:}

- Võlaõigusseadus, de 26 de septiembre de 2001 (Ley de Obligaciones).

- FINLANDIA:

- Laki potilaan asemasta ja oikeuksista 785/1992, de 17 de agosto (Ley de situación y derecho del paciente).

- Sosiaali- ja terveysministeriön asetus potilasasiakirjoista. Decreto 30.3.2009/298 (De la historia clínica del paciente).

- FRANCIA:

- LOI n 2002-303 du 4 mars 2002 relative aux droits des malades et à la qualité du système de santé (Ley sobre los derechos de los pacientes y de la calidad del sistema sanitario).

- LOI n 2005-370 du 22 avril 2005 relative aux droits des malades et à la fin de vie (Ley sobre los derechos de los pacientes y el fin de la vida).

- GRECIA:

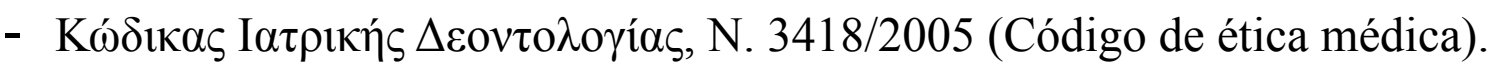

- HUNGRIA:

- 1997. évi CLIV. törvény az egészségügyről (Ley del Cuidado de la Salud). 
- IRLANDA:

- Assisted decision-making (Capacity) Bill 2013. Act. No. 83/ 2013 (Proyecto de Ley de toma de decisiones asistida).

- ITALIA:

- Codice di Deontologia Médica, de 18 de mayo de 2014 (Código de Deontología Médica).

- LETONIA:

- Ārstniecības likums, de 12 de Junio de 1997, última modificación en diciembre de 2009 (Ley del tratamiento médico).

- LITUANIA:

- Likums Par Pacientu tiesības, de 17 de diciembre de 2009 (Ley de los derechos de los pacientes).

- LUXEMBURGO:

- Loi du 16 mars 2009 relative aux soins palliatifs, à la directive anticipée et à l'accompagnemen (Ley sobre cuidados paliativos, directivas anticipadas y acompañamiento).

- Loi du 24 juillet 2014 relative aux droits et obligations du patient, portant création d'un service national d'information et de médiation dans le domaine de la santé (Ley de derechos y obligaciones del paciente, que 
establece un servicio nacional de información y la mediación en el ámbito de la salud).

- MALTA:

- ATT Nru. XI tal-2013, 1-Att tal-2013 dwar is-Saћћa, de 23 de octubre (Ley de Salud).

- PAISES BAJOS:

- Nederlands Burgerlijk Wetboek. Boek 7 Bijzondere overeenkomsten. (Código Civil Holandés).

- Levensbeëindiging op verzoek en hulp bij zelfdoding Wet, de 1 de abril de 2002 (Derecho al suicidio asistido).

- POLONIA:

- Przepisy wprowadzające ustawę o prawach pacjenta i Rzeczniku Praw Pacjenta, ustawę o akredytacji $\mathrm{w}$ ochronie zdrowia oraz ustawę $\mathrm{o}$ konsultantach w ochronie zdrowia, de 24 de abril de 2009 (Ley sobre los derechos del paciente y el defensor del pueblo, acreditación en la atención sanitaria y consultores en el cuidado de la salud).

- PORTUGAL:

- Lei n. ${ }^{\circ}$ 25/2012 de 16 de julho. Regula as diretivas antecipadas de vontade, designadamente sob a forma de testamento vital, e a nomeação de procurador de cuidados de saúde e cria o Registo Nacional do Testamento 
Vital (RENTEV) (Ley que regula las voluntades anticipadas, en forma de testamento vital, y el nombramiento de representante en materia de salud y crea el Registro Nacional de Testamento Vital).

- REINO UNIDO:

- The Mental Capacity Act 2005 (MCA). (Ley de capacitación mental)

- REPUBLICA CHECA:

- Zákon N 20/1966 o zdravotní péči (Ley N²0/1966 sobre la atención de salud).

- Zákonem č. 372/2011 Sb., o zdravotnických službách (Ley relativa a los servicios de salud).

- RUMANIA:

- Legea nr. 46 din 21 ianuarie 2003 drepturilor pacientului (Ley de derechos del paciente).

- SUECIA:

- Lagen om hälso- och sjukvård (1982: 763) (Ley de salud y servicio médico). 


\subsection{Método.}

3.2.1. Recogida de la legislación sobre Voluntades Anticipadas y el Documento de Voluntades Anticipadas, vigente en el Estado español.

La legislación a la que se hace referencia son las leyes enumeradas y descritas en el apartado 3.1.1. El acceso a las mismas se realizó a través de internet.

3.2.2. Análisis y extracción de las principales características del Documento de Voluntades Anticipadas o Instrucciones Previas, según la legislación española.

Las características más destacables de la legislación española vigente sobre Voluntades Anticipadas son:

A. España desarrolló en 2002, en virtud de su adhesión y ratificación del Convenio de Oviedo, legislación específica en materia de Voluntades Anticipadas. Posteriormente en 2007, vio la luz la creación del Registro de Voluntades Anticipadas.

B. Vinculante, lo cual quiere decir que esta sujeta a obligación, o lo que es lo mismo, es de obligado cumplimiento.

C. Debe plasmarse por escrito. En la legislación española se establece que para tener validez legal, las Voluntades Anticipadas deben quedar reflejadas por escrito, en el Documento de Voluntades Anticipadas. 
D. Queda previsto el modo de formalización del documento. En el estado español para que las Voluntades Anticipadas sean vinculantes se exige que el Documento de Voluntades Anticipadas sea redactado ante, al menos, tres testigos. Estos deberán encontrarse adecuadamente identificados y deberán firmar el Documento. También puede ser refrendado por un notario que con su firma dé validez legal al documento. Hasta en 10 Comunidades Autónomas se contempla también como mecanismo válido la formalización ante un representante de la Administración.

E. Permite la designación de un representante, y en este caso, en el mismo documento. El representante solo tiene potestad para tomar las decisiones en materia de salud que más le convienen al enfermo, en el caso de que este no pueda tomarlas por si mismo y, además debe hacerlo siguiendo las directrices de las Voluntades Anticipadas.

F. Contempla la existencia de un registro centralizado, cuyo objetivo es el de facilitar el acceso al Documento de Voluntades Anticipadas por parte del personal facultativo que atiende al paciente, en cualquier punto del país con independencia de la Comunidad Autónoma donde se hayan emitido. También se recomienda que exista constancia en la historia clínica del paciente.

G. Prevé quién puede tener acceso al documento una vez que este ha llegado al registro. Queda previsto por tanto quienes pueden solicitar la información que recoge el Documento de Voluntades Anticipadas, una vez el paciente se encuentra en situación de no poder tomar decisiones por si mismo. 
H. No exige revisiones periódicas del mismo. En el caso de la legislación española, no se exige la realización de revisiones frecuentes ni periódicas del contenido del Documento de Voluntades Anticipadas. No se establece un plazo tras el cual el documento pierde validez.

I. Permite su modificación en cualquier momento. El Documento válido sería el más reciente, siempre y cuando cumpla con las directrices que han sido expuestas anteriormente, es decir, firmado por tres testigos o por un notario. En caso de encontrarse ya recogido en el registro de Voluntades Anticipadas, debe notificarse y remitir la nueva versión.

J. Permite su revocación en cualquier momento. En caso de que el otorgante quiera desdecirse de la totalidad del Documento de Voluntades Anticipadas simplemente puede hacerlo, dejando constancia por escrito. En el caso de que el Documento se encuentre en el registro de Voluntades Anticipadas, se solicita que la revocación se notifique para que el documento previo pierda validez y no existan conflictos.

K. Limita las directrices que puede contener el documento, invalidando las que van en contra de la ley vigente, no permitiendo la eutanasia activa.

\subsubsection{Tabla comparativa.}

Elaboración de una tabla con las características más destacables que la legislación española confiere al Documento de Voluntades Anticipadas y que ya hemos enumerado y definido. (ver tabla 2). 
CARACTERÍSTICAS DE LA LEGISLACIÓN SOBRE VOLUNTADES ANTICIPADAS Y EL DOCUMENTO DE VOLUNTADES ANTICIPADAS

Tabla 2. Características de las VA y DVA según la legislación española.

PAÍS:

A.- Normativa específica

B.- Vinculante

C.- Formato escrito vs oral

D.- Formalización

E.- Designación de representante

F.- Personas que tienen acceso

G.- Registro

H.- Precisa de revisiones

I.- Modificable en cualquier momento

J.- Revocable

K.- Características del contenido 
Esta tabla servirá como base para el análisis y comparación de la legislación vigente en el resto de países de la Unión Europea.

\subsubsection{Legislación europea.}

Búsqueda, identificación y recogida de la normativa legal vigente en relación a los derechos del paciente, las Voluntades Anticipadas y el Documento de Voluntades Anticipadas en:

A. El Consejo de Europa.

B. Países que conforman en la actualidad la Unión Europea.

Estos países son: Alemania, Austria, Bélgica, Bulgaria, Chipre, Croacia, Dinamarca, Eslovaquia, Eslovenia, España, Estonia, Finlandia, Francia, Grecia, Hungría, Irlanda, Italia, Letonia, Lituania, Luxemburgo, Malta, Países Bajos, Polonia, Portugal, Reino Unido, República Checa, Rumanía, y Suecia.

Toda esta documentación se ha recogido a través de internet.

\subsubsection{Análisis.}

Análisis comparativo de las características que confieren la leyes nacionales a las Voluntades Anticipadas y al Documento de Voluntades Anticipadas en los restantes países de la Unión Europea, con respecto a las características que le confiere la legislación vigente en España. 
Capítulo 4

Resultados 



\subsection{El Convenio de Oviedo.}

El 60\% de los países de la Unión Europea son firmantes del tratado de adhesión y ratificación del Convenio de Oviedo, y se distribuyen de la siguiente manera (tabla 3):

\begin{tabular}{|c|c|}
\hline \multicolumn{2}{|c|}{ Tabla 3. Países de la UE y ratificación del Convenio de Oviedo } \\
\hline $\begin{array}{l}\text { PAÍSES DE LA UE QUE HAN } \\
\text { RATIFICADO EL CO }\end{array}$ & $\begin{array}{c}\text { PAÍSES DE LA UE QUE NO HAN } \\
\text { RATIFICADO EL CO }\end{array}$ \\
\hline BULGARIA & ALEMANIA \\
\hline CHIPRE & AUSTRIA \\
\hline CROACIA & BÉLGICA \\
\hline DINAMARCA & IRLANDA \\
\hline ESLOVAQUIA & ITALIA* \\
\hline ESLOVENIA & LUXEMBURGO* \\
\hline ESPAÑA & MALTA \\
\hline ESTONIA & PAISES BAJOS* \\
\hline FINLANDIA & POLONIA* \\
\hline FRANCIA & SUECIA* \\
\hline GRECIA & REINO UNIDO \\
\hline \multicolumn{2}{|l|}{ HUNGRÍA } \\
\hline \multicolumn{2}{|l|}{ LETONIA } \\
\hline \multicolumn{2}{|l|}{ LITUANIA } \\
\hline \multicolumn{2}{|l|}{ PORTUGAL } \\
\hline \multicolumn{2}{|l|}{ REPUBLICA CHECA } \\
\hline RUMANIA & \\
\hline
\end{tabular}

* Países que han firmado el tratado de adhesión al Convenio de Oviedo, pero que no han cumplimentado el mecanismo de ratificación. 
El mecanismo de ratificación de un tratado internacional de estas características contempla dos fases. Un primera fase de firma del tratado (adhesión) y una posterior de ratificación. Algunos de los países referidos anteriormente, como es el caso de Italia, Luxemburgo, Países Bajos, Polonia y Suecia, han firmado su adhesión al Convenio pero no han iniciado o completado el mecanismo de ratificación, que a su vez consta de dos fases, una nacional y otra internacional.

\subsection{Legislación específica sobre Voluntades Anticipadas.}

De los 28 países que forman parte de la Unión Europea, solo 15 (53\%) han desarrollado legislación específica sobre Voluntades Anticipadas y se agrupan de la siguiente forma (tabla 4):

Tabla 4. Países con legislación específica sobre Voluntades Anticipadas.

\begin{tabular}{|c|c|}
\hline PAÍSES CON LEGISLACIÓN ESPECIFICA & PAÍSES SIN LEGISLACIÓN ESPECÍFICA \\
SOBRE VA & SOBRE VA \\
\hline ALEMANIA & BULGARIA \\
\hline AUSTRIA & CHIPRE \\
BÉLGICA & CROACIA \\
\hline DINAMARCA & ESLOVAQUIA \\
\hline ESLOVENIA & GRECIA \\
\hline ESPAÑA & IRLANDA \\
ESTONIA & ITALIA \\
\hline FINLANDIA & LITUANIA \\
FRANCIA & MALTA \\
HUNGRÍA & POLONIA \\
\hline LETONIA & REPÚBLICA CHECA \\
\hline LUXEMBURGO & RUMANIA \\
\hline PAÍSES BAJOS & SUECIA \\
\hline PORTUGAL & \\
\hline REINO UNIDO & \\
\hline
\end{tabular}


De los países que han desarrollado legislación específica solo algunos, aunque son la mayoría, han ratificado el Convenio de Oviedo. La tabla 5 muestra los países que han desarrollado legislación en materia de Voluntades Anticipadas, el año en que se publicó y el año de ratificación del Convenio de Oviedo, en caso de que lo hicieran:

Tabla 5. Países con legislación específica en VA, año de publicación y ratificación del CO

\begin{tabular}{|c|c|c|}
\hline PAIS & AÑO DE PUBLICACION & RATIFICACION CONVENIO DE \\
OVIEDO
\end{tabular}

Llama la atención que en los casos de Dinamarca, Estonia, Finlandia y Letonia, se ha publicado primero la legislación sobre Voluntades Anticipadas y con posterioridad se ha firmado la adhesión al Convenio y su ratificación. 
También destaca el caso de países que a pesar de formar parte de la Unión Europea y del Consejo de Europa y haber legislado en materia de Voluntades Anticipadas, no han desarrollado el mecanismo pertinente para la posterior ratificación del Convenio de Oviedo. Este es el caso de Alemania, Austria, Bélgica, Luxemburgo, Países Bajos y Reino Unido.

También hay que señalar el caso de países que no han desarrollado legislación propia en materia de Voluntades Anticipadas, algunos de ellos a pesar de haber ratificado el Convenio de Oviedo (Tabla 6).

Tabla 6. Países sin legislación específica en VA firmantes del Convenio de Oviedo

\begin{tabular}{|c|c|}
\hline PAÍSES SIN LEGISLACIÓN SOBRE DVA & FIRMA Y RATIFICACIÓN DEL CONVENIO DE \\
OVIEDO & SI (2003) \\
\hline BULGARIA & SI (2002) \\
CHIPRE & SI (2003) \\
CROACIA & SI (1998) \\
\hline ESLOVAQUIA & SI (1998) \\
GRECIA & NO \\
\hline IRLANDA & NO \\
\hline ITALIA & SI (2002) \\
\hline LITUANIA & NO \\
\hline MALTA & NO \\
\hline POLONIA & SI (2002) \\
\hline REPÚBLICA CHECA & SI (2001) \\
\hline RUMANÍA & NO \\
\hline SUECIA & \\
\hline &
\end{tabular}

Del total de los 28 países que forman la Unión Europea solo 5 (Irlanda, Italia, Malta, Polonia y Suecia) no han desarrollado legislación sobre Voluntades Anticipadas ni se han adherido al Convenio de Oviedo (Tabla 6 y 7). 
Tabla 7. Países de la UE, año de publicación de legislación de VA y ratificación del CO

\begin{tabular}{|c|c|c|}
\hline PAIS & $\begin{array}{l}\text { AÑO DE PUBLICACION DE } \\
\text { LEGISLACIÓN EN VA }\end{array}$ & $\begin{array}{c}\text { RATIFICACION CONVENIO } \\
\text { DE OVIEDO }\end{array}$ \\
\hline ALEMANIA & 2009 & NO \\
\hline AUSTRIA & 2006 & NO \\
\hline BELGICA & 2002 & NO \\
\hline BULGARIA & - & SI (2003) \\
\hline CHIPRE & _ & SI (2002) \\
\hline CROACIA & - & SI (2003) \\
\hline DINAMARCA & 1998 & SI (1999) \\
\hline ESLOVAQUIA & - & SI (1998) \\
\hline ESLOVENIA & 2008 & SI (1999) \\
\hline ESPAÑA & 2002 & SI (2000) \\
\hline ESTONIA & 2001 & SI (2002) \\
\hline FINLANDIA & 2005 & SI (2010) \\
\hline FRANCIA & 2005 & SI (2012) \\
\hline GRECIA & - & SI (1998) \\
\hline HUNGRIA & 2009 & SI (2002) \\
\hline IRLANDA & - & NO \\
\hline ITALIA & - & NO \\
\hline LETONIA & 2009 & SI (2010) \\
\hline LITUANIA & - & SI (2002) \\
\hline LUXEMBURGO & 2009 & NO \\
\hline MALTA & - & NO \\
\hline PAISES BAJOS & 1994 & NO \\
\hline POLONIA & - & NO \\
\hline PORTUGAL & 2012 & SI (2001) \\
\hline REINO UNIDO & 2005 & NO \\
\hline REPUBLICA CHECA & - & SI (2002) \\
\hline RUMANÍA & - & SI (2002) \\
\hline SUECIA & - & NO \\
\hline
\end{tabular}




\subsection{Legislación vinculante.}

Casi la totalidad de los países que han desarrollado legislación específica en materia de Voluntades Anticipadas (13 de 15, es decir, el 86\%) le otorgan valor legal vinculante. La única excepción se da en el caso de Dinamarca y Francia, que le otorgan valor orientativo, y no determinante, en la toma de decisiones por parte del equipo médico.

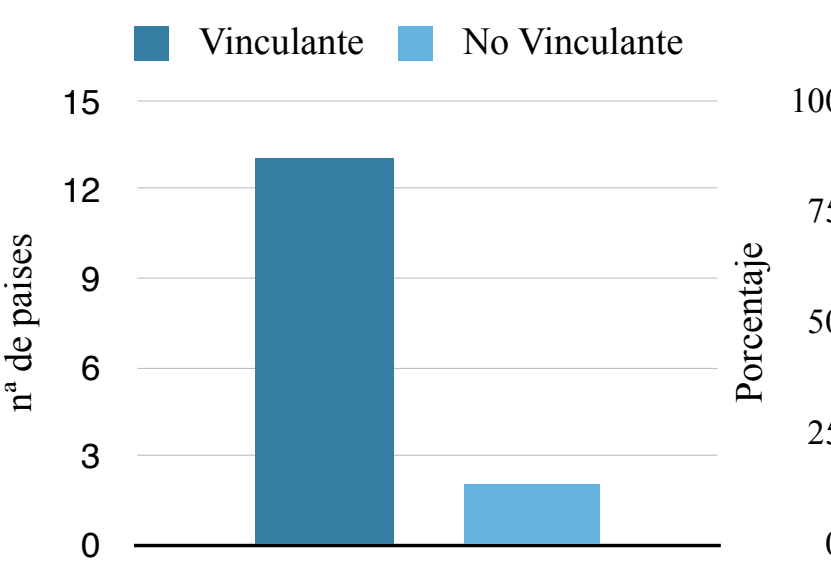

Fig. 1 Países con legislación vinculante (Nums. absolutos)

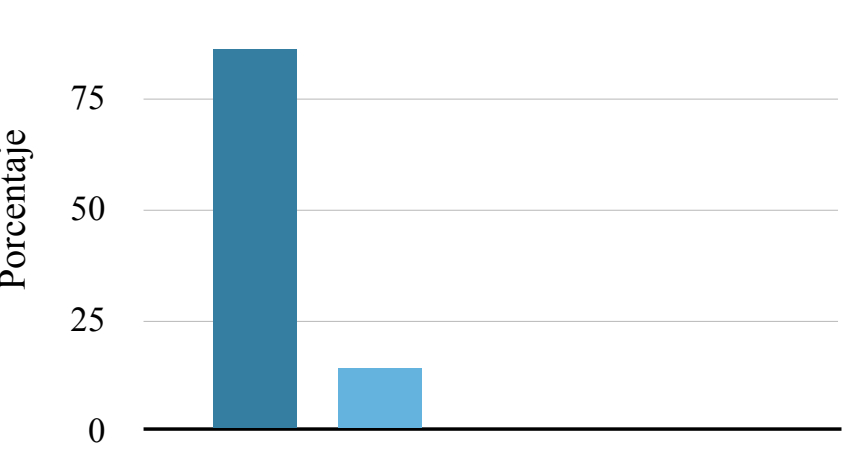

Fig.2 Países con legislación vinculante (porcentaje)

\subsection{Formulación escrita.}

La mayoría de los países han optado por la formulación escrita de las Voluntades Anticipadas, lo que supone el $86 \%$ del total. Solo el $14 \%$ restante da valor a las Voluntades Anticipadas expresadas de forma oral. Estos países son Finlandia y Estonia. Aún así, el caso de Estonia es especial. En la legislación desarrollada en este país se utilizada la fórmula "expresado" sin hacer referencia al formato que debería adoptarse. Es por ello que puede entenderse que la expresión oral es tan válida como la escrita. 


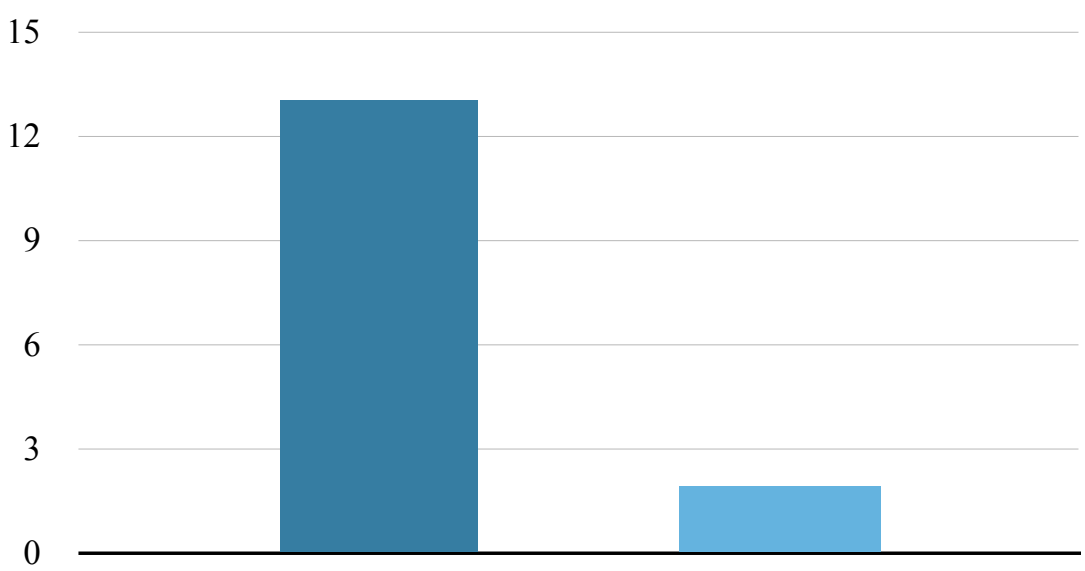

Fig 3. Número de países que exigen formato escrito

\subsection{Formalización.}

La formalización de las Voluntades Anticipadas, según contempla la legislación vigente en los pases de la Unión Europea, puede llevarse a cabo de varias formas:

A. Ante notario. El Documento de Voluntades Anticipadas se recoge en un acta notarial y es firmado por un notario que le da validez legal. Este modo en admitido en 4 países: Austria, España, Hungría y Portugal.

B. Ante testigos. El documento, tras ser cumplimentado, es firmado por un número variable de testigos ( 2 o 3 en la mayoría de los casos). Precisa de la correcta identificación de los testigos. Esta modo de formalización es válida en 3 países: España, Luxemburgo y Reino Unido. 
C. Ante la Administración. En este caso un funcionario de la Administración es el encargado de ayudar a la formalización y dar validez legal al documento. Este vía de formalización se contempla en 4 de los países: Austria, Dinamarca, España (en el caso de 10 Comunidades Autónomas) y Portugal.

D. Indeterminada. La legislación en materia de Voluntades Anticipadas no establece un modo de formalización específico y deja abierta cualquier posibilidad en un número importante de países. Normalmente en este caso, el paciente y/o su representante, en caso de existir, son los encargados de poner en conocimiento del médico responsable la existencia de Voluntades Anticipadas. Este es el caso de ocho países: Alemania, Bélgica, Estonia, Finlandia, Francia, Letonia, Luxemburgo y Países Bajos.

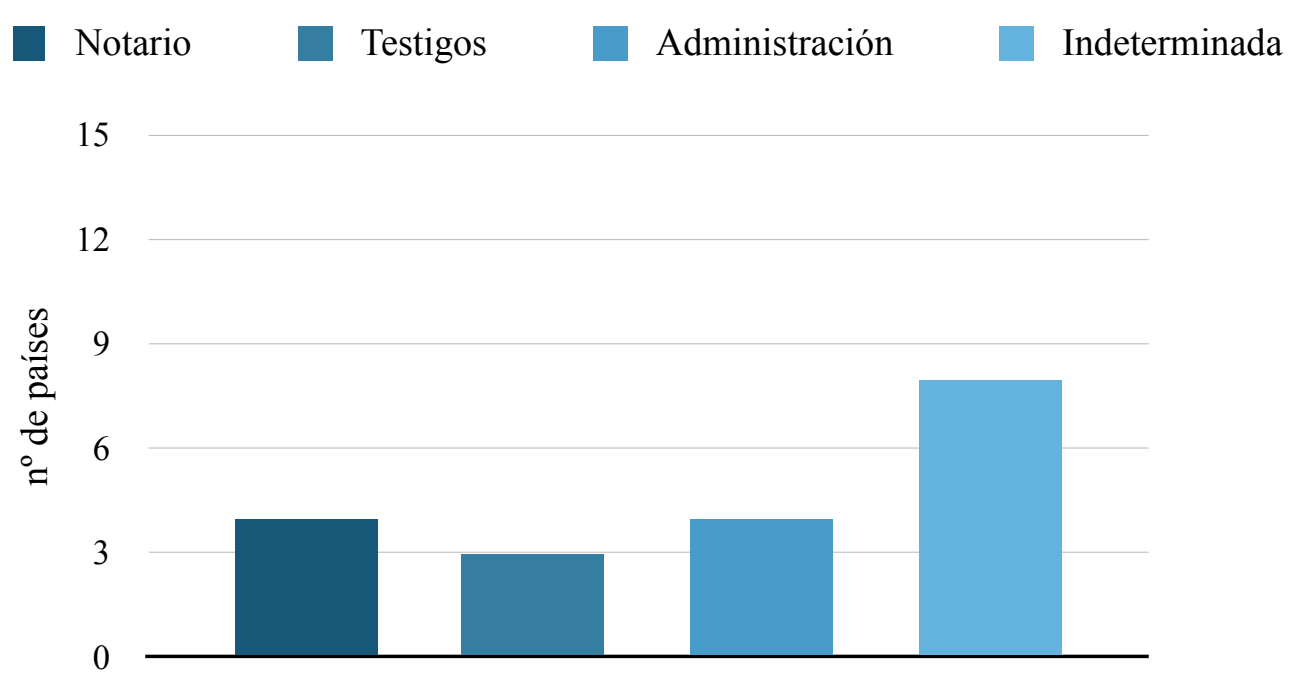

Fig 4. Modo de formalización 


\subsection{Designación de representante.}

Del total de países que han desarrollado legislación en materia de Voluntades Anticipadas, hasta en 11 de ellos se contempla la designación de representante en materia de salud. Aún así, en 6 de los mismos (Austria, Bélgica, Eslovenia, Finlandia, Hungría y Reino Unido), la designación de representante debe hacerse de forma paralela, en un documento específico y separado del Documento de Voluntades Anticipadas, si es que se pretende que dicha designación tenga carácter vinculante.

En el resto (España, Luxemburgo, Países Bajos y Portugal), la legislación contempla la posibilidad de designación de un representante en materia de salud como parte del propio Documento de Voluntades Anticipadas sin precisar de otros vías de formalización para su validez.

Solo 4 países no contemplan la designación de representante mediante el Documento de Voluntades Anticipadas. Estos son: Alemania, Dinamarca, Francia y Estonia.

En DVA En otro documento No designación de representante 15

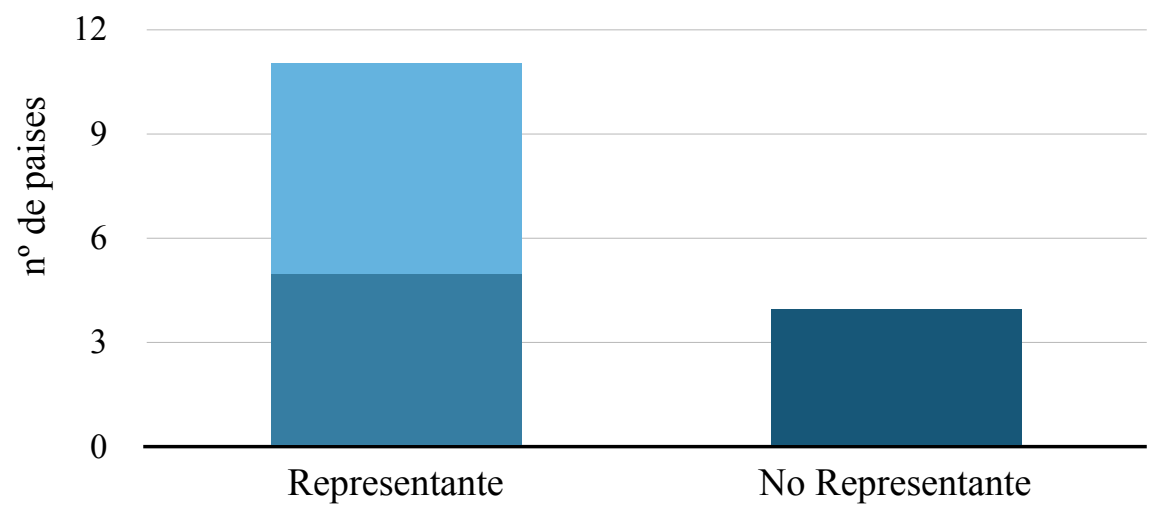

Fig 5. Designación de representante 


\subsection{El registro de Voluntades Anticipadas.}

La existencia de un registro de Voluntades Anticipadas solo se considera en una minoría de los países que tienen legislación en dicha materia. Estos son Dinamarca, España y Portugal.

El resto no contempla una localización específica para el Documento de Voluntades Anticipadas. En la mayoría de los casos se recomienda que sea el propio paciente el que ponga en conocimiento del médico responsable la existencia de Voluntades Anticipadas y que, posteriormente, quede reflejado en la historia clínica del paciente.

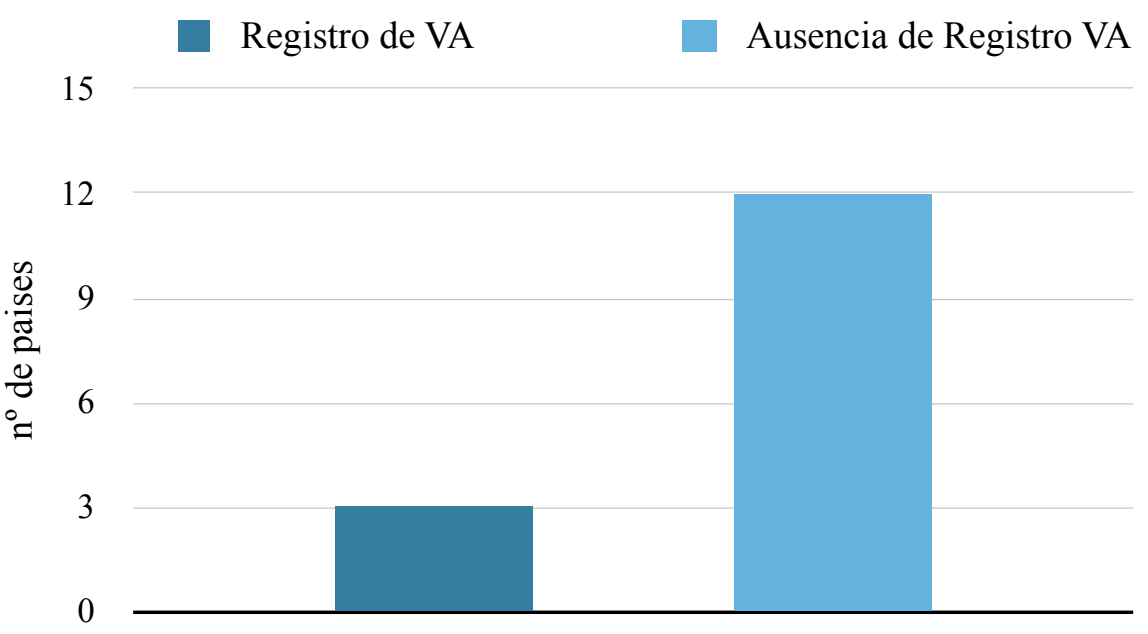

Fig. 6. Países con registro de VA

\subsection{Acceso al Documento de Voluntades Anticipadas.}

Este punto es, probablemente, uno de los más ambiguos en la legislación. En ninguna de las legislaciones vigentes en este momento en la Unión Europea se 
recoge de forma explícita quién puede tener acceso a Documento de Voluntades Anticipadas emitido por otra persona. Es de entender que el médico responsable debe tener acceso ya que, un número no desdeñable de legislaciones recomiendan que la existencia de de Voluntades Anticipadas debe ser puesta en conocimiento del médico responsable del paciente, como ya se ha referido anteriormente, y estar recogida en la historia clínica.

En los países en los que se contempla la existencia de representante, este también tiene acceso al Documento de Voluntades Anticipadas.

\subsection{Revisiones periódicas.}

Las legislaciones vigentes en la Unión Europea en materia de Voluntades Anticipadas tampoco son homogéneas en este punto. En 5 de los países es requisito imprescindible la realización de revisiones periódicas, que también son diferentes en función de cada país. En el resto de países no se contempla esta necesidad y la validez del documento es extensible a un periodo indefinido, sin pérdida de vigencia del Documento (ver tabla 8).

No obstante, en muchos de los países donde no es requisito imprescindible la revisión periódica de las Voluntades Anticipadas, la legislación si manifiesta de forma explícita la recomendación de que se hayan emitido de forma reciente. Este detalle hace referencia a que, probablemente, si las Voluntades Anticipadas han sido emitidas en un momento más cercano a aquel en que deben ser analizadas, estas serán, presumiblemente, más ajustadas a la situación real que sufre el paciente. 
Tabla 8. Distribución según necesidad de revisión del DVA

\begin{tabular}{|c|c|}
\hline $\begin{array}{c}\text { PRECISA REVISIÓN PERIODICA } \\
\text { (PERIODICIDAD) }\end{array}$ & NO PRECISA REVISIÓN PERIÓDICA \\
\hline AUSTRIA (5 años) & ALEMANIA \\
\hline ESLOVENIA (5 años) & BÉLGICA \\
\hline FRANCIA (3 años) & DINAMARCA \\
\hline HUNGRÍA (2 años) & ESPAÑA \\
\hline PORTUGAL (5 años) & ESTONIA \\
& FINLANDIA \\
& LETONIA \\
& LUXEMBURGO \\
& PAÍSES BAJOS \\
& REINO UNIDO \\
\hline
\end{tabular}

\subsection{Modificaciones de las Voluntades Anticipadas.}

En el total de las legislaciones estudiadas se contempla que las Voluntades Anticipadas y el Documento de Voluntades Anticipadas pueden ser modificados en cualquier momento, siguiendo los mismo pasos y directrices que se establecen para la primera vez que se otorgan.

\subsection{Revocación de las Voluntades Anticipadas.}

La totalidad de los países que han desarrollado legislación en materia de Voluntades Anticipadas, contemplan la posibilidad de revocación de la manifestación oral o documento escrito, en cualquier momento y sin formulación específica. Es más, en la mayoría de los casos puede entenderse por 
revocación cualquier mínima sospecha de que el otorgante ha cambiado de idea, y no precisa de su confirmación. Únicamente en el caso de Eslovenia y Luxemburgo se establece la necesidad de documento escrito, y en España se recomienda dejar constancia escrita.

\subsection{Características del contenido.}

De forma bastante homogénea, la legislación en materia de Voluntades Anticipadas en todos los países que la han desarrollado, contempla que el Documento de Voluntades Anticipadas debe recoger la solicitud de limitación de tratamiento en situaciones determinadas. Existe, no obstante, una alta variabilidad en la forma de expresarlo y de plasmarlo y presentan, así mismo, detalles que las diferencian unas de otras de forma importante.

En 12 países del total de 15 con legislación sobre Voluntades Anticipadas, se establece que el contenido del documento de Voluntades Anticipadas debe ser de rechazo a determinadas medidas de tratamiento, es decir, debe ser para denegar el consentimiento a dichas medidas. Estos países son: Alemania, Austria, Bélgica, Eslovenia, España, Estonia, Francia, Hungría, Luxemburgo, Países Bajos, Portugal y Reino Unido.

En Dinamarca (donde las Voluntades Anticipadas no se consideran vinculantes) y en Finlandia, la legislación sobre Voluntades Anticipadas contempla la inclusión de preferencias de estilo de vida y gustos personales (ropa, comida, música...), que en determinados momentos pueden ser orientativos a la hora de ofrecer cuidados. 
Limitación de tratamiento Solicitud de tratamiento orientativa

15

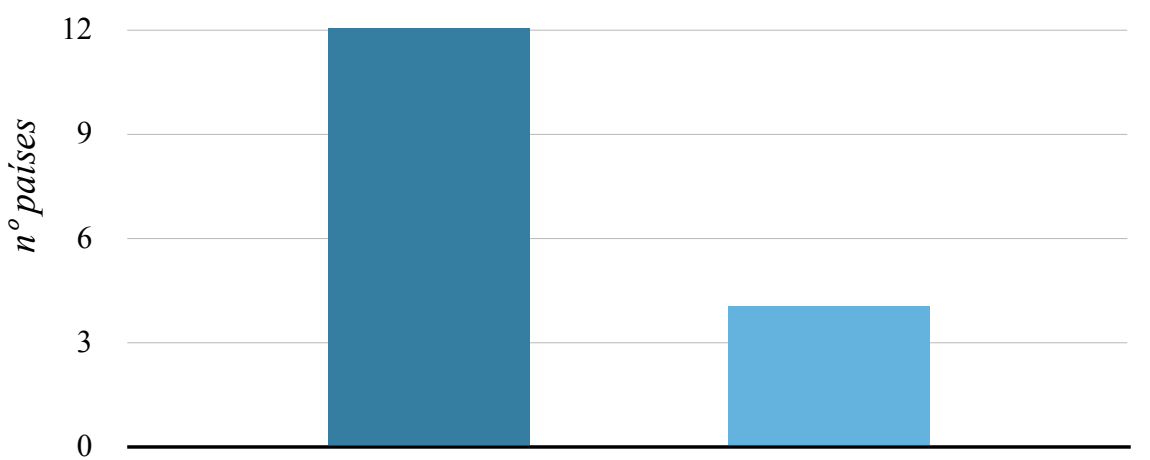

Fig 7. Característcas del contenido

En el caso de Letonia la legislación sobre Voluntades Anticipadas solo contempla la designación de representante, sin referencias a otras cuestiones.

En 4 legislaciones (Alemania, Dinamarca, España y Finlandia) se contempla de forma explícita que la solicitud de determinadas medidas de tratamiento, como contenido de las Voluntades Anticipadas no tiene validez legal, pero si puede ser considerado una guía orientativa a la hora de tomar decisiones por parte del personal médico o de su representante, si es el caso. No se contempla la administración de un determinado tratamiento solicitado por el paciente y considerado no indicado o fútil por el personal médico.

Únicamente en Bélgica y España, se contempla la posibilidad de establecer el destino de los órganos y del cuerpo en el Documento de Voluntades Anticipadas, mientras que en Hungría se puede utilizar el propio Documento para rechazar la donación de órganos. 
En tres países de la Unión Europea (Bélgica, Luxemburgo y Países Bajos), es legal la eutanasia activa y puede solicitarse, pero esta materia ocupa un lugar claramente diferenciado en la legislación. Precisa de un documento diferente y de un procedimiento específico que no es el objeto de este estudio, pero dado que hay sectores que opinan que su solicitud podría formar parte de la Voluntades Anticipadas, le dedicaré un apartado en el capítulo de Discusión.

A continuación se recogen las tablas que han servido como base para el desarrollo del presente trabajo y en las que se pueden resumir las principales características de la legislación vigente en materia de Voluntades Anticipadas, en aquellos países que la han desarrollado, incluido España (tablas 9 a 23). 

CARACTERÍSTICAS DE LA LEGISLACIÓN SOBRE VOLUNTADES ANTICIPADAS Y EL DOCUMENTO DE VOLUNTADES ANTICIPADAS

\section{PAÍS: ALEMANIA}

A.- Normativa específica

Sí (2009)

B.- Vinculante

Sí

C.- Formato escrito vs oral

Escrito

D.- Formalización

No precisa

E.- Designación de representante

No (representante legal)

F.- Personas que tienen acceso

Médico/Familia

G.- Registro

No

H.- Precisa de revisiones

No

I.- Modificable en cualquier momento

Sí

J.- Revocable

Sí

K.- Características del contenido

Rechazo tto.para prolongar la vida Solicitud de tto. paliativo 


\section{CARACTERÍSTICAS DE LA LEGISLACIÓN SOBRE VOLUNTADES ANTICIPADAS Y EL DOCUMENTO DE VOLUNTADES ANTICIPADAS}

\begin{tabular}{l|l} 
PAÍS: AUSTRIA & Sí (2006) \\
A.- Normativa específica & Sí \\
B.- Vinculante & $\begin{array}{l}\text { Escrito vinculante. } \\
\text { Oral orientativo } \\
\text { C.- Formato escrito vs oral }\end{array}$ \\
\begin{tabular}{ll} 
D.- Formalización & $\begin{array}{l}\text { Precisa de valoración de capacidad. } \\
\text { Ante notario, abogado, Admón. }\end{array}$ \\
E.- Designación de representante & Sí. (documento específico) \\
F.- Personas que tienen acceso & $\begin{array}{l}\text { Médico } \\
\text { Represenante }\end{array}$ \\
G.- Revocable & $\begin{array}{l}\text { No. Recogida en H.C. } \\
\text { I.- Modificable en cualquier momento }\end{array}$ \\
H.- Precisa de revisiones & $\begin{array}{l}\text { Sí, cada } 5 \text { años, hasta pérdida de } \\
\text { capacidad }\end{array}$ \\
\hline Designación de represente.
\end{tabular} \\
\hline
\end{tabular}


CARACTERÍSTICAS DE LA LEGISLACIÓN SOBRE VOLUNTADES ANTICIPADAS Y EL DOCUMENTO DE VOLUNTADES ANTICIPADAS

\begin{tabular}{|c|c|}
\hline A.- Normativa específica & Sí (2002) \\
\hline B.- Vinculante & Sí \\
\hline C.- Formato escrito vs oral & Escrito \\
\hline D.- Formalización & Sin fórmula específica \\
\hline E.- Designación de representante & Sí (documento específico) \\
\hline F.- Personas que tienen acceso & Cualquiera \\
\hline G.- Registro & No \\
\hline H.- Precisa de revisiones & No \\
\hline I.- Modificable en cualquier momento & Sí \\
\hline J.- Revocable & Sí \\
\hline K.- Características del contenido & $\begin{array}{l}\text { Rechazo tto. / Donación de órganos } \\
\text { Designación de represente* y Eutanasia activa* } \\
\text { (*leyes específicas) }\end{array}$ \\
\hline
\end{tabular}




\section{CARACTERÍSTICAS DE LA LEGISLACIÓN SOBRE VOLUNTADES ANTICIPADAS Y EL DOCUMENTO DE VOLUNTADES ANTICIPADAS}

\begin{tabular}{|c|c|}
\hline \multicolumn{2}{|l|}{ PAÍS: DINAMARCA } \\
\hline A.- Normativa específica & Sí (2005) \\
\hline B.- Vinculante & No (situación clínica) \\
\hline C.- Formato escrito vs oral & Escrito \\
\hline D.- Formalización & $\begin{array}{l}\text { Documento oficial en registro } \\
\text { Documento firmado en HC }\end{array}$ \\
\hline E.- Designación de representante & No (representante legal) \\
\hline F.- Personas que tienen acceso & $\begin{array}{l}\text { Personal de la Admón. } \\
\text { Personal sanitario }\end{array}$ \\
\hline G.- Registro & Sí \\
\hline H.- Precisa de revisiones & No \\
\hline I.- Modificable en cualquier momento & Sí \\
\hline J.- Revocable & Sí (escrito y oral) \\
\hline K.- Características del contenido & $\begin{array}{l}\text { Rechazo al tto. para prolongar la vida. } \\
\text {-En enfermedad terminal: puede ser vinculante } \\
\text {-En enfermedad degenerativa: No vinculante }\end{array}$ \\
\hline
\end{tabular}




\section{CARACTERÍSTICAS DE LA LEGISLACIÓN SOBRE VOLUNTADES ANTICIPADAS Y EL DOCUMENTO DE VOLUNTADES ANTICIPADAS}

\begin{tabular}{|c|c|}
\hline \multicolumn{2}{|l|}{ PAÍS: ESLOVENIA } \\
\hline A.- Normativa específica & Sí (2008) \\
\hline B.- Vinculante & Sí (en enfermedad terminal) \\
\hline C.- Formato escrito vs oral & Escrito \\
\hline D.- Formalización & Formulario específico \\
\hline E.- Designación de representante & Sí (documento específico notarial) \\
\hline F.- Personas que tienen acceso & $\begin{array}{l}\text { Médico responsable } \\
\text { Representante }\end{array}$ \\
\hline G.- Registro & No \\
\hline H.- Precisa de revisiones & Sí, cada 5 años \\
\hline I.- Modificable en cualquier momento & Sí \\
\hline J.- Revocable & Sí, por escrito \\
\hline K.- Características del contenido & $\begin{array}{l}\text { Rechazo al tto. para prolongar la vida. } \\
\text {-En enfermedad terminal: vinculante } \\
\text {-En enfermedad degenerativa: No vinculante }\end{array}$ \\
\hline
\end{tabular}


CARACTERÍSTICAS DE LA LEGISLACIÓN SOBRE VOLUNTADES ANTICIPADAS Y EL DOCUMENTO DE VOLUNTADES ANTICIPADAS

\section{PAÍS: ESPAÑA}

A.- Normativa específica

Sí (2002)

B.- Vinculante

Sí

C.- Formato escrito vs oral

Escrito

D.- Formalización

E.- Designación de representante

F.- Personas que tienen acceso

G.- Registro

Ante notario, testigos, personal de la Administración

Sí

Representante, médico, y personal de la Administración

Sí

H.- Precisa de revisiones

No

I.- Modificable en cualquier momento Sí

J.- Revocable

Sí

K. Características del contenido

Rechazo tto. para prolongar la vida. Solicitud tto. paliativo.

Designar de represente. Donación de órganos 
CARACTERÍSTICAS DE LA LEGISLACIÓN SOBRE VOLUNTADES ANTICIPADAS Y EL DOCUMENTO DE VOLUNTADES ANTICIPADAS

\section{PAÍS: ESTONIA}

A.- Normativa específica

B.- Vinculante

C.- Formato escrito vs oral

D.- Formalización

E.- Designación de representante

F.- Personas que tienen acceso

G.- Registro

H.- Precisa de revisiones

I.- Modificable en cualquier momento

J.- Revocable

K.- Características del contenido
Sí (2001)

(no desarrollada)

Sí

"expresado"

Sin legislar

No (representante legal)

Cualquiera

No

No

Sí

Sin referencia

Rechazo a tratamiento para prolongar la vida 


\section{CARACTERÍSTICAS DE LA LEGISLACIÓN SOBRE VOLUNTADES ANTICIPADAS Y EL DOCUMENTO DE VOLUNTADES ANTICIPADAS}

\begin{tabular}{|c|c|}
\hline \multicolumn{2}{|l|}{ PAÍS: FINLANDIA } \\
\hline A.- Normativa específica & Sí (1992) \\
\hline B.- Vinculante & Sí \\
\hline C.- Formato escrito vs oral & $\begin{array}{l}\text { Escrito ante testigos } \\
\text { Oral }\end{array}$ \\
\hline D.- Formalización & No precisado \\
\hline E.- Designación de representante & Sí. (documento específico) \\
\hline F.- Personas que tienen acceso & Personal médico \\
\hline G.- Registro & $\begin{array}{l}\text { No. } \\
\text { Recogido en H.C. y firmado }\end{array}$ \\
\hline H.- Precisa de revisiones & No \\
\hline I.- Modificable en cualquier momento & Sí \\
\hline J.- Revocable & Sí \\
\hline K.- Características del contenido & $\begin{array}{l}\text { Rechazo tto. para prolongar la vida. } \\
\text { Solicitud tto. paliativo. Designar represente. }\end{array}$ \\
\hline
\end{tabular}




\section{CARACTERÍSTICAS DE LA LEGISLACIÓN SOBRE VOLUNTADES ANTICIPADAS Y EL DOCUMENTO DE VOLUNTADES ANTICIPADAS}

Tabla 17. Características de las VA y DVA en Francia

\begin{tabular}{|l|l|}
\hline PAÍS: FRANCIA & Sí (2002) \\
A.- Normativa específica & No \\
B.- Vinculante & Escrito y firmado \\
C.- Formato escrito vs oral & No precisa \\
D.- Formalización & $\begin{array}{l}\text { No ("persona de confianza", que no es } \\
\text { determinante) }\end{array}$ \\
E.- Designación de representante & Personal médico \\
F.- Personas que tienen acceso & Sí \\
J.- Revocable & Solicitud tto. paliativo. Designar represente. \\
G.- Registro & Cada 3 años. \\
H.- Precisa de revisiones & \\
\hline
\end{tabular}




\section{CARACTERÍSTICAS DE LA LEGISLACIÓN SOBRE VOLUNTADES ANTICIPADAS Y EL DOCUMENTO DE VOLUNTADES ANTICIPADAS}

\section{Tabla 18. Características de las VA y DVA en Hungría}

\section{PAÍS: HUNGRÍA}

A.- Normativa específica
B.- Vinculante
C.- Formato escrito vs oral
D.- Formalización

E.- Designación de representante

F.- Personas que tienen acceso

G.- Registro

H.- Precisa de revisiones

I.- Modificable en cualquier momento

J.- Revocable

K.- Características del contenido
Sí (1997)

Sí

Escrito

Acto notarial, previa valoración médica no anterior a un mes

Sí. Acto notarial diferente, con dos testigos y examinado por comité científico

Médico responsable

No

Cada dos años

Sí

Sí

Rechazo tto. para prolongar la vida.

Designar represente.

Rechazar donación de órganos. 


\section{CARACTERÍSTICAS DE LA LEGISLACIÓN SOBRE VOLUNTADES ANTICIPADAS Y EL DOCUMENTO DE VOLUNTADES ANTICIPADAS}

\section{PAÍS: LETONIA}

A.- Normativa específica

B.- Vinculante

C.- Formato escrito vs oral

D.- Formalización

E.- Designación de representante

F.- Personas que tienen acceso

G.- Registro

H.- Precisa de revisiones

I.- Modificable en cualquier momento

J.- Revocable

K.- Características del contenido
Sí (2009)

Sí, en designación de representante

Escrito

Informar a la institución sanitaria

Sí

Personal sanitario

No

No

Sí

Sí

Designación de representante 


\section{CARACTERÍSTICAS DE LA LEGISLACIÓN SOBRE VOLUNTADES ANTICIPADAS Y EL DOCUMENTO DE VOLUNTADES ANTICIPADAS}

\section{PAÍS: LUXEMBURGO}

A.- Normativa específica

B.- Vinculante

C.- Formato escrito vs oral

D.- Formalización

E.- Designación de representante

F.- Personas que tienen acceso

G.- Registro

H.- Precisa de revisiones

I.- Modificable en cualquier momento

J.- Revocable

K.- Características del contenido
Sí (2014)

Sí

Escrito (fecha y firma)

Oral ante testigos

No precisa acto notarial

Sí

Médico responsable

No. Recogido en HC

No

Sí

En cualquier momento, por escrito con fecha y firma

Rechazo tto. para prolongar la vida.

Solicitat tto. paliativo. Designar de represente.

Eutanasia (legal) precisa de otro documento 
CARACTERÍSTICAS DE LA LEGISLACIÓN SOBRE VOLUNTADES ANTICIPADAS Y EL DOCUMENTO DE VOLUNTADES ANTICIPADAS

Tabla 21. Características de las VA y DVA en los Países Bajos

PAÍS: PAISES BAJOS

A.- Normativa específica

Sí (1995)

B.- Vinculante

Sí

C.- Formato escrito vs oral

Escrito

D.- Formalización

Sin formalización específica

E.- Designación de representante

Sí

F.- Personas que tienen acceso

Personal sanitario

G.- Registro

No

H.- Precisa de revisiones

No

I.- Modificable en cualquier momento

Sí

J.- Revocable

Sí, en cualquier momento

K.- Características del contenido

Rechazo tto. para prolongar la vida Eutanasia legal (ley específica) 
CARACTERÍSTICAS DE LA LEGISLACIÓN SOBRE VOLUNTADES ANTICIPADAS Y EL DOCUMENTO DE VOLUNTADES ANTICIPADAS

PAÍS: PORTUGAL

A.- Normativa específica

Sí (2012)

B.- Vinculante

Sí

C.- Formato escrito vs oral

Escrito

D.- Formalización

E.- Designación de representante

F.- Personas que tienen acceso

G.- Registro

En el registro

Ante notario

Sí

Personal médico y representante

Sí

H.- Precisa de revisiones

Cada 5 años

I.- Modificable en cualquier momento Sí

J.- Revocable

Sí, en cualquier momento

Rechazo tto. para prolongar la vida.

K.- Características del contenido 


\section{CARACTERÍSTICAS DE LA LEGISLACIÓN SOBRE VOLUNTADES ANTICIPADAS Y EL DOCUMENTO DE VOLUNTADES ANTICIPADAS}

\section{PAÍS: REINO UNIDO}

A.- Normativa específica

Sí

B.- Vinculante

Sí

C.- Formato escrito vs oral

Escrito, con firma

Oral válida

D.- Formalización

Firmada por un testigo

E.- Designación de representante

F.- Personas que tienen acceso

Personal sanitario, familiares

G.- Registro

No. Recogida en H.C.

H.- Precisa de revisiones

No

I.- Modificable en cualquier momento Sí

J.- Revocable

Sí, en cualquier momento

Rechazo tto. para prolongar la vida.

K.- Características del contenido 

Capítulo 5

Discusión 

Con la publicación en España de la Ley 41/2002 27 , Básica reguladora de la autonomía del paciente y de derechos y obligaciones en materia de información y documentación clínica, se legisla, por fin, en el ámbito estatal sobre Voluntades Anticipadas. Podría parecer, y no deja de ser cierto, que se ha tardado demasiado en otorgar la autonomía a los pacientes y darles la posibilidad de formar parte de la toma de decisiones aun en situación de incapacidad, bien sea su aparición lenta y progresiva o inesperada.

Aunque ya la Ley General de Sanidad ${ }^{54}$ puso en valor el principio de autonomía, no alcanzó a tratar sobre las Voluntades Anticipadas. En España, la firma y posterior ratificación del Convenio de Oviedo, supuso el estímulo necesario para que los legisladores tomaran conciencia de la importancia de esta materia y la demanda creciente que hacía la sociedad española en particular, y la europea en general, en relación a esta cuestión.

Como decía, si bien parece que la legislación sobre Voluntades Anticipadas ha tardado demasiado en España, cabe resaltar que es de los primeros países que disponen de una ley completa y hasta cierto punto ambiciosa, a pesar de que evidentemente, se le pueden hacer muchas críticas ${ }^{1,31,38}$.

Nuestra ley sobre Voluntades Anticipadas, entre otras cosas es vinculante, abierta en su contenido y permite la designación de un representante, sin la necesidad de que este sea representante legal, al que otorga la capacidad de tomar las decisiones oportunas en materia de salud, buscando el juicio sustitutivo. Pero esto no es constante, ni homogéneo, en el resto de países que forman la Unión Europea, con independencia de su adhesión al Convenio de Oviedo. Las características de la legislación en cada país, donde se ha 
desarrollado, difieren en mayor o menor grado unas respecto de otras. El panorama dista mucho de ser uniforme, como se desprende de este trabajo.

\subsection{El Convenio de Oviedo. Legislación en materia de Voluntades Anticipadas.}

El Consejo de Europa es una organización intergubernamental que actualmente comprende 47 estados miembros, incluyendo los 28 estados que forman parte de la Unión Europea. Su función es salvaguardar y proteger los ideales y principios que son patrimonio común de sus estados miembros: democracia, derechos humanos y el respeto de la ley ${ }^{59}$. Todos los estados miembros del Consejo de Europa han firmado el Convenio Europeo de Derechos Humanos ${ }^{60}$, un tratado diseñado para la protección de los derechos humanos, la democracia y para garantizar el respeto de la ley.

En la actualidad, la Unión Europea esta conformada por 28 países, siendo el último en adherirse Croacia, en 2013. Todos los países que forman parte de la Unión Europea se encuentran a su vez incluidos en el Consejo de Europa, pero solo una parte de ellos, en concreto 17 (ver tabla 3), han ratificado el Convenio de Oviedo.

Antes de continuar, y dada la trascendencia que tiene a la hora de interpretar los resultados de este trabajo, quiero aclarar el significado de algunos términos ${ }^{61}$, lo que permitirá dar a cada expresión la importancia que tiene en el contexto que nos ocupa: 
Convenio: Es el acuerdo formal entre los Estados, sinónimo de "tratado". Generalmente es un documento abierto a la participación de la comunidad internacional.

Firma o Adhesión: Es el acto por el cual un Estado expresa su interés en el tratado y su intención de convertirse en parte del mismo. El Estado que firma la adhesión no está obligado por la firma. Sin embargo, tiene la obligación de no frustrar el objeto y fin del mismo.

Ratificación: La ratificación es un acto por el cual el Estado expresa su consentimiento definitivo a obligarse por el tratado. A partir de ese momento, debe respetar las disposiciones del tratado y aplicarlas. Generalmente el mecanismo de ratificación consta de dos partes. La primera, de ámbito nacional, es aquella por la que el Consejo de Ministros remite a las Cortes Generales, si procede, el tratado y una vez aprobado se emite por el Ministerio de Asuntos Exteriores el correspondiente instrumento de ratificación, que debe ser firmado por el Jefe del Estado y refrendado por el Ministerio de Asuntos Exteriores. Posteriormente, en una segunda fase, internacional, es este Ministerio el que debe adoptar las medidas pertinentes para proceder al depósito del instrumento de ratificación del tratado, en este caso, en la Secretaria del Consejo de Europa.

Aclarada la terminología y llegados a este punto, podemos afirmar, sin miedo a equivocarnos, que el Convenio de Oviedo es un documento de aplicación internacional, de la mayor relevancia, equiparado a la Declaración Universal de Derechos Humanos, que es considerado uno de los cinco documentos más importantes a nivel mundial ${ }^{41}$ y que supone un marco legislativo común para los países firmantes ${ }^{3}$. 
Sin embargo, el Convenio no ha sido adoptado por la totalidad de los estados miembros del Consejo de Europa, ni por la totalidad de los países integrantes de la Unión Europea ${ }^{3}$. Esto pone de manifiesto las diferencias importantes que existen, sobre las Voluntades Anticipadas, en el seno de la Unión Europea, ámbito geopolítico objetivo del presente estudio.

No obstante, la no adhesión al Convenio de Oviedo no implica la ausencia de legislación en materia de Voluntades Anticipadas. Por otra parte, la ratificación de dicho convenio tampoco implica el haber desarrollado la legislación pertinente. Así son 15 países de la Unión Europea (ver tabla 4) los que han desarrollado legislación propia en materia de Voluntades Anticipadas, con independencia de su adhesión al Convenio de Oviedo.

Ante este panorama se puede hacer ya una valoración inicial. Si bien el Consejo de Europa, comenzando por el Convenio de Oviedo y siguiendo por el estímulo a la elaboración de legislación propia en cada país, trata de otorgar una importante solidez jurídica a las Voluntades Anticipadas, el marco legislativo europeo es tan heterogéneo que difícilmente en el momento actual podemos encontrar dos estados con legislaciones similares. No obstante podemos establecer un esquema general de la siguiente manera:

Grupo A. Países que han ratificado el Convenio de Oviedo y han desarrollado legislación específica en materia de Voluntades Anticipadas: Dinamarca, Eslovenia, España, Estonia, Finlandia, Francia, Hungría, Letonia y Portugal.

Los países incluidos en este grupo firmaron su adhesión al Convenio de Oviedo el mismo día de su apertura a la firma ${ }^{3}$ a excepción de Hungría, 
que lo hizo dos años más tarde. La posterior ratificación del Convenio ha estado ligada al desarrollo de legislación propia en materia de Voluntades Anticipadas, a pesar de las características diferenciales que cada país ha introducido.

Grupo B. Países que han ratificado el Convenio de Oviedo y no han desarrollado legislación específica en materia de Voluntades Anticipadas: Bulgaria, Chipre, Croacia, Eslovaquia, Grecia, Lituania, República Checa y Rumanía.

La mitad de los países integrantes de este grupo firmaron el Convenio de Oviedo el día de su apertura a la firma y el resto han ido firmando su adhesión al mismo de forma progresiva. Todos ellos lo han ratificado. No obstante, este compromiso no ha servido de suficiente empuje para la aprobación de legislación propia en materia de Voluntades Anticipadas.

Grupo C. Países que no han ratificado el Convenio de Oviedo y si han desarrollado legislación específica en materia de Voluntades Anticipadas: Alemania, Austria, Bélgica, Luxemburgo, Países Bajos y Reino Unido.

Los países integrantes de este grupo, destacan por su importante tradición y activismo dentro del continente europeo, en favor de los derechos del paciente, así como el respeto a la autonomía del individuo. Tanto es así, que no podemos pasar por alto que en este grupo se encuentran Bélgica, Países Bajos y Luxemburgo, estados en los que se ha legalizado la eutanasia activa $^{62,63,64}$. A pesar de todo ello, los países integrantes de este grupo, no han firmado su adhesión al Convenio de Oviedo. 


\section{Grupo D. Países que no han ratificado el Convenio de Oviedo ni han desarrollado legislación específica en materia de Voluntades Anticipadas: Irlanda, Italia, Malta, Polonia y Suecia.}

Las circunstancias de Irlanda e Italia difieren sensiblemente de las del resto de sus compañero de grupo. En Italia, el proyecto de Ley "Disposizioni in materia di alleanza terapeutica, di consenso informato e di dichiarazioni anticipate di trattamento" se encuentra en trámites actualmente. Tras ser aprobada por la Camara Baja, está pendiente de su confirmación por el Senado, eso sí, desde 2011. Por otra parte, a fecha de 1 de Abril de 2015, Italia sigue sin haber ratificado el Convenio de Oviedo a pesar de haberlo firmando, puesto que no se han completado los mecanismos previstos para su ratificación. Por su parte, Irlanda no ha firmado el Convenio de Oviedo, pero sí se encuentra en trámites de aprobar una ley en materia de Voluntades Anticipadas ${ }^{65}$ (Assisted decision-making (Capacity) Bill).

Polonia y Suecia, a pesar de haber firmado su adhesión al Convenio, no lo han ratificado y tampoco han desarrollado legislación específica sobre Voluntades Anticipadas.

Aun así, el hecho de no haber desarrollado legislación específica en relación a las Voluntades Anticipadas no implica la ausencia de un marco legislativo mínimo vinculante. En el caso de los países que han ratificado el Convenio de Oviedo (Grupo B), pasaría a tener validez el artículo 9 del Convenio de Oviedo (Deseos expresados anteriormente) según el cual "Serán tomados en consideración los deseos expresados anteriormente con respecto a una intervención médica por un paciente que, en el momento de la intervención, no se encuentre en situación de expresar su voluntad"3. 
Así pues, dado el carácter vinculante del texto, en todos aquellos países que han ratificado el Convenio, los deseos expresados anteriormente, en relación a una situación de enfermedad, cuando el paciente ya no puede expresarse, deben ser tenidos en cuenta como una expresión de libertad y autonomía.

Además, estos conceptos son respaldados por otros artículos recogidos también en el Convenio de Oviedo, como son el artículo 5 que garantiza que no se puede llevar a cabo ninguna intervención sin el consentimiento previo de la persona, poniendo en valor así la autonomía del sujeto, de la misma forma que el artículo 2 pone en valor la libertad, ya que refiere que los intereses y el bienestar del ser humano prevalecerá sobre los intereses de la ciencia y la sociedad ${ }^{66}$.

Por su parte, el Consejo de Europa ha llevado a cabo diversas iniciativas con el objeto de estimular a los países integrantes en el desarrollo de medidas legislativas en relación a la autonomía del paciente ${ }^{51,52}$, la última de las cuales ha sido la publicación de una guía para el proceso de toma de decisiones, en relación al tratamiento al final de la vida, con carácter únicamente informativo ${ }^{67}$.

No obstante, tanto las medidas legislativas como las no legislativas han tenido un seguimiento desigual a pesar de que sus implicaciones son evidentes. Esto puede ser debido a que no existe consenso en la forma de entender y aceptar el alcance del propio documento; efectivamente, podemos encontrar en la bibliografía autores que se refieren al Convenio de Oviedo como un "documento internacional", en otras ocasiones como un "documento europeo" y en otras ocasiones se refieren al Convenio como una "ley importante" 68 . Esta variabilidad no tiene sentido teniendo en cuenta que el Convenio de Oviedo se define a sí mismo de la siguiente manera: 
"The Convention is the first legally-binding international text designed to preserve human dignity, rights and freedoms, through a series of principles and prohibitions against the misuse of biological and medical advances" ${ }^{\prime 3}$.

(El Convenio es el primer texto internacional legalmente vinculante diseñado para preservar la dignidad humana, los derechos y las libertades a través de una serie de principios y prohibiciones contra el mal uso de los avances médicos y biológicos).

\subsection{Legislación vinculante.}

El texto, tal y como se ha referido anteriormente, fue concebido para generar un marco legal homogéneo y vinculante. Quiere esto decir que las Voluntades Anticipadas tienen validez legal y que, salvando las situaciones donde no es aplicable, bien por no encontrarse en el escenario descrito por el documento o bien por ser contrarias a la ley, debe ser respetado.

En la mayoría de los países donde se ha desarrollado legislación específica sobre Voluntades Anticipadas se ha dotado a las mismas de carácter vinculante (ver fig.1 y fig.2), salvo en casos como el de Dinamarca, donde la solicitud de limitación del tratamiento solo tiene carácter vinculante en las situaciones de muerte "inevitable", donde la aplicación de tratamiento agresivo podría llegar a ser considerado futilidad. En el caso de edad avanzada, accidente, parada cardiaca o incapacidad física o mental, las Voluntades Anticipadas solo servirán al médico responsable "como guía", a modo orientativo, en las consideraciones relativas al tratamiento que se debe aplicar ${ }^{69}$. La Ley de Salud danesa ha sufrido varias modificaciones a lo largo de su existencia, pero no se han registrado 
variaciones en lo relativo a las Voluntades Anticipadas (Livstestamenter). En Francia las Voluntades Anticipadas tampoco cumplen su objetivo último, puesto que la ley no las ha refrendado con carácter vinculante ${ }^{70}$.

En el resto de países se han desarrollado legislaciones con Voluntades Anticipadas legalmente vinculantes aunque, algunos de ellos, con matices. Es el caso de Alemania ${ }^{71}$ y de Países Bajos ${ }^{72}$, donde la ley exige que la situación clínica del paciente sea exactamente la que se describe en las Voluntades Anticipadas ("se deben cumplir todos los requisitos") para poder tener efecto vinculante. En Austria la formalización ante notario genera validez legal mientras que un documento manuscrito, sin necesidad de firmas de testigos, no es vinculante ${ }^{73}$. En el caso de Eslovenia solo tienen efecto vinculante si el paciente se encuentra en situación terminal ${ }^{74}$.

En Hungría, el carácter vinculante de las Voluntades Anticipadas esta sujeto a un protocolo de elaboración estricto y encorsetado que dificulta su acceso de forma evidente y que sigue sin dar preferencia al principio de autonomía, ya que el efecto vinculante está sujeto a la aceptación de las Voluntades Anticipadas por parte de un comité de valoración, compuesto por el médico responsable, otro especialista del área y un psiquiatra ${ }^{75}$. En Reino Unido se da la opción al equipo médico de no cumplir con las Voluntades Anticipadas, aduciendo exigencias relativas a la situación clínica del paciente o dando más importancia al criterio médico que al del paciente o al de su representante. No obstante, para hacer valer este punto se exige justificación evidente y razonada ${ }^{76}$.

En cuanto a los países que no han desarrollado legislación específica, destacar de nuevo que, aquellos firmantes del Convenio de Oviedo, que sí es de carácter vinculante, deberían regirse por el artículo nueve ("serán tomados en consideración los deseos expresados con anterioridad (...)”. 


\subsection{Formato escrito. Validez de las Voluntades Anticipadas expresadas de forma oral.}

El Convenio de Oviedo ve la luz con una referencia explicita a la validez de expresión de voluntad por anticipado y con omisión, probablemente intencionada, de la forma o formato que esta expresión debe tener.

Las iniciativas del Consejo de Europa para estimular a sus países miembros a legislar en favor de las Voluntades Anticipadas, no obstante, plantean la necesidad de un formato escrito y, en ese caso, es cada país el que debe decidir en que dirección quiere legislar. Así, en la Recommendation CM/Rec(2009)11 del Consejo de Europa ${ }^{51}$, en el punto 1 del Principio 16 (Forma) podemos leer: "Los Estados deben considerar si las Voluntades Anticipadas o determinados tipos de Voluntades Anticipadas deben ser plasmadas o recogidas en formato escrito si se busca su efecto legal vinculante".

Mayoritariamente, hasta un $86 \%$ de los países que han legislado en materia de Voluntades Anticipadas, han optado por el formato escrito (ver fig. 3). Únicamente Finlandia y Letonia dan valor vinculante a las Voluntades expresadas de forma oral, aunque ambas leyes son expresamente vagas en su redacción en cuanto a la formalización, dejando demasiado margen a la duda sobre su validez. No obstante y haciendo una interpretación literal de ambas legislaciones, a la hora de hacer referencia a las Voluntades Anticipadas utilizan la fórmula "expresadas", sin hacer mención a si esa expresión puede ser oral o debe ser por escrito.

En cualquier caso la reflexión adecuada en este punto sería ¿es necesario un Documento de Voluntades Anticipadas? Desde mi punto de vista la repuesta es 
sí. Sí es necesario un documento que permita dejar "expresada" la voluntad del sujeto, pero no debería ser imprescindible. Es cierto que la redacción de un documento supone dejar constancia de cual es la voluntad del paciente mas allá de las palabras y opiniones que los testigos de una conversación puedan recordar, y puede ser muy útil en caso de conflicto, pero no por ello una conversación en la que el paciente exprese su voluntad debe ser menos válida. No deberíamos dejarnos arrastrar por una corriente legalista que haga el procedimiento menos ágil y se limite únicamente a constatar si existe un papel firmado en el que se expresen unas cuantas ideas que se hayan de interpretar de forma literal, ni olvidar la idea de que las Voluntades Anticipadas, desde un punto de vista ético, constituyen un proceso que permita constatar la propia voluntad, más que un fin en sí mismas.

\subsection{Formalización.}

La formalización del Documento de Voluntades Anticipadas supone un trámite administrativo no exento de escollos, que son múltiples y variopintos en función del país de la Unión Europea en el que nos encontremos.

En el caso de la legislación española, una vez redactado el Documento de Voluntades Anticipadas, para ser legalmente vinculante precisa de firma notarial o de la firma de 3 testigos sin relación familiar ni contractual. Otra forma de darle validez, aceptada en muchas de nuestras Comunidades Autónomas, aunque no en la Comunidad Valenciana, es procurar la firma de un representante de la Administración, situación también factible en algunos países europeos. Estas tres posibilidades son las que más se repiten en las legislaciones europeas disponibles (ver fig. 4). 
El caso de Austria es especialmente restrictivo comparado con el resto de su entorno. En la legislación austriaca ${ }^{77}$ se exige la valoración previa de capacidad del paciente por un médico. Esta valoración no debe tener una antigüedad superior a un mes en el momento de la consignación del Documento de Voluntades Anticipadas. También implica, por parte del médico, la estimación del grado de comprensión que el paciente hace de su situación y de las consecuencias que implica el emitir las Voluntades Anticipadas, así como de su contenido. Una vez cumplimentado este paso, el Documento de Voluntades Anticipadas debe ser presentado ante un notario, un abogado o un representante de la Administración. En los dos primeros casos el proceso se encarece de forma bastante importante, puesto que los honorarios por este tipo de procedimientos pueden alcanzar en Austria hasta los $500 \operatorname{euros}^{73}$, lo que puede suponer una limitación considerable en el acceso al Documento de Voluntades Anticipadas.

La legislación húngara ${ }^{75}$ presenta similitudes con el caso anterior: precisa de la valoración médica, no más antigua de un mes en el momento de la consignación del documento, y exige que la valoración se realice por un comité compuesto por el médico responsable del paciente, un médico especialista del área y un psiquiatra. Tras esta valoración, el documento emitido precisa de un acta notarial que le otorgue validez legal.

En el resto de países donde se contempla como posible la formalización ante notario, España y Portugal, esta no es la única vía. Puede hacerse también ante personal de la Administración en el caso de Portugal, como sucede también en Dinamarca. En España, como ya se ha referido, también puede hacerse ante testigos y, en algunas Comunidades Autónomas (en concreto Andalucía, Balerares, Canarias, Castilla La Mancha, Castilla-León, La Rioja, Madrid, Murcia y País Vasco), ante un representante de la Administración. En el caso de la Comunidad Valenciana, la ley establece que el Documento de Voluntades 
Anticipadas podrá ser formalizado ante 3 testigos, ante notario o "cualquier otro procedimiento que sea establecido legalmente" 78 .

Probablemente la forma más sencilla y asequible sea la utilización de testigos, puesto que permite generar un documento vinculante sin necesidad de un desembolso económico importante y sin necesidad de desplazamiento por parte del paciente. De esta manera sería posible que un paciente con limitación de la movilidad, hospitalizado por ejemplo, pueda emitir sus Voluntades Anticipadas sin ninguna dificultad. Solo precisaría de dos o tres testigos (en función de su localización geográfica), sin relación familiar ni patrimonial y posteriormente asegurarse de que su médico responsable es conocedor de ellas.

Existe un grupo de países, que suponen mas del 50\% de los países con legislación en materia de Voluntades Anticipadas, que no contemplan ningún procedimiento específico para la formalización del Documento de Voluntades Anticipadas. Así pues, son el paciente, sus allegados o, en caso de existir, el representante, los encargados de hacer llegar las Voluntades Anticipadas al médico responsable, en cualquier formato..

Otra opción sería consignar el propio Documento de Voluntades Anticipadas como un documento más de la historia clínica. Esto nos abre una importante posibilidad. Los defensores de la Bioética y del proceso de toma de decisiones desde la autonomía del paciente, defienden las Voluntades Anticipadas como un proceso y no como un fin en sí mismo. Un proceso de información, asimilación, conocimiento y decisión mediante el cual el paciente, tras entender la situación y las consecuencias de determinados actos, toma decisiones con respecto a su futuro ${ }^{36,79}$. Este proceso debería ser iniciado, en cualquier momento por el médico responsable, buscando la mejor atención posible ${ }^{80}$ y probablemente con la consignación de estas conversaciones y de las decisiones tomadas en la 
documentación del paciente (su historia clínica), sería suficiente para saber que actitudes debe tomar el cuerpo médico llegado el momento.

\subsection{Designación de representante.}

La designación de un representante es uno de los puntos clave en el desarrollo de la legislación sobre Voluntades Anticipadas, aunque esta figura puede tener diferentes atribuciones según el país de la Unión Europea en el que nos encontremos.

La representación en materia de salud y específicamente, en materia de Voluntades Anticipadas, se contempla en la legislación vigente desde dos puntos de vista. Por una parte podemos hablar de representación en materia de salud de forma exclusiva, donde el representante solo tiene como cometido servir de interlocutor válido en cuestiones referentes a la salud o enfermedad del paciente. Por otra parte podemos hablar de "representante legal", que es el qué tiene la función de tomar decisiones, siempre en beneficio del paciente, en cualquier materia, incluida la sanitaria, o no, según se determine en el documento redactado a propósito.

En España, la Ley 41/2002 ${ }^{27}$, en su artículo 11, contempla de la siguiente manera la designación de un representante y sus funciones:

“(...) El otorgante del documento puede designar, además, un representante para que, llegado el caso, sirva como interlocutor suyo con el médico o el equipo sanitario para procurar el cumplimiento de las instrucciones previas." 
Tanto en la normativa de aplicación estatal como en la desarrollada en las Comunidades Autónomas (ver Tabla 1) se estima que la función del representante es servir de interlocutor autorizado con el equipo médico para interpretar las Voluntades Anticipadas, consignadas en un documento, o no, y hacerlas valer en el proceso de toma de decisiones ${ }^{36}$. Esta representación se encuentra limitada, por tanto, a materia de salud y/o enfermedad, y solo se contempla en caso de que el paciente no pueda expresar su voluntad.

De forma mayoritaria la designación de un representante en materia de salud se encuentra recogida en las legislaciones desarrolladas, amparado probablemente, por las ventajas que aporta esta figura en el momento de la aplicación de las Voluntades Anticipadas. La representación puede facilitar la toma de decisiones por parte del equipo médico, ya que permite contar con la presencia de una persona con capacidad para interpretar los deseos del paciente y con potestad para decidir sobre las actuaciones posibles.

No obstante, esta representación adquiere diferentes características en función del país en el que nos encontremos. Podemos, a modo de síntesis, encontrarnos ante tres situaciones:

1.- El representante únicamente en materia de salud no se contempla según la legislación vigente. La representación puede llevarse a cabo bajo la figura de representante o tutor legal. Este es el caso de Alemania, Dinamarca, Estonia y Francia.

2.- Se contempla la existencia de representante en materia de salud y puede ser designado mediante el Documento de Voluntades Anticipadas pero precisa de formalización específica asociada para tener validez legal. Es el caso de Austria, Bélgica, Eslovenia, Finlandia, Hungría y Reino Unido. 
3.- Se contempla la existencia de representante en materia de salud y su designación se puede realizar mediante el Documento de Voluntades Anticipadas, sin precisar de otros mecanismos de formalización.

En el primer caso se ha preferido utilizar la figura del "representante legal". Esto es así probablemente porque el avance social que han presentado las Voluntades Anticipadas es debido, en una parte muy importante, al activismo que han llevado a cabo asociaciones relacionadas con enfermedades degenerativas, demencias y, principalmente, la enfermedad de Alzheimer ${ }^{81}$. Estos colectivos, organizados y concienciados con situaciones personales, sociales y familiares altamente invalidantes han desarrollado diversas estrategias que han llevado a que las diferentes instituciones nacionales y europeas se posicionen en la materia que nos ocupa, incentivando la designación de representantes tanto en materia de salud como en el resto de cuestiones. En casos de demencia, cuando la evolución de la enfermedad puede ser rápida, generando un deterioro importante de la capacidades cognitivas, se ha abogado por la representación legal, que facilita llegado el momento las intervenciones necesarias en materia de salud, económicas, vivienda, etc..., que en cierta manera permite facilitar la toma de decisiones en todos los aspectos de la vida.

Este activismo social e institucional ha dado pie a que desde el Consejo de Europa, de forma paralela al desarrollo de las Voluntades Anticipadas, se haya estimulado también la designación de la figura del representante, que en el entorno europeo recibe la denominación "continuing powers of attorney". Este representante legal tiene como objeto asumir la responsabilidad en cualquier materia que pueda ser útil al enfermo, incluso adquiriendo su tutela, en caso de enfermedad incapacitante y prolongada. 
En esta línea se postula la "Recommendation CM/Rec(2009)11 of the Committee of Ministers to member states on principles concerning continuing powers of attorney and advance directives for incapacity" ${ }^{51}$ :

\section{Part II - Continuing powers of attorney}

\section{Principle 3 - Content}

States should consider whether it should be possible for a continuing power of attorney to cover economic and financial matters, as well as health, welfare and other personal matters, and whether some particular matters should be excluded.

\section{Parte II - Representante \\ Principio 3 - Contenido}

Los estados deben considerar si sería posible que el representante asumiera cuestiones económicas y financieras, así como, cuestiones en materia de salud, bienestar y de carácter personal y valorar sí algunos temas de carácter particular deben ser excluidos.

Así, países como Alemania, Dinamarca, Estonia y Francia han desarrollado su legislación en esta línea, abogando por la representación legal, no únicamente en materia de salud.

La legislación alemana no permite la representación aislada en materia de salud, sino que insta a la designación de un representante legal y a la realización de un Documento de Voluntades Anticipadas, ya que no considera la representación informal por parte de familiares. No obstante, dado que es un juzgado el encargado de determinar la representación de oficio de un paciente, la representación puede asignada a un familiar, por supuesto ${ }^{82}$. Este proceso es 
rápido y suele estar resuelto en un periodo de tiempo que oscila entre 24 y 48 horas, pero deja un intervalo en el que las decisiones deben ser tomadas por el equipo médico, siempre bajo la visión de beneficio supuesto para el paciente ${ }^{40,82}$.

Por su parte Dinamarca, tampoco contempla la designación de un representante en materia de salud mediante el Documento de Voluntades Anticipadas. La representación debe ser llevada a cabo mediante la designación de un representante legal, que debe ser concertada de antemano. Así la representación informal por familiares solo se encuentra amparada por precepto legal en el caso de que se trate de un incapacitado permanente. En el caso de un incapacitado temporal la representación informal por parte de familiares no tiene cabida ${ }^{83}$, lo cual deja sin representación efectiva, por ejemplo, a muchas de las personas que ingresarían en una Unidad de Cuidados Intensivos.

En el caso de Estonia, no se contempla la designación de representante mediante el Documento de Voluntades Anticipadas. No obstante, la ley si contempla la representación "en caso de emergencia" llevada a cabo por familiares o personas cercanas $^{84}$.

Resulta especialmente llamativo el caso de Francia, donde el paciente puede designar a una "persona de confianza" (personne de confiance). Este figura tiene la función de acompañar al paciente y ayudarlo en la toma de decisiones. También es el encargado de recibir la información por parte del equipo médico en caso de incapacidad del enfermo, así como de transmitir su opinión, pero del mismo modo que las Voluntades Anticipadas no tienen carácter vinculante, la persona de confianza tampoco tiene capacidad legal para tomar decisiones ${ }^{70}$. Para ello se requiere de representante legal y su fomalización adecuada. 
En el resto de países la designación de representante en materia de salud es posible realizarla mediante el Documento de Voluntades Anticipadas pero su validez legal, en algunos casos, esta sujeta a la cumplimentación de otro formulario y su presentación en otro registro ad hoc.

Los diferentes matices surgen, como ya he comentado, en los requerimientos para la formalización de la designación del representante.

En el caso de Reino Unido, esta designación debe llevarse a cabo de forma paralela mediante la cumplimentación de un procedimiento específico ${ }^{76}$ que genera a su vez un documento de hasta 9 folios. Así mismo, se requiere su posterior notificación a la Oficina del Representante Público. En este documento se establecen los límites en las decisiones que el representante puede tomar; es el propio otorgante el que estipula sobre que materias puede tomar decisiones el representante, que pueden ser de salud únicamente o bien puede extenderse hasta otras cuestiones, como las económicas por ejemplo, debiendo quedar bien especificado en el documento.

La legislación británica establece cuales son las consideraciones que el representante debe valorar a la hora de la toma de decisiones, siempre buscando el mejor interés para su representado ${ }^{85}$, teniendo en cuenta las preferencias mostradas antes de la pérdida de capacidad, abogando de esta forma por el juicio sustitutivo ${ }^{86}$. Por otra parte, esta misma legislación exige ser muy conciso a la hora de redactar las Voluntades Anticipadas y de designar un representante, puesto que, en la práctica, la designación de representante en fecha posterior a la redacción de un Documento de Voluntades Anticipadas, invalidaría las directrices incluidas en este último ${ }^{87}$. Es importante destacar que, como en el caso de Alemania, la legislación británica no contempla la representación informal por parte de familiares. 
En Austria, si se contempla la representación por familiares u otras personas de confianza pero para poder ejercitar esta derecho es necesario encontrarse inscrito en el registro de representantes ${ }^{88}$.

El caso de Bélgica, Eslovenia, Finlandia y Hungría es sensiblemente diferente a lo referido anteriormente. Si bien para poder ser representado (o representante) se precisa de una formalización paralela a la determinada en el Documento de Voluntades Anticipadas, ante la ausencia de dicha formalización sí se contempla la representación "informal" por parte de familiares, estableciendo la ley un orden jerárquico ${ }^{74,75,89,90}$.

En países como España y Portugal, así como en Luxemburgo y Países Bajos, se opta por un modelo sencillo en el que la designación del representante se realiza de forma directa en el Documento de Voluntades Anticipadas, sin precisar de otras vías de formalización lo que le confiere muchas más agilidad al procedimiento.

Otro aspecto a destacar, que ya se ha nombrado, es la representación informal por parte de familiares, que está mucho mas arraigada en los países de la zona sur de Europa. Esto se ha atribuido, entre otras cosas, a una menor comunicación del diagnóstico al paciente y a una menor iniciación de la conversación sobre Voluntades Anticipadas por parte del médico responsable ${ }^{91}$, cuestiones atribuibles a su vez a factores sociales, culturales y religiosos. Si bien cabe pensar que las personas más allegadas han tenido la oportunidad de mantener conversaciones en esta línea con mucha mayor facilidad, factor decisivo en el cumplimiento de las Voluntades Anticipadas ${ }^{34}$, todos sabemos que esto no tiene porque ser así. Los modelos actuales de familia y sociedad hacen que tengamos que plantearnos otras posibilidades. 
Con independencia de la designación de un representante (o tutor) legal, creo que son notables las ventajas que la presencia de un representante en materia de salud ofrece. Además, también considero que el Documento de Voluntades Anticipadas es el lugar adecuado para la designación del mismo, sin precisar de más burocracia.

Siguiendo en la línea de la opinión expresada con anterioridad, el Documento de Voluntades Anticipadas en un recurso que debe ser utilizado para facilitar las relaciones entre el personal médico y el paciente y hacer valer la autonomía de este último. Para ello es deseable un proceso que permita que el futuro representante llegue a ser conocedor de los deseos y la voluntad de su representado.

\subsection{Registro de Voluntades Anticipadas y acceso al}

\section{Documento de Voluntades Anticipadas.}

La legislación española prevé la creación de un registro de Voluntades Anticipadas para facilitar el acceso del personal sanitario que presta atención al paciente, al Documento de Voluntades Anticipadas. Mediante este registro se pretende garantizar la asistencia según estas Voluntades Anticipadas con independencia de donde se hayan otorgado y de donde se encuentre el paciente en el momento de precisar de ellas ${ }^{58}$. La existencia de este registro pretende agilizar el proceso de localización y puesta en conocimiento del personal facultativo de la existencia de las Voluntades Anticipadas otorgadas por un paciente, sea cual sea su localización geográfica. Así, un paciente que emite sus Voluntades Anticipadas en una determinada ciudad del país y sufre un accidente 
en una ciudad de otra Comunidad Autónoma diferente puede ser atendido según sus Voluntades Anticipadas, si estas se encuentran en el registro.

No obstante, a pesar de ser, desde mi punto de vista, una medida muy adecuada y necesaria, no es obligatoria. No debe confundirse la idoneidad con la obligatoriedad. Como digo, no es necesario que se inscriba del Documento en el Registro de Voluntades Anticipadas para que este pueda tener efecto. En el ejemplo relatado anteriormente, el mismo paciente podría llevar en sus pertenencias, un documento redactado cumpliendo la legislación vigente y este sería igualmente válido. Otra situación posible es que la familia haga llegar el documento al personal sanitario, que debe cumplir lógicamente con los preceptos legales. Por tanto, el registro ofrece muchas ventajas pero no es la única vía y tampoco se trata de ningún requisito. Este registro informatizado tiene como finalidad únicamente facilitar el acceso al documento.

A mi modo de ver, otra de las ventajas importantes que ofrece la existencia del registro es la intimidad que aporta al procedimiento. Mientras muchos pacientes y personal sanitario se muestran partidarios de que se otorguen las Voluntades Anticipadas mediante un proceso dialogado y abierto ${ }^{38}$, en el que paciente, familiares y posibles representantes sean conocedores de las decisiones que se están tomando, no debemos obviar la posible existencia de un grupo de población que desee realizar este procedimiento de una forma más íntima y confidencial, características que ofrece esta vía de formalización y conservación de las Voluntades Anticipadas.

En este punto me gustaría insistir en que el Documento de Voluntades Anticipadas es un documento destinado al personal sanitario que atiende al paciente ${ }^{1}$, ya que son ellos los que pueden determinar que actitudes diagnósticoterapeúticas deben tomarse. Una vez planteadas la diferentes posibilidades 
debería ser el paciente el que tomara la decisión de someterse a ellas o no y, por lo tanto, es aquí donde juegan su papel las Voluntades Anticipadas, ya que manifiestan la voluntad del paciente. Parece lógico que deban ser accesibles y una localización adecuada sería la historia clínica del paciente. No obstante, para que esto fuera así, la historia clínica del paciente también debería ser única y accesible al personal médico que le atiende, en cualquier lugar, y esto, a día de hoy, aún no lo hemos conseguido.

En la Unión Europea son pocos los países que han optado por la creación de un registro de Voluntades Anticipadas (ver fig. 6). Únicamente, Dinamarca, España y Portugal contemplan esta situación en el desarrollo de su legislación. En el caso de España y Portugal el registro se encuentra en funcionamiento.

Otra cuestión importante en relación a la existencia del registro de Voluntades Anticipadas es determinar quién tiene acceso al documento una vez se ha inscrito. La solución que se le ha dado a esta cuestión en los países en los que existe es muy similar, puesto que tendrían acceso tanto el otorgante como su representante en materia de salud, y el representante legal también, lógicamente, así como el equipo médico que atiende al paciente. En España el registro centralizado se encuentra disponible en soporte informático en línea para poder ser consultado, mediante acreditación.

En consonancia con lo relatado anteriormente y sin detrimento de la libertad de elección de cada persona, considero al menos interesante la existencia de un registro de Voluntades Anticipadas europeo. Ante la movilidad de que disfrutamos en la actualidad es posible que necesitemos del Documento de Voluntades Anticipadas en cualquier localización y su disponibilidad es importante. Ya que muchos países no han iniciado su constitución puede parecer 
adecuado que cuando lo hagan, sea con miras amplias, con posibilidad de integración de la información a nivel internacional.

\subsection{Revisiones periódicas del Documento de Voluntades}

\section{Anticipadas.}

Plantear revisiones periódicas del Documento de Voluntades Anticipadas puede parecer adecuado, así lo creo, pero no sé hasta que punto puede "caducar" un Documento de Voluntades Anticipadas. Se abre aquí, como en todas las cuestiones sobre Voluntades Anticipadas, un punto de discusión interesante.

De forma mayoritaria los países del entorno europeo que han legislado sobre Voluntades Anticipadas han decidido no conceder límites temporales al documento otorgado (ver tabla 8). Así se asegura la validez del documento con independencia del momento en el que se redactara.

En otra línea, existen legislaciones más estrictas en lo que se refiere a la necesidad de revisar y renovar el Documento de Voluntades Anticipadas. Entre las más limitantes se encuentran Hungría y Francia, que exigen su renovación cada 2 y 3 años, respectivamente.

Sí que es cierto que una revisión periódica del Documento de Voluntades Anticipadas emitido sería adecuada con el objetivo de ajustar la voluntad del otorgante a la situación real que está viviendo. Una revisión frecuente del mismo asegura la adecuación y aplicabilidad de las Voluntades Anticipadas, ya que el otorgante puede valorar con más precisión la situación en la que se encuentra. 
En este caso las Voluntades Anticipadas perderían vaguedad, una de las críticas más importantes en todas la legislaciones europeas ${ }^{92}$.

Si bien parece recomendable que se realicen revisiones periódicas, estas no deberían implicar aumento de costes, como sucede en países como Austria, donde la redacción de las mismas exige validación notarial y los costes asociados son elevados. Tampoco debería implicar caducidad. Ciertamente, la mayoría de las legislaciones que imponen límite temporal, plantean que una vez superado el periodo de validez, aunque las Voluntades Anticipadas ya no sean legalmente vinculantes, sí deben ser tomadas en consideración, asumiendo que exponen las preferencias del paciente, y pueden tener más o menos peso, en función del tiempo que haya pasado desde que superaron su periodo de validez.

\subsection{Modificaciones y Revocación del Documento de Voluntades Anticipadas.}

Una vez otorgadas las Voluntades Anticipadas pueden necesitar modificaciones, principalmente en el caso de que el otorgante haya cambiado de opinión por cualquier motivo, por nimio que este sea.

En la totalidad de los países con legislación en materia de Voluntades Anticipadas esta establece que se podrán realizar modificaciones en cualquier momento, elaborando unas "nuevas" Voluntades Anticipadas que sustituyan a las anteriores. En cualquier caso deben cumplir con la legislación vigente y se deben lleva a cabo siguiendo la normativa aplicable al efecto. 
Esto debe ser así puesto que si el objetivo último es garantizar la aplicación de la voluntad del paciente, ante cualquier cambio en su situación o en sus preferencias, tiene que poder hacerlo constar, modificando el Documento de Voluntades Anticipadas.

De la misma forma, las Voluntades Anticipadas pueden ser revocadas de forma completa en cualquier momento $\mathrm{y}$, en la mayoría de los casos, este procedimiento no precisa de formalidades. La revocación puede ser oral y únicamente precisa de formato escrito en los casos de Eslovenia y Luxemburgo.

En el caso de España, donde la revocación precisa de formalización escrita, la Administración ha previsto 5 documentos diferentes a cumplimentar por el otorgante en el caso de revocación y modificación del Documento inscrito en el registro de Voluntades Anticipadas, generando una proceso probablemente demasiado tedioso.

Por una parte, facilitar el procedimiento de revocación, hace factible que no se apliquen unas Voluntades Anticipadas desfasadas y no deseadas, sobre las que el otorgante, presumiblemente, ha cambiado de opinión y no ha tenido opción a modificar.

Por otra parte, el simple hecho de que un familiar sugiera que el otorgante pudo retractarse de lo expresado en sus Voluntades Anticipadas, provoca que estas sean invalidadas, generando posible vulnerabilidad sobre el derecho del otorgante. El equilibrio en esta cuestión me parece difícil de lograr por la dificultad en asegurar el derecho a que se cumpla la voluntad del paciente. 


\subsection{El contenido de las Voluntades Anticipadas.}

Las Voluntades Anticipadas permiten una redacción abierta en la que formular una serie de disposiciones que, según la legislación vigente en la actualidad, se refieren, en sentido práctico, al rechazo de medidas diagnostico-terapéuticas en determinadas situaciones. Así pues, en la mayoría de los países de la Unión Europea, las Voluntades Anticipadas sirven para comunicar el deseo de no ser sometido a exploraciones o tratamiento, llegado un determinado estado de enfermedad que el paciente valora como no admisible, aun cuando estas medidas pudieran suponer la muerte del paciente.

No obstante, dado que en la mayoría de los casos el Documento de Voluntades Anticipadas no es un formulario donde marcar ítems, tienen también cabida una serie de solicitudes que podríamos interpretar como demandantes de tratamiento. Estas tipo de solicitudes, según la leyes vigentes no son valorables, salvo el caso de Alemania, Dinamarca, España y Finlandia (ver figura 6), que de forma explicita recogen que, si bien no son vinculantes, la solicitudes de tratamiento si pueden ser orientativas a la hora de la toma de decisiones por parte del equipo médico. Así pues, una solicitud de tratamiento considerado fútil no debe considerarse vinculante, pero nos puede acercar a la visión del paciente y nos puede ayudar a tomar decisiones sobre situaciones específicas que no se encuentren recogidas en el Documento de Voluntades Anticipadas.

Esto es, en general, lo que contienen la Voluntades Anticipadas. No obstante, hay cabida para muchas cosas más. En países como Finlandia, la ley en materia de Voluntades Anticipadas insta a manifestar preferencias y gustos en la comida, en la ropa, en la música, en la forma de vestir, etc..., que puedan servir de guía en los cuidados del paciente, y que pueden ser útiles en determinadas situaciones como la demencia, donde el paciente se encuentra invalidado pero aún es capaz 
de disfrutar de ciertos aspectos de la vida. Además de servir en la toma de decisiones sobre la idoneidad de un determinado tratamiento, el Documento de Voluntades Anticipadas puede resultar útil para tratar al paciente de la mejor manera posible, según su propia voluntad.

La legislación española, una de las más ambiciosas en cuanto a contenido ${ }^{93}$, también recoge de forma explicita la posibilidad de designación de representante en materia de salud.

Así, siguiendo el esquema que nos ofrece la legislación española, el contenido de las Voluntades Anticipadas se podría esquematizar de la siguiente manera:

1.- Disposiciones relativas al rechazo de medidas diagnóstico-terpeúticas, encaminadas únicamente a prolongar la vida del paciente en determinadas circunstancias.

2.- Disposiciones relativas a la solicitud de tratamiento paliativo, contra el dolor y el sufrimiento.

3.- Disposiciones relativas a aspectos generales (ropa, comida, gustos musicales, aficiones, etc...).

4.- Disposiciones relativas a la donación de órganos y destinos del cuerpo.

5.- Designación de representante (Referido en el punto 5.5).

De forma mayoritaria, las legislaciones vigentes en los países de la Unión Europea han optado por dar cabida únicamente al primer punto (rechazo de medidas diagnóstico-terpeúticas, en determinadas circunstancias) y, en algunos de ellos, también se incluye el punto dos (solicitud de tratamiento paliativo, contra el dolor y el sufrimiento). El tercer y cuarto punto (aspectos generales y donación de órganos y destinos del cuerpo, respectivamente) solo se contemplan de forma anecdótica. 
Finalmente, dado que estamos hablando de un documento que en la mayoría de los casos es de redacción libre, podemos encontrar en ellos la solicitud de eutanasia activa o suicidio asistido. En la mayoría de los países de la Unión Europea la eutanasia activa esta legalmente prohibida y se encuentra tipificada como delito penal. Únicamente, en el caso de Bélgica ${ }^{62}$, Luxemburgo ${ }^{64}$ y Países Bajos $^{63}$, se encuentra legalizada, pero se rige por una normativa diferente a la que incluye las Voluntades Anticipadas. Es por esto que, aunque se encuentre recogida como solicitud en el Documento de Voluntades Anticipadas, debe ser refrendada por la fórmula legal pertinente, según la ley que la regula y encontrarse en el registro creado para ello, si existe. Por tanto, para poder cumplir con esta disposición, en caso de encontrarse incluida en el Documento de Voluntades Anticipadas, antes se debe constatar que se han seguido los procedimientos pertinentes regulados, insisto, por normativa diferente.

En cuanto a los países donde la eutanasia activa no es legal, en su mayor parte, han incluido en sus legislaciones cláusulas que invalidan las solicitudes de tratamiento que son contrarias a la ley, lo cual invalida estas disposiciones, sin detrimento, en principio, del resto del contenido.

Un ejemplo es el de la legislación española, que incluye como límites al contenido, el ordenamiento jurídico, entre otros. No obstante, dado que la eutanasia activa no es legal en nuestro territorio, dicha disposición podría considerarse superflua ${ }^{38}$, ya que bajo ningún concepto pueden aplicarse medidas que son contrarias a la ley vigente.

Así pues, nada impide realmente que se solicite la eutanasia (activa) en un Documento de Voluntades Anticipadas en aquellos países donde no se considera legal, pero lógicamente ningún personal sanitario puede llevarla a cabo, por ser contrario a la ley. 


\subsection{Países sin legislación en materia de Voluntades} Anticipadas.

Hasta este punto simplemente hemos constatado que poco más de la mitad de los países miembros de la Unión Europea han desarrollado legislación específica sobre el tema que nos ocupa, y que esta legislación es heterogénea y divergente, lo que dificulta su puesta en práctica y aplicabilidad en el entorno europeo. Pero aún restan 13 países por dar salida a su legislación en esta materia y, la situación de este grupo restante tampoco es uniforme. De todos ellos cabe distinguir a los que han ratificado el Convenio de Oviedo: Bulgaria, Chipre, Croacia, Eslovaquia, Grecia, Lituania, República Checa y Rumanía. En este caso, dado que la ratificación del Convenio genera un marco legal vinculante, al menos es de aplicación el artículo 9 de dicho Convenio y, por lo tanto, es legalmente vinculante que los deseos expresados con anterioridad deben ser tenidos en cuenta. No obstante, la firma de dicho Convenio también implica la adquisición del compromiso de legislar sobre derechos del paciente y Voluntades Anticipadas. Las iniciativas dentro de cada país son diferentes y en algunos países se levantan voces en pro de la adopción de medidas que mejoren el sistema sanitario, incluida la protección de las cuestiones éticas y los derechos individuales de los pacientes, como en Bulgaria, ${ }^{94}$ Eslovaquia ${ }^{95}$ y Lituania donde ha sido la propia clase médica la que ha iniciado movimientos para llevar la ética y el principio de autonomía a la relación médico-paciente ${ }^{96}$.

Por otra parte se encuentran aquellos países que no han ratificado el Convenio de Oviedo, grupo donde también existe diversidad importante. En la actualidad Italia $^{97}$ e Irlanda ${ }^{98}$ se encuentran en vías de aprobar su ley sobre Voluntades Anticipadas, aceptando la necesidad de adaptar su situación legislativa a su entorno socio-político. En ambos casos esta ley se encuentra detenida y su 
aprobación se está dilatando durante un periodo que podemos contar por años, en parte debido a las presiones y solicitud de modificaciones por parte de sectores religiosos. A pesar de todo ello en Italia es también la clase médica la que ha tomado la iniciativa, siguiendo su Código de Etica Médica que, en el artículo 38, hace referencia a "el deber de tomar en consideración las directrices indicadas por el paciente, de un modo adecuado, respecto a su voluntad llegado el caso que no pueda expresarse" ${ }^{99}$. En Polonia, donde existe una tradición católica muy arraigada, la superposición de conceptos como Voluntades Anticipadas, eutanasia pasiva y eutanasia activa, hace que sea necesario establecer legislación que identifique y sitúe en su lugar cada circunstancia ${ }^{100}$.

\subsection{Consideraciones prácticas.}

En contraposición a la heterogeneidad que se puede observar en cualquier concepto que afecte a las Voluntades Anticipadas, existe una característica que, desafortunadamente, si es común en todos los países de la Unión Europea, y es la baja tasa de formalización del Documento de Voluntades Anticipadas que se evidencia.

Los datos disponibles también son escasos y, sobre todo en los países donde no existen registros, ni oficiales ni extraoficiales, contabilizar su penetración en la sociedad es difícil. Aun así, ni las estimaciones más optimistas en países con las tasas de documentos inscritos más altas, superan el 10\%, como sucede en Alemania y Países Bajos ${ }^{101,102}$. En el caso de España, la existencia de un registro por Comunidad Autónoma y un registro central donde a su vez se encuentra todas la formalizaciones realizadas en los registro autonómicos, facilita la obtención de estos datos, que a su vez son publicados en la página web del 
Ministerio de Sanidad, Asuntos Sociales e Igualdad ${ }^{103}$. En España los datos no han variado de forma importante en los últimos años, con un total de Documentos registrados en abril de 2015 de 185.665, lo que supone una tasa de 3,97\% Documentos de Voluntades Anticipadas inscritos, donde los documentos formalizados por mujeres suponen una amplia mayoría (57\% frente al 35\% que han sido formalizados por hombres). La causa de esta diferencia tan considerable se podría atribuir a una mayor esperanza de vida en las mujeres y, a su vez, a la posible mayor vivencia por parte del colectivo femenino del papel de cuidador, experiencia determinante que podría provocar el rechazo a medidas de soporte extraordinarias por no querer suponer la sobrecarga familiar y emocional que genera el cuidado de esta tipo de enfermos.

Cierto es que no todos los Documentos de Voluntades Anticipadas se encuentran necesariamente inscritos en el Registro de Voluntades Anticipadas y que determinar el número de Documentos emitidos a nivel europeo es especialmente dificultoso puesto que, en muchos de los países no existe la necesidad de formalización mas allá de un documento con fecha y firma que puede encontrarse en posesión del paciente hasta el momento de necesitar de su aplicación. Por otra parte, el hecho de que en otros países deba consignarse en la historia clínica del paciente, tampoco permite un contabilización adecuada. Aún suponiendo que los escasos estudios estuviesen subestimando la situación real, es incuestionable que su penetración es muy limitada en la población europea en general y en la española en particular ${ }^{104,105,106}$, sobre todo si lo comparamos con la población estadounidense ${ }^{107}$.

Otro aspecto a destacar es el bajo grado de conocimiento y aceptación que las Voluntades Anticipadas presentan en el ámbito de los profesionales sanitarios, donde un porcentaje bastante alto de facultativos manifiesta desconocimiento acerca del Documento de Voluntades Anticipadas ${ }^{108}$. 
Con todo lo referido hasta ahora es evidente que a pesar de las importantes ventajas que el Documento de Voluntades Anticipadas aportan a la relación médico-paciente, y sobre todo al individuo, estas no disfrutan de una aceptación equivalente. Esto puede ser debido a muchos factores y existen estudios que han intentado encontrar una explicación razonada. Algunas de las ideas que se apuntan son el miedo a la muerte y la voluntad de no ser informado por parte de un grupo de la sociedad, la tradición paternalista en la relación médico-paciente, asumida por los dos polos de la relación y la dificultad para establecer diálogo entre médico y paciente. Por otra parte también se apuntan la dificultad en el acceso de su cumplimentación y una vez cumplimentado, en el acceso a dicha información, el poco entendimiento que el paciente tiene de su situación de enfermedad y las diferencias de concepción que el paciente, su familia y su representante puedan tener ${ }^{109}$.

Asociado a todo esto existe una muy baja difusión de las ventajas y utilidades del Documento de Voluntades Anticipadas. El paternalismo en la relación medico-paciente se extrapola hasta los ámbitos institucionales, desde donde parece que se asume que existe bajo interés por este tema. Deben existir medidas de divulgación y deben ser adecuadas, y eso incluye la formación de los profesionales, que son los que mejor pueden difundir el conocimiento y uso adecuado de las Voluntades Anticipadas. No son suficientes medidas pasivas de divulgación (posters, panfletos o videos) ya que diversos estudios demuestran que, de forma aislada, no aumentan las tasas de formulación de Documentos de Voluntades Anticipadas, si no que se requieren medios de información y formación interactiva y repetida por parte del personal sanitario ${ }^{110}$, que informe de forma veraz sobre la enfermedad y su curso, así como las complicaciones y posibles situaciones reales a las que se puede enfrentar. 


\subsection{Consideraciones finales.}

El Documento de Voluntades Anticipadas aporta ventajas incuestionables a la relación medico-paciente: defiende la autonomía del paciente y facilita la actuación del personal sanitario conociendo la voluntad del enfermo y la de los familiares. La designación de representante en materia de salud también supone una ventaja indiscutible, mediante un procedimiento sencillo. Los inconvenientes son limitados, principalmente la no adecuación de la situación del enfermo al contenido del Documento, subsanable con la designación de un representante. Así pues, ¿por qué su inclusión en la población es tan baja? Probablemente porqué no se informe lo suficiente y porque se ha utilizado como cuestión política.

Parece bastante cierto que nuestro pasado cultural supone un lastre a la hora de abordar cuestiones relativas al fin de la vida y que limita en mucho iniciar conversaciones y disposiciones relativas a ella, pero es una cuestión irrenunciable y de la misma forma que queremos tomar las riendas de nuestra vida también debemos tener la posibilidad de mantenerlas hasta el final, aun cuando no seamos capaces de manifestarnos.

Las Voluntades Anticipadas suponen la expresión de la autonomía del individuo como paciente, suponen un manifiesto de voluntad perdurable y garantizan la toma de decisiones en función de las directrices marcadas por el emisor. Cuestión de gran importancia, quiero entender.

Desde mi punto de vista en este momento deberíamos exigir una legislación sobre Voluntades Anticipadas única para todos los integrantes de la Unión Europea, donde el contenido del Documento sea vinculante, con la existencia de 
un registro central con el único objetivo de facilitar el acceso a los Documentos, posibilidad de designación de representante en materia de salud en el mismo documento, sin otras fórmulas adicionales, con periodos de revisión recomendables, no necesarios, y formalización sencilla y gratuita, ante testigos o representante de la Administración. Debe darse validez a las Voluntades Anticipadas emitidas de forma oral y recogidas en la historia clínica, por ejemplo, o avaladas por el representante.

Cualquier situación distinta es una limitación para la autonomía del individuo, por no encontrarse garantizado este derecho. Los profesionales deben entender y respetar este principio, que debe aplicarse de forma razonada y adecuada a cada situación. Profesionales y usuarios somos responsables de ello y, como ciudadanos, debemos exigir a las autoridades pertinentes que legislen en conciencia, que difundan sus decisiones de forma adecuada y que las hagan cumplir. 

Capítulo 6

Conclusiones 



\subsection{Conclusiones}

Las conclusiones obtenidas a partir de los resultados del presente trabajo son:

1. La situación actual en relación a la legislación en materia de Voluntades Anticipadas en la Unión Europea es del todo heterogénea, con posibilidades limitadas para establecer un esquema común.

2. El desarrollo de legislación especifica no es uniforme y, ni todos los países que la han desarrollado son firmantes del Convenio de Oviedo, ni todos los países firmantes del Convenio han desarrollado legislación específica.

3. La legislación especifica desarrollada es legalmente vinculante de forma mayoritaria, aunque con matices.

4. La legislación actual da escasa validez a las Voluntades Anticipadas expresadas de forma oral.

5. La formalización del Documento de Voluntades Anticipadas se entiende como un mero trámite burocrático, perdiendo el auténtico valor de proceso de toma de decisiones que este debería representar.

6. La figura del representante en materia de salud, no esta recogida de forma mayoritaria en la legislación europea. 
7. Unicamente tres países contemplan la existencia de registro de Voluntades Anticipadas.

8. Las necesidades de actualización del Documento se contemplan de forma desigual desde las diferentes legislaciones en contraposición a la posibilidad de revocación, ya que todas la contemplan en cualquier momento y sin formalismos de forma mayoritaria.

9. El Documento de Voluntades Anticipadas contempla principalmente la inclusión de solicitud de medidas de limitación del esfuerzo terapéutico.

\subsection{Puntos de reflexión y mejora de la legislación vigente}

La elaboración del presente estudio lleva implícito el establecimiento de puntos de reflexión y posibilidades de mejora del marco legislativo europeo actual. Estas son algunas de la posibilidades sin dejar de lado otras muchas que podrían surgir:

Existe la necesidad de un marco legislativo común a todos los países sobre derechos del paciente y Voluntades Anticipadas, que debe ser legalmente vinculante.

La figura del representante en materia de salud debería ganar protagonismo y, a su vez, ser una consecuencia directa de la elaboración del Documento de Voluntades Anticipadas 
Se deberían buscar los mecanismos que faciliten la elaboración, formalización y revisión del Documento de Voluntades Anticipadas, así como su disponibilidad, tanto a la población general para su elaboración, como para los profesionales que atienden a los pacientes, para su consulta y aplicación.

La creación de un registro europeo de Voluntades Anticipadas puede ser un punto de partida útil para la divulgación y homogeneización de las legislaciones europeas. Puede facilitar, a su vez, la disponibilidad del documento para su consulta.

Considero que a la luz del presenta trabajo, se puede establecer que la legislación española tiene unas características ajustadas a las necesidades actuales a pesar de sus deficiencias y que puede servir de base para la elaboración de una normativa común europea.

Se deben poner los medios adecuados para la elaboración de normativa adecuada pero también para su difusión a la población y formación de los profesionales sanitarios. 

Capítulo 7

Referencias Bibliográficas 

${ }^{1}$ Broggi MA. Las voluntades anticipadas. Humanitas, humanidades médicas. 2003;1(1),61-70.

${ }^{2}$ Gracia D. Como arqueros al blanco. Estudios de bioética. Madrid: Triacastela, 2004.

${ }^{3}$ Convention for the Protection of Human Rights and Dignity of the Human Being with regard to the Application of Biology and Medicine: Convention on Human Rights and Biomedicine. Disponible en http://conventions.coe.int/ Treaty/en/Treaties/Html/164.htm

${ }^{4}$ Van den Block L, Deschepper R, Bilsen J, Bossuyt N, Van Casteren V, Deliens L. Euthanasia and other end-of-life decisions: a mortality follow-back study in Belgium. BMC Public Health. 2009;9(1),79. Disponible en http:// www.biomedcentral.com/1471-2458/9/79

${ }^{5}$ Biblioteca Clásica Gredos. Tratados Hipocráticos 1. Madrid: Gredos, 1990.

${ }^{6}$ Will JF. A brief historical and theoretical perspective on patient autonomy and medical decision making: part I: the beneficence model. CHEST. 2011;139(3), 669-673.

${ }^{7}$ Faden RR, Beauchamp TL. A history and theory of informed consent. New York, NY: Oxford University Press Inc; 1986.

${ }^{8}$ Rothman DJ. Strangers at the bedside: a history of how law and bioethics transformed medical decision making. New York: Basic Books; 1992. 
${ }^{9}$ Lázaro J, Gracia D. La relación médico-enfermo a través de la historia. An Sist Sanit Navarra. 2006;29(Supl 3):7-17.

${ }^{10}$ Leclercq WKG, Keulers BJ, Scheltinga MRM, Spauwen PHM, Van der Wilt G-J. A Review of Surgical Informed Consent: Past, Present, and Future. A Quest to Help Patients Make Better Decisions. World J Surg 2010;34(7):1406-1415. doi:10.1007/s00268-010-0542-0.

${ }^{11}$ Schloendorff v. Society of New York Hospital, 211 N.Y. 125, 105 N.E. 92 (1914).

${ }^{12}$ Katz J. Reflections on informed consent: 40 years after its birth. J Am Coll Surg. 1998;186(4):466-474

${ }^{13}$ Código de Nuremberg, 1947. Disponible en http://www.bioeticanet.info/ documentos/Nuremberg.pdf

${ }^{14}$ National Institutes of Health. World Medical Association. Declaration of Helsinki: ethical principles for medical research involving human subjects. Office of Human Subjects research. Disponible en http://ohsr.od.nih.gov/ guidelines/helsinki.html

${ }^{15}$ Beecher H. Ethics and Clinical Research. N Engl J Med. 1966;274:1354-60.

${ }^{16}$ Potter V. Bioethics: The Science of Survival. Perspect Biol Med. 1970;14(1), 127-153.

${ }^{17}$ Reich W T. Encyclopedia of bioethics: Revised edition (vol. 3). New York: Simon \& Schuster, 1995. 
${ }^{18}$ Informe Belmont. Principios y guías éticos para la protección de los sujetos humanos de investigación.Traducción española disponible en http:// www.unav.es/cdb/usotbelmont.html

${ }^{19}$ Siurana Aparisi JC. Los principios de la bioética y el surgimiento de una bioética intercultural. Veritas. 2010;22:121-157. Disponible en http://dx.doi.org/ $\underline{10.4067 / \mathrm{S} 0718-92732010000100006}$

${ }^{20}$ Beauchamp TL, Childress J. The Principles of Bio- medical Ethics. New York, NY: Oxford University Press; 2001.

${ }^{21}$ Daniels N. Just health care. New York, Cambridge University Press, 1985.

${ }^{22}$ Sánchez-Barroso JA. Vigencia y operatividad de los principios en la bioética en la solución de problemas a partir de la deliberación moral y de la argumentación jurídica. Pers Bioet. 2010;14(2):187-204.

${ }^{23}$ Gracia D. Procedimientos de decisión en ética clínica. Madrid: Eudema; 1991.

${ }^{24}$ Gracia D. La deliberación moral: el método de la ética clínica. Med Clin (Barc). 2001;117:18-23.

25 Jaworska, Agnieszka. "Advance Directives and Substitute Decision-Making", The Stanford Encyclopedia of Philosophy (Summer 2009 Edition), Edward N. Zalta (ed.), http://plato.stanford.edu/archives/sum2009/entries/advancedirectives/>.

${ }^{26}$ Capron A. Advance Directives. In: Kuhse, H. Singer, P. A Companion to Bioethics. Oxford, UK: Blackwell Publishers Ltd, 1999. p. 299-311. 
${ }^{27}$ Ley 41/2002, de 14 de noviembre, básica reguladora de la autonomía del paciente $\mathrm{y}$ de derechos $\mathrm{y}$ obligaciones en materia de información y documentación clínica. BOE, no 274, (15-10-2002).

${ }^{28}$ Broggi MA. El documento de voluntades anticipadas. Med Clin. 2001; 117:114-5.

${ }^{29}$ Seoane JA. Derecho y planificación anticipada de la atención: panorama jurídico de las instrucciones previas en España. Derecho y Salud. 2006;14(2), 285-296.

${ }^{30}$ Declaracion de la AMM sobre la Voluntad Anticipada ("Testamentos Vitales"). Adoptada por la 54a Asamblea General de la AMM, Helsinki, Septiembre 2003 y reafirmada por la 194a Sesión del Consejo, Bali, Indonesia, Abril 2013. Disponible en http://www.wma.net/es/30publications/10policies/w14/index.html

${ }^{31}$ Martínez K. Los documentos de voluntades anticipadas. An Sist Sanit Navar. 2007;30 (Supl 3):S87-102.

${ }^{32}$ Nauck F, Becker M, King C, Radbruch L, Voltz R, Jaspers B. To what extent are the wishes of a signatory reflected in their advance directive: a qualitative analysis. BMC Med Ethics. 2014;15(1):52.

${ }^{33}$ Lo B, McLeod GA, Saika G. Patient attitudes to discussing life-sustaining treatment. Arch Intern Med. 1986;146(8):1613-1615.

${ }^{34}$ Majesko A, Hong SY, Weissfeld L, White DB. Identifying family members who may struggle in the role of surrogate decision maker. Crit Care Med. 2012; 40(8):2281-2286. 
${ }^{35}$ Emanuel L, Emanuel E. The medical directive - a new comprehensive advance care document. JAMA. 1989;26:3288-3293.

${ }^{36}$ Casado M. Aspectos ético y legales de las instrucciones previas. Ciencia Forense. 2009;9(2010):135-148.

37 Ley 1/2003, de 28 de enero, de derechos e información al paciente de la Comunidad Valenciana.. DOCV, $\mathrm{n}^{\circ}$ 4430, (31.01.2003).

38 Couceiro A. Las directivas anticipadas en España: contenido, límites y aplicaciones clínicas. Rev Calid Asist. 2007;22:213-222.

${ }^{39}$ California's natural death act. West J Med. 1978 Apr;128(4):318-328.

${ }^{40}$ Gevers S, Dute J, Nys H. Surrogate decision-making for incompetent elderly patients: The role of informal representatives. Eur J Health Law. 2012;19(1), 61-68.

41 Palacios M. Sobre la Convención de Asturias de bioética. En: Martinez Calcerrada L, de Lorenzo y Montero R, editores. Derecho Médico. Tratado de Derecho Sanitario I. pp 753-767. Madrid: Colex; 2001.

${ }^{42}$ Art 33. Convention for the Protection of Human Rights and Dignity of the Human Being with regard to the Application of Biology and Medicine: Convention on Human Rights and Biomedicine. Disponible en http:// conventions.coe.int/treaty/en/Treaties/Html/164.htm 
${ }^{43}$ Art 34. Convention for the Protection of Human Rights and Dignity of the Human Being with regard to the Application of Biology and Medicine:

Convention on Human Rights and Biomedicine. Disponible en http:// conventions.coe.int/treaty/en/Treaties/Html/164.htm

44 García-Ortega C, Cózar-Murillo M, Almenara-Barrios J. La autonomía del paciente y los derechos en materia de información y documentación clínica en el contexto de la ley 41/2002. Rev Esp Salud Pública. 2004;78(2004), 469-479.

${ }^{45}$ Art 6 y 7. Convention for the Protection of Human Rights and Dignity of the Human Being with regard to the Application of Biology and Medicine: Convention on Human Rights and Biomedicine. Disponible en http:// conventions.coe.int/treaty/en/Treaties/Html/164.htm

${ }^{46}$ Art 8. Convention for the Protection of Human Rights and Dignity of the Human Being with regard to the Application of Biology and Medicine: Convention on Human Rights and Biomedicine. Disponible en http:// conventions.coe.int/treaty/en/Treaties/Html/164.htm

${ }^{47}$ Convention for the Protection of Human Rights and Dignity of the Human Being with regard to the Application of Biology and Medicine: Convention on Human Rights and Biomedicine. Chart of signatures and ratifications. Disponible en http://conventions.coe.int/Treaty/Commun/ChercheSig.asp? $\underline{\mathrm{NT}}=164 \& \mathrm{CM}=\& \mathrm{DF}=\& \mathrm{CL}=\mathrm{ENG}$

48 Rapport de la comisión de la sante chargée d'etudier la petición d'Exit concernant une réforme de la loi sur la santé - testament biologique. Disponible en: http://www.geneve.ch/grandconseil/memorial/data/ 530208/30/530208 30_partie20.asp\#ancre94 
49 Denmark. Law No. 482 of 1 July 1998 on patients' rights. (Lottidende, 1998, Part $A$, 2 July 1998, No. 99, pp. 2883-2888) Den. 99.1 Internacional Digest of Health Legislation. 1999: 50(1). Disponible en http://waml.haifa.ac.il/index/ reference/legislation/denmark/denmark1.htm

${ }^{50}$ Andorno R. The previously expressed wishes relating to healthcare. Common principles and differing rules in national legal systems. Conseil de l'Europe. Steering Committee on Bioethics (CDBI). 35th meeting. 2-5 Diciembre 2008. Strasbourg.

${ }^{51}$ Recommendation $\mathrm{CM} / \operatorname{Rec}(2009) 11$ of the Committee of Ministers to member states on principles concerning continuing powers of attorney and advance directives for incapacity. Consejo de Europa. Disponible en https://wcd.coe.int/

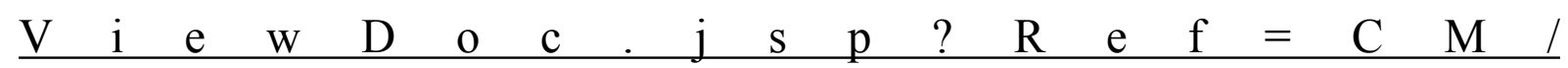
$\underline{\operatorname{Rec}(2009) 11 \& \text { Language }=\text { lanEnglish } \& \text { Site }=\mathrm{CM} \& \text { BackColorInternet }=\mathrm{DBDCF} 2}$ $\underline{\& \text { BackColorIntranet }=\text { FDC864\&BackColorLogged=FDC864 }}$

52 Resolution 1859 (2012) del Consejo de Europa. Protecting human rights and dignity by taking into account previously expressed wishes of patients. Disponible en http://assembly.coe.int/Main.asp?link=/Documents/AdoptedText/ ta12/ERES1859.htm

${ }^{53}$ Constitución Española. BOE, nº 311, (29-12-1978).

${ }^{54}$ Ley 14/1986, de 25 de abril, General de Sanidad.. BOE, no 102, (29-4-1986).

${ }^{55}$ Simón P, Barrio IM. ¿Quién decidirá por mí?. Ética de las decisiones clínicas en pacientes incapaces. Madrid: Triacastela; 2004. p. 164-5. 
56 Ley 21/2000, de 29 de diciembre, sobre los derechos de información concernientes a la salud y a la autonomía del paciente, y la documentación clínica. DOGC, nº 3303, (11-01-2001). BOE, nº 29, (2-2-2001).

${ }^{57}$ Andorno R, Biller-Andorno N, Brauer S. Advance health care directives: towards a coordinated European policy?. Eur J Health Law. 2009;16(3): 207-227.

${ }^{58}$ Real Decreto 124/2007, de 2 de febrero, por el que se regula el Registro nacional de instrucciones previas y el correspondiente fichero automatizado de datos de carácter personal. BOE, $\mathrm{n}^{\mathrm{0}}$ 40, (15-02-2007).

${ }^{59}$ Council of Europe. Guide on the decision-making process regarding medical treatment in the end-of-life situation. Mayo 2014. Disponible en: https:// edoc.coe.int/en/bioethics/6093-guide-on-the-decision-making-processregarding-medical-treatment-in-end-of-life-situations.html

${ }^{60}$ Council or Europe. Convention for the Protection of Human Rights and Fundamental Freedoms. Disponible en : http://conventions.coe.int/treaty/en/ treaties $/ \mathrm{html} / 005 . \mathrm{htm}$

${ }^{61}$ Council of Europe. Glossary on the treaties. Disponible en: http:// conventions.coe.int/?pg=/Treaty/Glossary_en.asp

${ }^{62}$ Loi relative à l'euthanasie (1) 28-mai-2002. Moniteur belge. $\mathrm{N}^{\mathrm{o}}$ 2002-2141, 22'06-2004. Disponible en: http://www.health.belgium.be/internet2Prd/groups/ public/@public/@dg1/@acutecare/documents/ie2law/14888537.pdf 
${ }^{63}$ Levensbeëindiging op verzoek en hulp bij zelfdoding Wet, 1-04-2002. Disponible en: http://wetten.overheid.n1/BWBR0012410/ geldigheidsdatum_09-05-2015

${ }^{64}$ Loi du 16 mars 2009 sur l'euthanasie et l'assistance au suicide. Memorial Journal Officiel du Grand-Duche de Luxembourg. 2009, A - nr 46:615-619

65 O'Neill D. Towards realistic and flexible advance care planning. Ir Med J. 2013;106(10):293-4.

${ }^{66}$ Beširevic V. End-of-life care in the 21st century: Advance directives in universal rights discourse. Bioethics. 2010;24(3):105-112

${ }^{67}$ Council of Europe. Guide on the decision-making process regarding medical treatment in the end-of-life situation. Mayo 2014. Disponible en: https:// edoc.coe.int/en/bioethics/6093-guide-on-the-decision-making-processregarding-medical-treatment-in-end-of-life-situations.html

${ }^{68}$ Sandor J. Human rights and bioethics: Competitors or allies? The role of international law in shaping the contours of a new discipline. Med Law. 2008 Mar;27(1):15-28.

${ }^{69}$ Sundhedsloven. Lov nr. 546 af 24. juni 2005. Disponible en: https:// www.retsinformation.dk/Forms/r0710.aspx?id=152710

${ }^{70}$ Baumann A, Audibert G, Claudot F, Puybasset L. Ethics review: end of life legislation--the French model. Critical Care. 2009;13(1):204. 
${ }^{71}$ Wiesing U, Jox RJ, Hessler HJ, Borasio GD. A new law on advance directives in Germany. J Med Ethics. 2010Dec;36(12):779-83. doi: 10.1136/jme. 2010.036376.

72 Nederlands Burgerlijk Wetboek. Boek 7 Bijzondere overeenkomsten. Disponible en: http://wetten.overheid.n1/BWBR0005290/ geldigheidsdatum 22-04-2015

${ }^{73}$ Schaden E, Herczeg P, Hacker S, Schopper A, Krenn CG. The role of advance directives in end-of-life decisions in Austria: survey of intensive care physicians. BMC Med Ethics. 2010;21:11-19. doi: 10.1186/1472-6939-11-19

${ }^{74}$ Zakona o pacientovih pravicah (ZPacP), 15/2008. Artículos 30-32. Disponible en: http://www.uradni-list.si/1/objava.jsp?urlid=200815\&stevilka=455

75 1997. évi CLIV. törvény az egészségügyröl. (23-12-1997). Disponible en: http://www.complex.hu/kzldat/t9700154.htm/t9700154.htm

${ }^{76}$ Mental Capacity Act 2005. Code of practice Norwich: Stationery Office, 2007. Disponible en http://www.wiltshire.gov.uk/mentalcapacityactcodeofpractice.pdf

${ }^{77}$ Bundesgesetz über Patientenverfügungen. Bundesgesetzblatt für die Republik Österreich. (08-12-2006). Disponible en https://www.ris.bka.gv.at/ GeltendeFassung.wxe?Abfrage $=$ Bundesnormen $\&$ Gesetzesnummer $=20004723$

${ }^{78}$ Ley $1 / 2003$, de 28 de enero, de derechos e información al paciente de la Comunidad Valenciana. DOCV, $\mathrm{n}^{\circ} 4430,(31.01 .2003)$. 
${ }^{79}$ Emanuel LL. How living wills can help doctors and patients talk about dying. BMJ. 2000;320,1618-19.

${ }^{80}$ Broggi MA. Gestión de los valores «ocultos» en la relación clínica. Med Clin (Barc) 2003;121(18):705-9

${ }^{81}$ Alzheimer Europe. http://www.alzheimer-europe.org

${ }^{82}$ Michalsen A. Care for dying patients-German legislation. Intensive Care Med. 2007;33(10):1823-1826.

${ }^{83}$ Hybel U. Country Report Denmark. In: Taupitz, J (ed.) Regulations of Civil Law to Safeguard the Autonomy of Patients at the End of Their Life. Berlin: Springer; 2000. p. 491-528

${ }^{84}$ Nys H, Goffin T, Borry P, Dierichx K. "Patient Rights in the EU - Estonia", European Ethical-Legal Papers N5, Leuven, 2007.

85 Johnston C, Liddle J. The Mental Capacity Act 2005: a new framework for healthcare decision making. J Med Ethics. 2007;33(2):94-97.

${ }^{86}$ Dunn MC, Clare IC, Holland AJ, Gunn MJ. Constructing and reconstructing 'best interests': An interpretative examination of substitute decision-making under the Mental Capacity Act 2005. J Soc Welf Fam Law. 2007;29(2):117-133.

${ }^{87}$ Jox RJ, Michalowski S, Lorenz J, Schildmann J. Substitute decision making in medicine: comparative analysis of the ethico-legal discourse in England and Germany. Med Health Care and Philos. 2008;11(2):153-163. 
${ }^{88}$ Inthorn J. Austria. In: Brauer S, Biller-Andorno N, Andorno R. Advance directives: towards a coordinated European perspective?. Institute for Biomedical Ethics. Zürich, 2008. p. 6-7.

${ }^{89}$ Gastmans C. Belgium. In: Brauer S, Biller-Andorno N, Andorno R. Advance directives: towards a coordinated European perspective?. Institute for Biomedical Ethics. Zürich, 2008. p. 13-15.

${ }^{90}$ Louhiala P. Finland. In: Brauer S, Biller-Andorno N, Andorno R. Advance directives: towards a coordinated European perspective?. Institute for Biomedical Ethics. Zürich, 2008. p. 25-26.

91 Evans N, Pasman HR, Alonso TV, Van den Block L, Miccinesi G, Van Casteren V, Onwuteaka-Philipsen B. End-of-life decisions: a cross-national study of treatment preference discussions and surrogate decision-maker appointments. PloS One. 2013;8: e57965. doi: 10.1371/journal.pone.0057965

92 Buchanan A. Advance directives and the personal identity problem. Philos Public Aff. 1988;17(4):277-302.

${ }^{93}$ Simón P, Tamayo MI, Barrio IM. Advance directives in Spain. Perspectives from a medical bioethicist approach. Bioethics. 2008;22:346-54

${ }^{94}$ Marinova J, Dimitrova S, Benkova K, Parashkevova B, Chamova G, Petrova G, Hristova D. Patient's rights expanding through the advanced directives for health care and the bulgarian reality. Trakia Journal of Sciences. 2010;8(2), 466-470. 
${ }^{95}$ Kapalla M, Kapallová D, Turecký L. An overview of the healthcare system in the Slovak Republic. EPMA journal. 2010;1(4):549-561.

${ }^{96}$ Peicius E. Lithuania. In: Brauer S, Biller-Andorno N, Andorno R. Advance directives: towards a coordinated European perspective?. Institute for Biomedical Ethics. Zürich, 2008. p. 49-50.

${ }^{97}$ Gristina GR, Martin E, Ranieri VM. Regulation of advance directives in Italy: a bad law in the making. Intensive Care Med. 2012;38(11),1897-1900.

${ }^{98}$ Law Reform Commission. Report on Bioethics: Advance Care Directives. Dublin: Law Reform Commission, 2009.

${ }^{99}$ Busardò FP, Bello S, Gulino M, Zaami S, Frati P. Advance Health Care Directives and "Public Guardian": The Italian Supreme Court Requests the Status of Current and Not Future Inability. BioMed research international. 2014 (2014) Article ID 576391. Disponible en: http://dx.doi.org/10.1155/2014/576391

100 Śliwka M, Gałęska-Śliwka A. Regulating end of life decisions in Poland: legal dilemmas. Adv Pall Med. 2011;10(2),49-56.

${ }^{101}$ May AT. Germany. In: Brauer S, Biller-Andorno N, Andorno R. Advance directives: towards a coordinated European perspective?. Institute for Biomedical Ethics. Zürich, 2008. p. 31-35.

102 Rurup M. The Netherlands. In: Brauer S, Biller-Andorno N, Andorno R. Advance directives: towards a coordinated European perspective?. Institute for Biomedical Ethics. Zürich, 2008. p. 54-58. 
103 http://www.msssi.gob.es/ciudadanos/rnip/home.htm. Visitado por última vez 13-05-2015.

${ }^{104}$ Antolín A, Sánchez M, Miró O. Evolución temporal en el conocimiento y el posicionamiento de los pacientes con enfermedades crónicas respecto al testamento vital. Gac Sanit. 2011;25(5),412-418.

105 Mazuecos F. Voluntades anticipadas vs. instrucciones previas o testamento vital en atención primaria de salud. Rev Clin Med Fam. 2008;2,210-215.

106 Arauzo V, Trenado J, Busqueta G, Quintana S. Grado de conocimiento sobre la ley de voluntades anticipadas entre los familiares de los pacientes ingresados en un servicio de Medicina Intensiva. Med Clin (Barc). 2010;134(10),448-451.

107 Silveira MJ, Kim SY, Langa KM. Advance directives and outcomes of surrogate decision making before death. N Engl J Med. 2010;362(13), 1211-1218.

${ }^{108}$ Rodríguez AM, Arroyo AH, Vellisca MB. Instrucciones previas: actitud de los profesionales de emergencias. Emergencias. 2007;19(5),241-244.

109 Perkins HS. Controlling death: the false promise of advance directives. Ann Intern Med. 2007;147(1),51-57.

110 Tamayo-Velázquez MI, Simón-Lorda P, Villegas-Portero R, HiguerasCallejón C, García-Gutiérrez JF, Martínez-Pecino F, Barrio-Cantalejo IM. Interventions to promote the use of advance directives: An overview of systematic reviews. Patient Educ Couns. 2010;80(1),10-20. 
Capítulo 8

Apéndices 



\section{Apéndice A}

Ley 41/2002, básica reguladora de la autonomía del paciente y de derechos y obligaciones en materia de información y documentación clínica. 

22188 LEY 41/2002, de 14 de noviembre, básica reguladora de la autonomía del paciente y de derechos y obligaciones en materia de información y documentación clinica.

\section{JUAN CARLOS I}

REY DE ESPAQA

A todos los que la presente vieren y entendieren. Sabed: Que las Cortes Generales han aprobado y Yo vengo en sancionar la siguiente Ley.

\section{EXPOSICIÓN DE MOTINOS}

La importancia que tienen los derechos de los pacientes como eje básico de las relaciones clínico-asistenciales se pone de manifiesto al constatar el interés que han demostrado por los mismos casi todas las organizaciones internacionales con competencia en la materia. Ya desde el fin de la Segunda Guerra Mundial, organizaciones como Naciones Unidas, UNESCO o la Organización Mundial de la Salud, o, más recientemente, la Unión Europea o el Consejo de Europa, entre muchas otras, han impulsado declaraciones o, en algún caso, han promulgado normas jurídicas sobre aspectos genéricos o especificos relacionados con esta cuestión. En este sentido, es necesario mencionar la trascendencia de la Declaración universal de derechos humanos, del año 1948, que ha sido el punto de referencia obligado para todos los textos constitucionales promulgados posteriormente $\mathrm{o}$, en el ámbito más estrictamente sanitario, la Declaración sobre la promoción de los derechos de los pacientes en Europa, promovida el año 1994 por la Oficina Regional para Europa de la Organización Mundial de la Salud, aparte de múltiples declaraciones internacionales de mayor o menor alcance e influencia que se han referido a dichas cuestiones.

Últimamente, cabe subrayar la relevancia especial del Convenio del Consejo de Europa para la protección de los derechos humanos y la dignidad del ser humano respecto de las aplicaciones de la biología y la medicina (Convenio sobre los derechos del hombre y la biomedicinal, suscrito el día 4 de abril de 1997, el cual ha entrado en vigor en el Reino de España el 1 de enero de 2000. Dicho Convenio es una iniciativa capital: en efecto, a diferencia de las distintas declaraciones internacionales que lo han precedido, es el primer instrumento internacional con carácter jurídico vinculante para los países que lo suscriben. Su especial valía reside en el hecho de que establece un marco común para la protección de los derechos humanos y la dignidad humana en la aplicación de la biología y la medicina. El Convenio trata explicitamente, con detenimiento y extensión, sobre la necesidad de reconocer los derechos de los pacientes, entre los cuales resaltan el derecho a la información, el consentimiento informado y la intimidad de la información relativa a la salud de las personas, persiguiendo el alcance de una armonización de las legislaciones de los diversos paises en estas materias; en este sentido. es absolutamente conveniente tener en cuenta el Convenio en el momento de abordar el reto de regular cuestiones tan importantes.

Es preciso decir, sin embargo, que la regulación del derecho a la protección de la salud, recogido por el artículo 43 de la Constitución de 1978, desde el punto de vista de las cuestiones más estrechamente vinculadas a la condición de sujetos de derechos de las personas usuarias de los servicios sanitarios, es decir, la plasmación de los derechos relativos a la información clínica y la autonomía individual de los pacientes en lo relativo a su salud, ha sido objeto de una regulación básica en el ámbito del Estado, a través de la Ley 14/1986, de 25 de abril, General de Sanidad.

De otra parte, esta Ley, a pesar de que fija básica mente su atención en el establecimiento y ordenación del sistema sanitario desde un punto de vista organizativo, dedica a esta cuestión diversas previsiones, entre las que destaca la voluntad de humanización de los servicios sanitarios. Así mantiene el máximo respeto a la dignidad de la persona y a la libertad individual, de un lado, y, del otro, declara que la organización sanitaria debe permitir garantizar la salud como derecho inalienable de la población mediante la estructura del Sistema Nacional de Salud, que debe asegurarse en condiciones de escrupuloso respeto a la intimidad personal y a la libertad individual del usuario, garantizando la confidencialidad de la información relacionada con los servicios sanitarios que se prestan y sin ningún tipo de discriminación.

A partir de dichas premisas, la presente Ley completa las previsiones que la Ley General de Sanidad enunció como principios generales. En este sentido, refuerza y da un trato especial al derecho a la autonomía del paciente. En particular, merece mención especial la regulación sobre instrucciones previas que contempla, de acuerdo con el criterio establecido en el Convenio de Oviedo, los deseos del paciente expresados con anterioridad dentro del ámbito del consentimiento informado. Asimismo, la Ley trata con profundidad todo lo referente a la documentación clínica generada en los centros asistenciales, subrayando especialmente la consideración y la concreción de los derechos de los usuarios en este aspecto.

En septiembre de 1997, en desarrollo de un convenio de colaboración entre el Consejo General del Poder Judicial y el Ministerio de Sanidad y Consumo, tuvo lugar un seminario conjunto sobre información y documentación clínica, en el que se debatieron los principales aspectos normativos y judiciales en la materia. Al mismo tiempo, se constituyó un grupo de expertos a quienes se encargó la elaboración de unas directrices para el desarrollo futuro de este tema. Este grupo suscribió un dictamen el 26 de noviembre de 1997, que ha sido tenido en cuenta en la elaboración de los principios fundamentales de esta Ley.

La atención que a estas materias otorgó en su día la Ley General de Sanidad supuso un notable avance como reflejan, entre otros, sus articulos 9,10 y 61 . Sin embargo, el derecho a la información, como derecho del ciudadano cuando demanda la atención sanitaria ha sido objeto en los últimos años de diversas matizaciones y ampliaciones por Leyes y disposiciones de distinto tipo y rango, que ponen de manifiesto la necesidad de una reforma y actualización de la normativa contenida en la Ley General de Sanidad. Así, la Ley Orgánica 15/1999, de 13 de diciembre, de Protección de Datos de Carácter Personal, califica a los datos relativos a la salud de los ciudadanos como datos especialmente protegidos, estableciendo un régimen singularmente riguroso para su obtención, custodia y eventual cesión. Esta defensa de la confidencialidad había sido ya defendida por la Directiva comunitaria 95/46, de 24 de octubre, en la que, además de reafirmarse la defensa de los derechos y libertades de los ciudadanos europeos, en especial de su intimidad relativa a la información relacionada con su salud, se apunta la presencia de otros intereses generales como los estudios epidemiológicos, las situaciones de riesgo grave para la salud de la colectividad, la investigación y los ensayos clínicos que, cuando estén incluidos en normas de rango de Ley, pueden justificar una excepción motivada a los derechos del paciente. Se manifiesta asi una concepción comunitaria del derecho a la salud, en la que, junto al interés singular de cada individuo, como destinatario por excelencia de la información relativa a la salud, aparecen también otros 
agentes y bienes juridicos referidos a la salud pública, que deben ser considerados, con la relevancia necesaria, en una sociedad democrática avanzada. En esta línea, el Consejo de Europa, en su Recomendación de $13 \mathrm{de}$ febrero de 1997, relativa a la protección de los datos médicos, después de afirmar que deben recogerse y procesarse con el consentimiento del afectado, indica que la información puede restringirse si así lo dispone una Ley y constituye una medida necesaria por razones de interés general.

Todas estas circunstancias aconsejan una adaptación de la Ley General de Sanidad con el objetivo de aclarar la situación juridica y los derechos y obligaciones de los profesionales sanitarios, de los ciudadanos y de las instituciones sanitarias. Se trata de ofrecer en el terreno de la información y la documentación clínicas las mismas garantías a todos los ciudadanos del Estado, fortaleciendo con ello el derecho a la protección de la salud que reconoce la Constitución.

\section{CAPITULO I}

\section{Principios generales}

\section{Artículo 1. Ámbito de aplicación.}

La presente Ley tiene por objeto la regulación de los derechos y obligaciones de los pacientes, usuarios y profesionales, así como de los centros y servicios sanitarios, públicos y privados, en materia de autonomía del paciente y de información y documentación clínica.

\section{Artículo 2. Principios básicos.}

1. La dignidad de la persona humana, el respeto a la autonomia de su voluntad y a su intimidad orientarán toda la actividad encaminada a obtener, utilizar, archivar, custodiar y transmitir la información y la documentación clinica.

2. Toda actuación en el ámbito de la sanidad requiere, con carácter general, el previo consentimiento de los pacientes o usuarios. El consentimiento, que debe obtenerse después de que el paciente reciba una información adecuada, se hará por escrito en los supuestos previstos en la Ley.

3. El paciente o usuario tiene derecho a decidir libremente, después de recibir la información adecuada, entre las opciones clinicas disponibles.

4. Todo paciente o usuario tiene derecho a negarse al tratamiento, excepto en los casos determinados en la Ley. Su negativa al tratamiento constará por escrito. 5. Los pacientes o usuarios tienen el deber de facilitar los datos sobre su estado físico o sobre su salud de manera leal y verdadera, así como el de colaborar en su obtención, especialmente cuando sean necesarios por razones de interés público o con motivo de la asistencia sanitaria.

6. Todo profesional que interviene en la actividad asistencial está obligado no sólo a la correcta prestación de sus técnicas, sino al cumplimiento de los deberes de información y de documentación clínica, $\mathrm{y}$ al respeto de las decisiones adoptadas libre y voluntariamente por el paciente.

7. La persona que elabore o tenga acceso a la información y la documentación clínica está obligada a guardar la reserva debida.

\section{Artículo 3. Las definiciones legales.}

A efectos de esta Ley se entiende por.

Centro sanitario: el conjunto organizado de profesionales, instalaciones y medios técnicos que realiza acti- vidades y presta servicios para cuidar la salud de los pacientes y usuarios.

Certificado médico: la declaración escrita de un médico que da fe del estado de salud de una persona en un determinado momento.

Consentimiento informado: la conformidad libre, voluntaria y consciente de un paciente, manifestada en el pleno uso de sus facultades después de recibir la información adecuada, para que tenga lugar una actuación que afecta a su salud.

Documentación clínica: el soporte de cualquier tipo o clase que contiene un conjunto de datos e informaciones de carácter asistencial.

Historia clínica: el conjunto de documentos que contienen los datos, valoraciones e informaciones de cualquier índole sobre la situación y la evolución clínica de un paciente a lo largo del proceso asistencial.

nformación clínica: todo dato, cualquiera que sea su forma, clase o tipo, que permite adquirir o ampliar conocimientos sobre el estado físico y la salud de una persona, o la forma de preservarla, cuidarla, mejorarla o recuperarla.

Informe de alta médica: el documento emitido por el médico responsable en un centro sanitario al finalizar cada proceso asistencial de un paciente, que especifica los datos de éste, un resumen de su historial clínico, la actividad asistencial prestada, el diagnóstico y las recomendaciones terapéuticas.

Intervención en el ámbito de la sanidad: toda actuación realizada con fines preventivos, diagnósticos, terapéuticos, rehabilitadores o de investigación.

Libre elección: la facultad del paciente o usuario de optar, libre y voluntariamente, entre dos o más alternativas asistenciales, entre varios facultativos o entre centros asistenciales, en los términos y condiciones que establezcan los servicios de salud competentes, en cada caso.

Médico responsable: el profesional que tiene a su cargo coordinar la información y la asistencia sanitaria del paciente o del usuario, con el carácter de interlocutor principal del mismo en todo lo referente a su atención e información durante el proceso asistencial, sin perjuicio de las obligaciones de otros profesionales que participan en las actuaciones asistenciales.

Paciente: la persona que requiere asistencia sanitaria y está sometida a cuidados profesionales para el mantenimiento o recuperación de su salud.

Servicio sanitario: la unidad asistencial con organización propia, dotada de los recursos técnicos y del personal cualificado para llevar a cabo actividades sanitarias.

Usuario: la persona que utiliza los servicios sanitarios de educación y promoción de la salud, de prevención de enfermedades y de información sanitaria.

\section{CAPITULO ॥}

\section{El derecho de información sanitaria}

\section{Articulo 4. Derecho a la información asistencial.}

1. Los pacientes tienen derecho a conocer, con motivo de cualquier actuación en el ámbito de su salud, toda la información disponible sobre la misma, salvando los supuestos exceptuados por la Ley. Además, toda persona tiene derecho a que se respete su voluntad de no ser informada. La información, que como regla general se proporcionará verbalmente dejando constancia en la historia clínica, comprende, como mínimo, la finalidad y la naturaleza de cada intervención, sus riesgos y sus consecuencias.

2. La información clínica forma parte de todas las actuaciones asistenciales, será verdadera, se comunicará 
al paciente de forma comprensible y adecuada a sus necesidades y le ayudará a tomar decisiones de acuerdo con su propia y libre voluntad.

3. El médico responsable del paciente le garantiza el cumplimiento de su derecho a la información. Los profesionales que le atiendan durante el proceso asistencial o le apliquen una técnica o un procedimiento concreto también serán responsables de informarle.

Artículo 5. Titular del derecho a la información asistencial.

1. El titular del derecho a la información es el paciente. También serán informadas las personas vinculadas a él, por razones familiares o de hecho, en la medida que el paciente lo permita de manera expresa o tácita. 2. El paciente será informado, incluso en caso de incapacidad, de modo adecuado a sus posibilidades de comprensión, cumpliendo con el deber de informar también a su representante legal.

3. Cuando el paciente, según el criterio del médico que le asiste, carezca de capacidad para entender la información a causa de su estado físico o psíquico, la información se pondrá en conocimiento de las personas vinculadas a él por razones familiares o de hecho.

4. El derecho a la información sanitaria de los pacientes puede limitarse por la existencia acreditada de un estado de necesidad terapéutica. Se entenderá por necesidad terapéutica la facultad del médico para actuar profesionalmente sin informar antes al paciente, cuando por razones obietivas el conocimiento de su propia situación pueda perjudicar su salud de manera grave. Llegado este caso, el médico dejará constancia razonada de las circunstancias en la historia clínica y comunicará su decisión a las personas vinculadas al paciente por razones familiares o de hecho.

\section{Artículo 6. Derecho a la información epidemiológica.}

Los ciudadanos tienen derecho a conocer los problemas sanitarios de la colectividad cuando impliquen un riesgo para la salud pública o para su salud individual, y el derecho a que esta información se difunda en términos verdaderos, comprensibles y adecuados para la protección de la salud, de acuerdo con lo establecido por la Ley.

\section{CAPITULO III}

\section{Derecho a la intimidad}

Artículo 7. El derecho a la intimidad.

1. Toda persona tiene derecho a que se respete el carácter confidencial de los datos referentes a su salud. y a que nadie pueda acceder a ellos sin previa autorización amparada por la Ley.

2 . Los centros sanitarios adoptarán las medidas oportunas para garantizar los derechos a que se refiere el apartado anterior, y elaborarán, cuando proceda, las normas y los procedimientos protocolizados que garanticen el acceso legal a los datos de los pacientes.

\section{CAPITULO IV}

\section{El respeto de la autonomía del paciente}

Articulo 8. Consentimiento informado.

1. Toda actuación en el ámbito de la salud de un paciente necesita el consentimiento libre y voluntario del afectado, una vez que, recibida la información pre- vista en el artículo 4, haya valorado las opciones propias del caso.

2. El consentimiento será verbal por regla general. Sin embargo, se prestará por escrito en los casos siguientes: intervención quirúrgica, procedimientos diagnósticos y terapéuticos invasores y, en general, aplicación de procedimientos que suponen riesgos o inconvenientes de notoria y previsible repercusión negativa sobre la salud del paciente.

3. El consentimiento escrito del paciente será necesario para cada una de las actuaciones especificadas en el punto anterior de este artículo, dejando a salvo la posibilidad de incorporar anejos y otros datos de carácter general, y tendrá información suficiente sobre el procedimiento de aplicación y sobre sus riesgos.

4. Todo paciente o usuario tiene derecho a ser advertido sobre la posibilidad de utilizar los procedimientos de pronóstico, diagnóstico y terapéuticos que se le apliquen en un proyecto docente o de investigación, que en ningún caso podrá comportar riesgo adicional para su salud.

5. El paciente puede revocar libremente por escrito su consentimiento en cualquier momento.

Articulo 9. Limites del consentimiento informado yconsentimiento por representación.

1. La renuncia del paciente a recibir información está limitada por el interés de la salud del propio paciente, de terceros, de la colectividad y por las exigencias terapéuticas del caso. Cuando el paciente manifieste expresamente su deseo de no ser informado, se respetará su voluntad haciendo constar su renuncia documentalmente, sin perjuicio de la obtención de su consentimiento previo para la intervención.

2. Los facultativos podrán llevar a cabo las intervenciones clínicas indispensables en favor de la salud del paciente, sin necesidad de contar con su consentimiento, en los siguientes casos:

a) Cuando existe riesgo para la salud pública a causa de razones sanitarias establecidas por la Ley. En todo caso, una vez adoptadas las medidas pertinentes, de conformidad con lo establecido en la Ley Orgánica $3 / 1986$, se comunicarán a la autoridad judicial en el plazo máximo de 24 horas siempre que dispongan el internamiento obligatorio de personas.

b) Cuando existe riesgo inmediato grave para la integridad física o psiquica del enfermo y no es posible conseguir su autorización, consultando, cuando las circunstancias lo permitan, a sus familiares o a las personas vinculadas de hecho a él.

3. Se otorgará el consentimiento por representación en los siguientes supuestos:

a) Cuando el paciente no sea capaz de tomar decisiones, a criterio del médico responsable de la asistencia, o su estado físico o psíquico no le permita hacerse cargo de su situación. Si el paciente carece de representante legal, el consentimiento lo prestarán las personas vincurladas a él por razones familiares o de hecho.

b) Cuando el paciente esté incapacitado legalmente.

c) Cuando el paciente menor de edad no sea capaz intelectual ni emocionalmente de comprender el alcance de la intervención. En este caso, el consentimiento lo dará el representante legal del menor después de haber escuchado su opinión si tiene doce años cumplidos. Cuando se trate de menores no incapaces ni incapacitados, pero emancipados o con dieciséis años cumplidos, no cabe prestar el consentimiento por representación. Sin embargo, en caso de actuación de grave riesgo, según el criterio del facultativo, los padres serán informados y su opinión será tenida en cuenta para la toma de la decisión correspondiente. 
4. La interrupción voluntaria del embarazo, la práctica de ensayos clínicos y la práctica de técnicas de reproducción humana asistida se rigen por lo establecido con carácter general sobre la mayoria de edad y por las disposiciones especiales de aplicación.

5. La prestación del consentimiento por representación seráadecuada a las circunstancias y proporcionada a las necesidades que haya que atender, siempre en favor del paciente y con respeto a su dignidad personal. El paciente participará en la medida de lo posible en la toma de decisiones a lo largo del proceso sanitario.

Artículo 10. Condiciones de la información y consent timiento por escrito.

1. El facultativo proporcionará al paciente, antes de recabar su consentimiento escrito, la información básica siguiente:

a) Las consecuencias relevantes o de importancia que la intervención origina con seguridad

b) Los riesgos relacionados con las circunstancias personales o profesionales del paciente.

c) Los riesgos probables en condiciones normales, conforme a la experiencia y al estado de la ciencia o directamente relacionadọs con el tipo de intervención. d) Las contraindicaciones.

2. El médico responsable deberá ponderar en cada caso que cuanto más dudoso sea el resultado de una intervención más necesario resulta el previo consentimiento por escrito del paciente.

\section{Articulo 11. Instrucciones previas.}

1. Por el documento de instrucciones previas, una persona mayor de edad, capaz y libre, manifiesta anticipadamente su voluntad, con objeto de que ésta se cumpla en el momento en que llegue a situaciones en cuyas circunstancias no sea capaz de expresarlos personalmente, sobre los cuidados y el tratamiento de su salud o, una vez llegado el fallecimiento, sobre el destino de su cuerpo o de los órganos del mismo. El otorgante del documento puede designar, además, un representante para que, legado el caso, sirva como interlocutor suyo con el médico o el equipo sanitario para procurar el cumplimiento de las instrucciones previas.

2 . Cada servicio de salud regulará el procedimiento adecuado para que, llegado el caso, se garantice el cumplimiento de las instrucciones previas de cada persona, que deberán constar siempre por escrito.

3. No serán aplicadas las instrucciones previas contrarias al ordenamiento jurídico, a la elex artis" ni las que no se correspondan con el supuesto de hecho que el interesado haya previsto en el momento de manifestarlas. En la historia clínica del paciente quedará constancia razonada de las anotaciones relacionadas con estas previsiones.

4. Las instrucciones previas podrán revocarse libremente en cualquier momento dejando constancia por escrito.

5. Con el fin de asegurar la eficacia en todo el territorio nacional de las instrucciones previas manifestadas por los pacientes y formalizadas de acuerdo con lo dispuesto en la legislación de las respectivas Comunidades Autónomas, se creará en el Ministerio de Sanidad y Consumo el Registro nacional de instrucciones previas que se regirá por las normas que reglamentariamente se determinen, previo acuerdo del Consejo Interterritorial del Sistema Nacional de Salud.

Artículo 12. Información en el Sistema Nacional de Salud.

1. Además de los derechos reconocidos en los articur los anteriores, los pacientes y los usuarios del Sistema
Nacional de Salud tendrán derecho a recibir información sobre los servicios y unidades asistenciales disponibles, su calidad y los requisitos de acceso a ellos.

2. Los servicios de salud dispondrán en los centros y servicios sanitarios de una guía o carta de los servicios en la que se especifiquen los derechos y obligaciones de los usuarios, las prestaciones disponibles, las caracteristicas asistenciales del centro o del servicio, y sus dotaciones de personal, instalaciones y medios técnicos. Se facilitará a todos los usuarios información sobre las guías de participación y sobre sugerencias y reclamaciones.

3. Cada servicio de salud regulará los procedimientos y los sistemas para garantizar el efectivo cumplimiento de las previsiones de este artículo.

Articulo 13. Derecho a la información para la elección de médico y de centro.

Los usuarios y pacientes del Sistema Nacional de Salud, tanto en la atención primaria como en la especializáda, tendrán derecho a la información previa correspondiente para elegir médico, e igualmente centro, con arreglo a los términos y condiciones que establezcan los servicios de salud competentes.

\section{CAPITULO V}

\section{La historia clinica}

\section{Articulo 14. Definición y archivo de la historia clinica.}

1. La historia clínica comprende el conjunto de los documentos relativos a los procesos asistenciales de cada paciente, con la identificación de los médicos y de los demás profesionales que han intervenido en ellos, con objeto de obtener la máxima integración posible de la documentación clínica de cada paciente, al menos, en el ámbito de cada centro.

2. Cada centro archivará las historias clínicas de sus pacientes, cualquiera que sea el soporte papel, audiovisual, informático o de otro tipo en el que consten, de manera que queden garantizadas su seguridad, su correcta conservación y la recuperación de la información.

3. Las Administraciones sanitarias establecerán los mecanismos que garanticen la autenticidad del contenido de la historia clínica y de los cambios operados en ella, así como la posibilidad de su reproducción futura.

4. Las Comunidades Autónomas aprobarán las disposiciones necesarias para que los centros sanitarios puedan adoptar las medidas técnicas y organizativas adecuadas para archivar y proteger las historias clínicas y evitar su destrucción o su pérdida accidental.

Articulo 15. Contenido de la historia clínica de cada paciente.

1. La historia clínica incorporará la información que se considere trascendental para el conocimiento veraz y actualizado del estado de salud del paciente. Todo paciente o usuario tiene derecho a que quede constancia, por escrito o en el soporte técnico más adecuado, de a información obtenida en todos sus procesos asistenciales, realizados por el servicio de salud tanto en el ámbito de atención primaria como de atención especializada.

2. La historia clínica tendrá como fin principal facilitar la asistencia sanitaria, dejando constancia de todos aquellos datos que, bajo criterio médico, permitan el conocimiento veraz y actualizado del estado de salud. El contenido mínimo de la historia clínica será el siguiente: 
a) La documentación relativa a la hoja clínicoestadistica.

b) La autorización de ingreso.

c) El informe de urgencia.

d) La anamnesis y la exploración física.

e) La evolución.

f) Las órdenes médicas.

g) La hoja de interconsulta.

h) Los informes de exploraciones complementarias.

i) El consentimiento informado.

j) El informe de anestesia.

k) El informe de quirófano o de registro del parto.

1) El informe de anatomía patológica.

m) La evolución y planificación de cuidados de enfermería.

n) La aplicación terapéutica de enfermería.

ii) El gráfico de constantes.

o) El informe clínico de alta.

Los párrafos b), c), i), j), k), I), ñ) y o) sólo serán exigibles en la cumplimentación de la historia clínica cuando se trate de procesos de hospitalización o así se disponga.

3. La cumplimentación de la historia clínica, en los aspectos relacionados con la asistencia directa al paciente, será responsabilidad de los profesionales que intervengan en ella.

4. La historia clinica se llevará con criterios de unidad y de integración, en cada institución asistencial como mínimo, para facilitar el mejor y más oportuno conocimiento por los facultativos de los datos de un determinado paciente en cada proceso asistencial.

\section{Artículo 16. Usos de la historia clínica.}

1. La historia clinica es un instrumento destinado fundamentalmente a garantizar una asistencia adecuada al paciente. Los profesionales asistenciales del centro que realizan el diagnóstico o el tratamiento del paciente tienen acceso a la historia clínica de éste como instrumento fundamental para su adecuada asistencia.

2. Cada centro establecerá los métodos que posibiliten en todo momento el acceso a la historia clinica de cada paciente por los profesionales que le asisten.

3. El acceso a la historia clínica con fines judiciales, epidemiológicos, de salud pública, de investigación ọ de docencia, se rige por lo dispuesto en la Ley Orgánica 15/1999, de Protección de Datos de Carácter Personal, y en la Ley 14/1986, General de Sanidad, y demás normas de aplicación en cada caso. El acceso a la historia clínica con estos fines obliga a preservar los datos de identificación personal del paciente, separados de los de carácter clínico-asistencial, de manera que como regla general quede asegurado el anonimato, salvo que el propio paciente haya dado su consentimiento para no separarlos. Se exceptúan los supuestos de investigación de la autoridad judicial en los que se considere imprescindible la unificación de los datos identificativos con los clínico-asistenciales, en los cuales se estará a lo que dispongan los jueces y tribunales en el proceso correspondiente. El acceso a los datos y documentos de la historia clínica queda limitado estrictamente a los fines especificos de cada caso.

4. El personal de administración y gestión de los centros sanitarios sólo puede acceder a los datos de la historia clínica relacionados con sus propias funciones.

5. El personal sanitario debidamente acreditado que ejerza funciones de inspección, evaluación, acreditación y planificación, tiene acceso a las historias clínicas en el cumplimiento de sus funciones de comprobación de la calidad de la asistencia, el respeto de los derechos del paciente o cualquier otra obligación del centro en relación con los pacientes y usuarios o la propia Administración sanitaria.

6. El personal que accede a los datos de la historia clínica en el ejercicio de sus funciones queda sujeto al deber de secreto.

7. Las Comunidades Autónomas regularán el procedimiento para que quede constancia del acceso a la historia clínica y de su uso.

\section{Articulo 17. La conservación de la documentación clinica.}

1. Los centros sanitarios tienen la obligación de conservar la documentación clínica en condiciones que garanticen su correcto mantenimiento y seguridad, aunque no necesariamente en el soporte original, para la debida asistencia al paciente durante el tiempo adecuado a cada caso y como mínimo, cinco años contados desde la fecha del alta de cada proceso asistencial.

2. La documentación clínica también se conservará a efectos judiciales de conformidad con la legislación vigente. Se conservará, asimismo, cuando existan razones epidemiológicas, de investigación o de organización y funcionamiento del Sistema Nacional de Salud. Su tratamiento se hará de forma que se evite en lo posible la identificación de las personas afectadas.

3. Los profesionales sanitarios tienen el deber de cooperar en la creación y el mantenimiento de una documentación clínica ordenada y secuencial del proceso asistencial de los pacientes.

4. La gestión de la historia clínica por los centros con pacientes hospitalizados, o por los que atiendan a un número suficiente de pacientes bajo cualquier otra modalidad asistencial, según el criterio de los servicios de salud, se realizará a través de la unidad de admisión y documentación clínica, encargada de integrar en un solo archivo las historias clínicas. La custodia de dichas historias clínicas estará bajo la responsabilidad de la dirección del centro sanitario.

5. Los profesionales sanitarios que desarrollen su actividad de manera individual son responsables de la gestión y de la custodia de la documentación asistencial que generen.

6. Son de aplicación a la documentación clínica las medidas técnicas de seguridad establecidas por la legislación reguladora de la conservación de los ficheros que contienen datos de carácter personal y, en general, por la Ley Orgánica 15/1999, de Protección de Datos de Carácter Personal.

\section{Articulo 18. Derechos de acceso a la historia clinica.}

1. El paciente tiene el derecho de acceso, con las reservas señaladas en el apartado 3 de este artículo, a la documentación de la historia clínica y a obtener copia de los datos que figuran en ella. Los centros sanitarios regularán el procedimiento que garantice la observancia de estos derechos.

2. El derecho de acceso del paciente a la historia clínica puede ejercerse también por representación debidamente acreditada.

3. El derecho al acceso del paciente a la documentación de la historia clínica no puede ejercitarse en perjuicio del derecho de terceras personas a la confidencialidad de los datos que constan en ella recogidos en interés terapéutico del paciente, ni en perjuicio del derecho de los profesionales participantes en su elaboración, los cuales pueden oponer al derecho de acceso la reserva de sus anotaciones subjetivas.

4. Los centros sanitarios y los facultativos de ejercicio individual sólo facilitarán el acceso a la historia 
clínica de los pacientes fallecidos a las personas vinculadas a él, por razones familiares o de hecho, salvo que el fallecido lo hubiese prohibido expresamente y así se acredite. En cualquier caso el acceso de un tercero a la historia clínica motivado por un riesgo para su salud se limitará a los datos pertinentes. No se facilitará información que afecte a la intimidad del fallecido ni a las anotaciones subjetivas de los profesionales, ni que perjudique a terceros.

Artículo 19. Derechos relacionados con la custodia de la historia clinica.

El paciente tiene derecho a que los centros sanitarios establezcan un mecanismo de custodia activa y diligente de las historias clínicas. Dicha custodia permitirá la recogida, la integración, la recuperación y la comunicación de la información sometida al principio de confidencialidad con arreglo a lo establecido por el artículo 16 de la presente Ley.

\section{CAPITULO Vl}

\section{Informe de alta y otra documentación clínica}

\section{Articulo 20. Informe de alta.}

Todo paciente, familiar o persona vinculada a él, en su caso, tendrá el derecho a recibir del centro o servicio sanitario, una vez finalizado el proceso asistencial, un informe de alta con los contenidos mínimos que determina el artículo 3. Las características, requisitos y condiciones de los informes de alta se determinarán reglamentariamente por las Administraciones sanitarias autonómicas.

\section{Artículo 21. El alta del paciente.}

1. En caso de no aceptar el tratamiento prescrito, se propondrá al paciente o usuario la firma del alta voluntaria. Si no la firmara, la dirección del centro sanitario, a propuesta del médico responsable, podrá disponer el alta forzosa en las condiciones reguladas por la Ley. El hecho de no aceptar el tratamiento prescrito no dará lugar al alta forzosa cuando existan tratamientos alternativos, aunque tengan carácter paliativo, siempre que los preste el centro sanitario y el paciente acepte recibirlos. Estas circunstancias quedaran debidamente documentadas.

2. En el caso de que el paciente no acepte el alta, la dirección del centro, previa comprobación del informe clínico correspondiente, oirá al paciente y, si persiste en su negativa, lo pondrá en conocimiento del juez para que confirme o revoque la decisión.

\section{Artículo 22. Emisión de certifica dos médicos.}

Todo paciente o usuario tiene derecho a que se le faciliten los certificados acreditativos de su estado de salud. Estos serán gratuitos cuando así lo establezca una disposición legal o reglamentaria.

Artículo 23. Obligaciones profesionales de información técnica, estadística y administrativa.

Los profesionales sanitarios, además de las obligaciones señaladas en materia de información clínica, tienen el deber de cumplimentar los protocolos, registros, informes, estadisticas y demás documentación asistencial o administrativa, que guarden relación con los procesos clínicos en los que intervienen, y los que requieran los centros o servicios de salud competentes y las autoridades sanitarias, comprendidos los relacionados con la investigación médica y la información epidemiológica.

Disposición adicional primera. Carácter de legislación básica.

Esta Ley tiene la condición de básica, de conformidad con lo establecido en el articulo 149.1.1." y 16."de la Constitución.

El Estado y las Comunidades Autónomas adoptarán, en el ámbito de sus respectivas competencias, las medidas necesarias para la efectividad de esta Ley.

Disposición adicional segunda. Aplicación supletoria.

Las normas de esta Ley relativas a la información asistencial, la información para el ejercicio de la libertad de elección de médico y de centro, el consentimiento informado del paciente y la documentación clínica, serán de aplicación supletoria en los proyectos de investigación médica, en los procesos de extracción y trasplante de órganos, en los de aplicación de técnicas de reproducción humana asistida y en los que carezcan de regulación especial.

Disposición adicional tercera. Coordinación de las his. torias clinicas.

El Ministerio de Sanidad y Consumo, en coordinación y con la colaboración de las Comunidades Autónomas competentes en la materia, promoverá, con la participación de todos los interesados, la implantación de un sistema de compatibilidad que, atendida la evolución y disponibilidad de los recursos técnicos, y la diversidad de sistemas y tipos de historias clínicas, posibilite su uso por los centros asistenciales de España que atiendan a un mismo paciente, en evitación de que los atendidos en diversos centros se sometan a exploraciones y procedimientos de innecesaria repetición.

Disposición adicional cuarta. Necesidades asociadas a la discapacidad.

El Estado y las Comunidades Autónomas, dentro del ámbito de sus respectivas competencias, dictarán las disposiciones precisas para garantizar a los pacientes - usuarios con necesidades especiales, asociadas a la discapacidad, los derechos en materia de autonomía, información y documentación clínica regulados en esta Ley.

Disposición adicional quinta. Información y document tación sobre medicamentos y productos sanitarios.

La información, la documentación y la publicidad relativas a los medicamentos y productos sanitarios, así como el régimen de las recetas y de las órdenes de prescripción correspondientes, se regularán por su normativa especifica, sin perjuicio de la aplicación de las reglas establecidas en esta Ley en cuanto a la prescripción y uso de medicamentos o productos sanitarios durante los procesos asistenciales.

\section{Disposición adicional sexta. Régimen sancionador.}

Las infracciones de lo dispuesto por la presente Ley quedan sometidas al régimen sancionador previsto en el capítulo VI del Título I de la Ley 14/1986, General de Sanidad, sin perjuicio de la responsabilidad civil o penal y de la responsabilidad profesional o estatutaria procedentes en derecho. 
Disposición transitoria única. Informe de alta.

El informe de alta se regirá por lo dispuesto en la Orden del Ministerio de Sanidad, de 6 de septiembre de 1984, mientras no se desarrolle legalmente lo dispuesto en el artículo 20 de esta Ley.

Disposición derogatoria única. Derogación generaly de preceptos concretos.

Quedan derogadas las disposiciones de igual o inferior rango que se opongan a lo dispuesto en la presente Ley y, concretamente, los apartados $5,6,8,9$ y 11 del artículo 10, el apartado 4 del artículo 11 y el artículo 61 de la Ley 14/1986, General de Sanidad.

\section{Disposición final única. Entrada en vigor.}

La presente Ley entrará en vigor en el plazo de seis meses a partir del día siguiente al de su publicación en el «Boletín Oficial del Estados.

Por tanto,

Mando a todos los españoles, particulares y autoridades, que guarden y hagan guardar esta Ley.

Madrid, 14 de noviembre de 2002.

\section{JUAN CARLOS R}

E Presidante dal Gobiamo,

JOSE MARIA ATNAA LOPE?

22189 LEY 42/2002, de 14 de noviembre, de creación del Colegio de Prácticos de Puerto.

\section{JUAN CARLOS I}

REY DE ESPANA

A todos los que la presente vieren y entendieren. Sabed: Que las Cortes Generales han aprobado y Yo vengo en sancionar la siguiente Ley.

\section{EXPOSICIÓN DE MOTINOS}

La promulgación de la Ley 27/1992, de 24 de noviembre, de Puertos del Estado y de la Marina Mercante, ha supuesto un cambio radical en lo referente a la estructura del practicaje, configurándolo como un servicio portuario cuya titularidad corresponde a las autoridades portuarias, al tiempo que se residencian en la Administración marítima competencias sobre su regulación por razones de seguridad marítima.

Los prácticos de puerto constituyen en la actualidad un conjunto de profesionales con suficientes sen̂as de identidad propias e intereses comunes cuyas legitimas aspiraciones de agrupamiento corporativo merecen ser atendidas por medio del correspondiente cauce legal. En este sentido, la Federación de Prácticos de Puerto de España ha solicitado la creación de un Colegio Oficial Nacional de Prácticos de Puerto adscrito al Ministerio de Fomento.

Por otra parte, no faltan razones de interés público que justifiquen la creación del Colegio Oficial de Prácticos de Puerto, ya que puede coadyuvar muy eficazmente a la mejor prestación del servicio de practicaje y servir como organo cualificado para participar en los procedimientos de elaboración de normas susceptibles de afectar a dicho servicio con carácter general.

En consecuencia, parece pertinente la creación de un Colegio Oficial de ámbito nacional que, sin perjuicio de las competencias que en esta materia tienen constitucionalmente reconocidas las Comunidades Autónomas, atienda los fines anteriormente referidos y venga a llenar un vacio largamente sentido en el ejercicio de la profesión.

\section{Articulo 1}

Se crea el Colegio Oficial Nacional de Prácticos de Puerto, que tendrá personalidad jurídica y plena capa cidad para el cumplimiento de sus fines con sujeción a la Ley.

\section{Artículo 2}

1. El Colegio Oficial Nacional de Prácticos de Puerto agrupará a todos los profesionales con nombramiento de práctico expedido por las autoridades competentes. Asimismo, integrará a aquellos prácticos que estén en posesión del título de Práctico de Número de Puerto y Práctico de Puerto de España y a todos los prácticos de atraques otorgados en concesión.

2. Para ejercer legalmente la profesión, será requisito indispensable estar incorporado al Colegio y cumplir los requisitos legales y estatutarios exigidos por la Ley de Colegios Profesionales y demás normativa que, como prácticos profesionales, les fuere de aplicación.

\section{Artículo 3}

El Colegio Oficial Nacional de Prácticos de Puerto se relacionará con la Administración General del Estado a través del Ministerio de Fomento $\mathrm{y}$, en lo sucesivo, con aquel que tenga atribuidas las competencias en la materia.

Dicho Ministerio ostentará la capacidad de convocar al Colegio Profesional para participar en los Consejos u organismos consultivos de la Administración que considere oportunos.

\section{Disposición transitoria primera.}

El Ministro de Fomento, a propuesta de la Federación de Prácticos de Puerto de España, aprobará los Estatutos provisionales del Colegio, que regularán, conforme a la Ley, los requisitos para la adquisición de la condición de colegiado que permita participar en las elecciones de los órganos de gobierno, el procedimiento y plazo de convocatoria de las mencionadas elecciones, así como la constitución de los órganos de gobierno.

\section{Disposición transitoria segunda.}

Constituidos los órganos de gobierno colegiales, según lo establecido en la disposición precedente, aquéllos remitirán al Ministerio de Fomento, en el plazo de seis meses, los Estatutos a que se refiere la legislación vigente sobre Colegios Profesionales. El citado Ministerio someterá a la aprobación del Gobierno los mencionados Estatutos. La citada aprobación dejará sin efecto dichos Estatutos provisionales.

\section{Disposición final primera.}

Se faculta al Ministro de Fomento para dictar las disposiciones necesarias para la ejecución de la presente Ley. 



\section{Apéndice B}

Convention for the Protection of Human Rights and Dignity of the Human Being with regard to the Application of Biology and Medicine: Convention on Human Rights and Biomedicine 



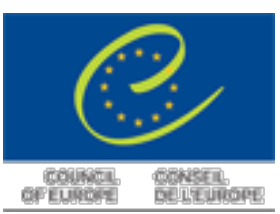

Convention for the Protection of Human Rights and Dignity of the Human Being with regard to the Application of Biology and Medicine: Convention on Human Rights and Biomedicine

Oviedo, 4.IV.1997

The Treaty of Lisbon amending the Treaty on European Union and the Treaty establishing the European Community entered into force on 1 December 2009. As a consequence, as from that date, any reference to the European Community shall be read as the European Union.

\section{Preamble}

The member States of the Council of Europe, the other States and the European Community, signatories hereto,

Bearing in mind the Universal Declaration of Human Rights proclaimed by the General Assembly of the United Nations on 10 December 1948;

Bearing in mind the Convention for the Protection of Human Rights and Fundamental Freedoms of 4 November 1950;

Bearing in mind the European Social Charter of 18 October 1961;

Bearing in mind the International Covenant on Civil and Political Rights and the International Covenant on Economic, Social and Cultural Rights of 16 December 1966;

Bearing in mind the Convention for the Protection of Individuals with regard to Automatic Processing of Personal Data of 28 January 1981;

Bearing also in mind the Convention on the Rights of the Child of 20 November 1989;

Considering that the aim of the Council of Europe is the achievement of a greater unity between its members and that one of the methods by which that aim is to be pursued is the maintenance and further realisation of human rights and fundamental freedoms;

Conscious of the accelerating developments in biology and medicine;

Convinced of the need to respect the human being both as an individual and as a member of the human species and recognising the importance of ensuring the dignity of the human being;

Conscious that the misuse of biology and medicine may lead to acts endangering human dignity;

Affirming that progress in biology and medicine should be used for the benefit of present and future generations;

Stressing the need for international co-operation so that all humanity may enjoy the benefits of biology and medicine;

Recognising the importance of promoting a public debate on the questions posed by the application of biology and medicine and the responses to be given thereto; 
Wishing to remind all members of society of their rights and responsibilities;

Taking account of the work of the Parliamentary Assembly in this field, including Recommendation 1160 (1991) on the preparation of a convention on bioethics;

Resolving to take such measures as are necessary to safeguard human dignity and the fundamental rights and freedoms of the individual with regard to the application of biology and medicine,

Have agreed as follows:

\section{Chapter I - General provisions}

\section{Article 1 - Purpose and object}

Parties to this Convention shall protect the dignity and identity of all human beings and guarantee everyone, without discrimination, respect for their integrity and other rights and fundamental freedoms with regard to the application of biology and medicine.

Each Party shall take in its internal law the necessary measures to give effect to the provisions of this Convention.

\section{Article 2 - Primacy of the human being}

The interests and welfare of the human being shall prevail over the sole interest of society or science.

\section{Article 3 - Equitable access to health care}

Parties, taking into account health needs and available resources, shall take appropriate measures with a view to providing, within their jurisdiction, equitable access to health care of appropriate quality.

\section{Article 4 - Professional standards}

Any intervention in the health field, including research, must be carried out in accordance with relevant professional obligations and standards.

\section{Chapter II - Consent}

\section{Article 5 - General rule}

An intervention in the health field may only be carried out after the person concerned has given free and informed consent to it.

This person shall beforehand be given appropriate information as to the purpose and nature of the intervention as well as on its consequences and risks.

The person concerned may freely withdraw consent at any time.

\section{Article 6 - Protection of persons not able to consent}

1. Subject to Articles 17 and 20 below, an intervention may only be carried out on a person who does not have the capacity to consent, for his or her direct benefit.

2. Where, according to law, a minor does not have the capacity to consent to an intervention, the intervention may only be carried out with the authorisation of his or her representative or an authority or a person or body provided for by law.

3. The opinion of the minor shall be taken into consideration as an increasingly determining factor in proportion to his or her age and degree of maturity.

4. Where, according to law, an adult does not have the capacity to consent to an intervention because of a mental disability, a disease or for similar reasons, the intervention may only be carried out with the authorisation of his or her representative or an authority or a person or body provided for by law.

5. The individual concerned shall as far as possible take part in the authorisation procedure.

6 . The representative, the authority, the person or the body mentioned in paragraphs 2 and 3 above shall be given, under the same conditions, the information referred to in Article 5. 
7. The authorisation referred to in paragraphs 2 and 3 above may be withdrawn at any time in the best interests of the person concerned.

\section{Article 7 - Protection of persons who have a mental disorder}

Subject to protective conditions prescribed by law, including supervisory, control and appeal procedures, a person who has a mental disorder of a serious nature may be subjected, without his or her consent, to an intervention aimed at treating his or her mental disorder only where, without such treatment, serious harm is likely to result to his or her health.

\section{Article 8 - Emergency situation}

When because of an emergency situation the appropriate consent cannot be obtained, any medically necessary intervention may be carried out immediately for the benefit of the health of the individual concerned.

\section{Article 9 - Previously expressed wishes}

The previously expressed wishes relating to a medical intervention by a patient who is not, at the time of the intervention, in a state to express his or her wishes shall be taken into account.

\section{Chapter III - Private life and right to information}

\section{Article 10 - Private life and right to information}

1. Everyone has the right to respect for private life in relation to information about his or her health.

2. Everyone is entitled to know any information collected about his or her health. However, the wishes of individuals not to be so informed shall be observed.

3. In exceptional cases, restrictions may be placed by law on the exercise of the rights contained in paragraph 2 in the interests of the patient.

\section{Chapter IV - Human genome}

\section{Article 11 - Non-discrimination}

Any form of discrimination against a person on grounds of his or her genetic heritage is prohibited.

\section{Article 12 - Predictive genetic tests}

Tests which are predictive of genetic diseases or which serve either to identify the subject as a carrier of a gene responsible for a disease or to detect a genetic predisposition or susceptibility to a disease may be performed only for health purposes or for scientific research linked to health purposes, and subject to appropriate genetic counselling.

\section{Article 13 - Interventions on the human genome}

An intervention seeking to modify the human genome may only be undertaken for preventive, diagnostic or therapeutic purposes and only if its aim is not to introduce any modification in the genome of any descendants.

\section{Article 14 - Non-selection of sex}

The use of techniques of medically assisted procreation shall not be allowed for the purpose of choosing a future child's sex, except where serious hereditary sex-related disease is to be avoided.

\section{Chapter V - Scientific research}

\section{Article 15 - General rule}

Scientific research in the field of biology and medicine shall be carried out freely, subject to the provisions of this Convention and the other legal provisions ensuring the protection of the human being. 


\section{Article 16 - Protection of persons undergoing research}

Research on a person may only be undertaken if all the following conditions are met:

a. there is no alternative of comparable effectiveness to research on humans;

b. the risks which may be incurred by that person are not disproportionate to the potential benefits of the research;

c. the research project has been approved by the competent body after independent examination of its scientific merit, including assessment of the importance of the aim of the research, and multidisciplinary review of its ethical acceptability;

d. the persons undergoing research have been informed of their rights and the safeguards prescribed by law for their protection;

f. the necessary consent as provided for under Article 5 has been given expressly,

specifically and is documented. Such consent may be freely withdrawn at any time.

\section{Article 17 - Protection of persons not able to consent to research}

1. Research on a person without the capacity to consent as stipulated in Article 5 may be undertaken only if all the following conditions are met:

a. the conditions laid down in Article 16, sub-paragraphs i to iv, are fulfilled;

b. the results of the research have the potential to produce real and direct benefit to his or her health;

c. research of comparable effectiveness cannot be carried out on individuals capable of giving consent;

d. the necessary authorisation provided for under Article 6 has been given specifically and

in writing; and

e. the person concerned does not object.

2. Exceptionally and under the protective conditions prescribed by law, where the research has not the potential to produce results of direct benefit to the health of the person concerned, such research may be authorised subject to the conditions laid down in paragraph 1 , sub-paragraphs $\mathrm{i}$, iii, iv and $\mathrm{v}$ above, and to the following additional conditions:

a. the research has the aim of contributing, through significant improvement in the scientific understanding of the individual's condition, disease or disorder, to the ultimate attainment of results capable of conferring benefit to the person concerned or to other persons in the same age category or afflicted with the same disease or disorder or having the same condition;

b. the research entails only minimal risk and minimal burden for the individual concerned.

\section{Article 18 - Research on embryos in vitro}

1. Where the law allows research on embryos in vitro, it shall ensure adequate protection of the embryo.

2. The creation of human embryos for research purposes is prohibited.

\section{Chapter VI - Organ and tissue removal from living donors for transplantation purposes}

\section{Article 19 - General rule}

1. Removal of organs or tissue from a living person for transplantation purposes may be carried out solely for the therapeutic benefit of the recipient and where there is no suitable organ or tissue available from a deceased person and no other alternative therapeutic method of comparable effectiveness.

2. The necessary consent as provided for under Article 5 must have been given expressly and specifically either in written form or before an official body.

\section{Article 20 - Protection of persons not able to consent to organ removal}

1. No organ or tissue removal may be carried out on a person who does not have the capacity to consent under Article 5.

2. Exceptionally and under the protective conditions prescribed by law, the removal of regenerative tissue from a person who does not have the capacity to consent may be authorised provided the following conditions are met: 


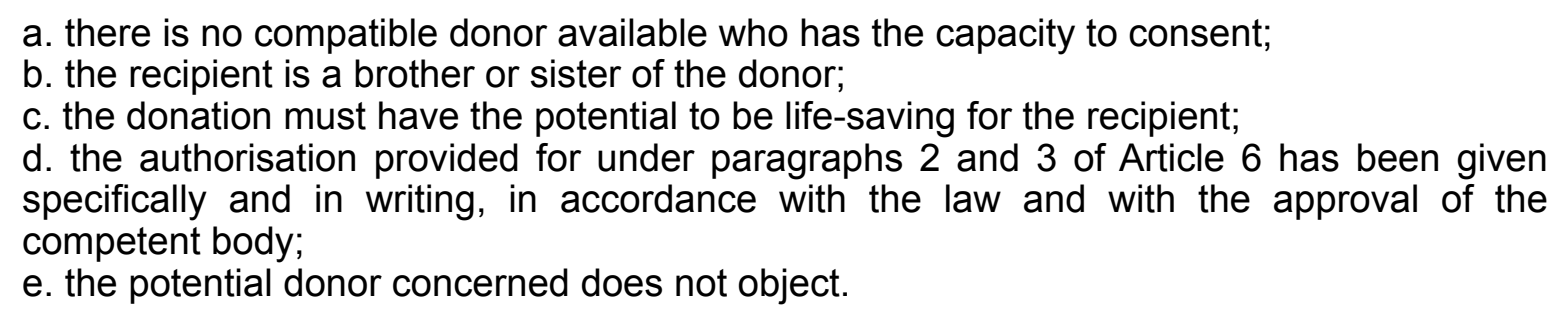

\section{Chapter VII - Prohibition of financial gain and disposal of a part of the human body}

\section{Article 21 - Prohibition of financial gain}

The human body and its parts shall not, as such, give rise to financial gain.

\section{Article 22 - Disposal of a removed part of the human body}

When in the course of an intervention any part of a human body is removed, it may be stored and used for a purpose other than that for which it was removed, only if this is done in conformity with appropriate information and consent procedures.

\section{Chapter VIII - Infringements of the provisions of the Convention}

\section{Article 23 - Infringement of the rights or principles}

The Parties shall provide appropriate judicial protection to prevent or to put a stop to an unlawful infringement of the rights and principles set forth in this Convention at short notice.

\section{Article 24 - Compensation for undue damage}

The person who has suffered undue damage resulting from an intervention is entitled to fair compensation according to the conditions and procedures prescribed by law.

\section{Article 25 - Sanctions}

Parties shall provide for appropriate sanctions to be applied in the event of infringement of the provisions contained in this Convention.

\section{Chapter IX - Relation between this Convention and other provisions}

\section{Article 26 - Restrictions on the exercise of the rights}

1. No restrictions shall be placed on the exercise of the rights and protective provisions contained in this Convention other than such as are prescribed by law and are necessary in a democratic society in the interest of public safety, for the prevention of crime, for the protection of public health or for the protection of the rights and freedoms of others.

2 . The restrictions contemplated in the preceding paragraph may not be placed on Articles $11,13,14,16,17,19,20$ and 21.

\section{Article 27 - Wider protection}

None of the provisions of this Convention shall be interpreted as limiting or otherwise affecting the possibility for a Party to grant a wider measure of protection with regard to the application of biology and medicine than is stipulated in this Convention.

\section{Chapter X - Public debate}

\section{Article 28 - Public debate}

Parties to this Convention shall see to it that the fundamental questions raised by the developments of biology and medicine are the subject of appropriate public discussion in the light, in particular, of relevant medical, social, economic, ethical and legal implications, and that their possible application is made the subject of appropriate consultation. 


\section{Chapter XI - Interpretation and follow-up of the Convention}

\section{Article 29 - Interpretation of the Convention}

The European Court of Human Rights may give, without direct reference to any specific proceedings pending in a court, advisory opinions on legal questions concerning the interpretation of the present Convention at the request of:

- the Government of a Party, after having informed the other Parties;

- the Committee set up by Article 32, with membership restricted to the Representatives of the Parties to this Convention, by a decision adopted by a two-thirds majority of votes cast.

\section{Article 30 - Reports on the application of the Convention}

On receipt of a request from the Secretary General of the Council of Europe any Party shall furnish an explanation of the manner in which its internal law ensures the effective implementation of any of the provisions of the Convention.

\section{Chapter XII - Protocols}

\section{Article 31 - Protocols}

Protocols may be concluded in pursuance of Article 32, with a view to developing, in specific fields, the principles contained in this Convention.

The Protocols shall be open for signature by Signatories of the Convention. They shall be subject to ratification, acceptance or approval. A Signatory may not ratify, accept or approve Protocols without previously or simultaneously ratifying accepting or approving the Convention.

\section{Chapter XIII - Amendments to the Convention}

\section{Article 32 - Amendments to the Convention}

1. The tasks assigned to "the Committee" in the present article and in Article 29 shall be carried out by the Steering Committee on Bioethics (CDBI), or by any other committee designated to do so by the Committee of Ministers.

2. Without prejudice to the specific provisions of Article 29, each member State of the Council of Europe, as well as each Party to the present Convention which is not a member of the Council of Europe, may be represented and have one vote in the Committee when the Committee carries out the tasks assigned to it by the present Convention.

3. Any State referred to in Article 33 or invited to accede to the Convention in accordance with the provisions of Article 34 which is not Party to this Convention may be represented on the Committee by an observer. If the European Community is not a Party it may be represented on the Committee by an observer.

4. In order to monitor scientific developments, the present Convention shall be examined within the Committee no later than five years from its entry into force and thereafter at such intervals as the Committee may determine.

5. Any proposal for an amendment to this Convention, and any proposal for a Protocol or for an amendment to a Protocol, presented by a Party, the Committee or the Committee of Ministers shall be communicated to the Secretary General of the Council of Europe and forwarded by him to the member

States of the Council of Europe, to the European Community, to any Signatory, to any Party, to any State invited to sign this Convention in accordance with the provisions of Article 33 and to any State invited to accede to it in accordance with the provisions of Article 34.

6 . The Committee shall examine the proposal not earlier than two months after it has been forwarded by the Secretary General in accordance with paragraph 5 . The Committee shall submit the text adopted by a two-thirds majority of the votes cast to the Committee of Ministers for approval. After its approval, this text shall be forwarded to the Parties for ratification, acceptance or approval.

7. Any amendment shall enter into force, in respect of those Parties which have accepted it, on the first day of the month following the expiration of a period of one month after the date 
on which five Parties, including at least four member States of the Council of Europe, have informed the Secretary General that they have accepted it.

8. In respect of any Party which subsequently accepts it, the amendment shall enter into force on the first day of the month following the expiration of a period of one month after the date on which that Party has informed the Secretary General of its acceptance.

\section{Chapter XIV - Final clauses}

\section{Article 33 - Signature, ratification and entry into force}

1. This Convention shall be open for signature by the member States of the Council of Europe, the non-member States which have participated in its elaboration and by the European Community.

2. This Convention is subject to ratification, acceptance or approval. Instruments of ratification, acceptance or approval shall be deposited with the Secretary General of the Council of Europe.

3. This Convention shall enter into force on the first day of the month following the expiration of a period of three months after the date on which five States, including at least four member States of the Council of Europe, have expressed their consent to be bound by the Convention in accordance with the provisions of paragraph 2 of the present article.

4. In respect of any Signatory which subsequently expresses its consent to be bound by it, the Convention shall enter into force on the first day of the month following the expiration of a period of three months after the date of the deposit of its instrument of ratification, acceptance or approval.

\section{Article 34 - Non-member States}

1. After the entry into force of this Convention, the Committee of Ministers of the Council of Europe may, after consultation of the Parties, invite any non-member State of the Council of Europe to accede to this Convention by a decision taken by the majority provided for in Article 20, paragraph d, of the Statute of the Council of Europe, and by the unanimous vote of the representatives of the Contracting States entitled to sit on the Committee of Ministers. 2. In respect of any acceding State, the Convention shall enter into force on the first day of the month following the expiration of a period of three months after the date of deposit of the instrument of accession with the Secretary General of the Council of Europe.

\section{Article 35 - Territories}

1. Any Signatory may, at the time of signature or when depositing its instrument of ratification, acceptance or approval, specify the territory or territories to which this Convention shall apply. Any other State may formulate the same declaration when depositing its instrument of accession.

2. Any Party may, at any later date, by a declaration addressed to the Secretary General of the Council of Europe, extend the application of this Convention to any other territory specified in the declaration and for whose international relations it is responsible or on whose behalf it is authorised to give undertakings. In respect of such territory the Convention shall enter into force on the first day of the month following the expiration of a period of three months after the date of receipt of such declaration by the Secretary General.

3. Any declaration made under the two preceding paragraphs may, in respect of any territory specified in such declaration, be withdrawn by a notification addressed to the Secretary General. The withdrawal shall become effective on the first day of the month following the expiration of a period of three months after the date of receipt of such notification by the Secretary General.

\section{Article 36 - Reservations}

1. Any State and the European Community may, when signing this Convention or when depositing the instrument of ratification, acceptance, approval or accession, make a reservation in respect of any particular provision of the Convention to the extent that any law then in force in its territory is not in conformity with the provision. Reservations of a general character shall not be permitted under this article. 
2. Any reservation made under this article shall contain a brief statement of the relevant law. 3. Any Party which extends the application of this Convention to a territory mentioned in the declaration referred to in Article 35, paragraph 2, may, in respect of the territory concerned, make a reservation in accordance with the provisions of the preceding paragraphs.

4. Any Party which has made the reservation mentioned in this article may withdraw it by means of a declaration addressed to the Secretary General of the Council of Europe. The withdrawal shall become effective on the first day of the month following the expiration of a period of one month after the date of its receipt by the Secretary General.

\section{Article 37 - Denunciation}

1. Any Party may at any time denounce this Convention by means of a notification addressed to the Secretary General of the Council of Europe.

2. Such denunciation shall become effective on the first day of the month following the expiration of a period of three months after the date of receipt of the notification by the Secretary General.

\section{Article 38 - Notifications}

The Secretary General of the Council of Europe shall notify the member States of the Council, the European Community, any Signatory, any Party and any other State which has been invited to accede to this Convention of:

a. any signature;

b. the deposit of any instrument of ratification, acceptance, approval or accession;

c. any date of entry into force of this Convention in accordance with Articles 33 or 34;

d. any amendment or Protocol adopted in accordance with Article 32, and the date on which such an amendment or Protocol enters into force;

e. any declaration made under the provisions of Article 35;

f. any reservation and withdrawal of reservation made in pursuance of the provisions of Article 36;

g. any other act, notification or communication relating to this Convention.

In witness whereof the undersigned, being duly authorised thereto, have signed this Convention.

Done at Oviedo (Asturias), this 4th day of April 1997, in English and French, both texts being equally authentic, in a single copy which shall be deposited in the archives of the Council of Europe. The Secretary General of the Council of Europe shall transmit certified copies to each member State of the Council of Europe, to the European Community, to the nonmember States which have participated in the elaboration of this Convention, and to any State invited to accede to this Convention. 


\section{Apéndice $\mathrm{C}$}

Recommendation CM/Rec(2009)11 of the Committee of Ministers to member states on principles concerning continuing powers of attorney and advance directives for incapacity. 



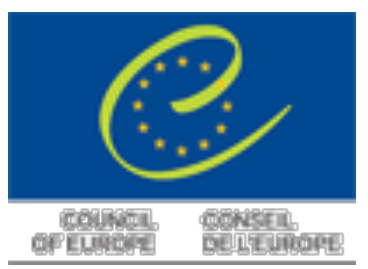

Recommendation $\mathrm{CM} / \operatorname{Rec}(2009) 11$ of the Committee of Ministers to member states on principles concerning continuing powers of attorney and advance directives for incapacity

(Adopted by the Committee of Ministers on 9 December 2009 at the 1073rd meeting of the Ministers'Deputies)

The Committee of Ministers, under the terms of Article 15.b of the Statute of the Council of Europe,

Considering that the aim of the Council of Europe is to achieve a greater unity between its member states, in particular by promoting adoption of common rules in legal matters;

Noting that demographic changes have resulted in an increasing number of elderly people who have become incapable of protecting their interests by reason of an impairment or insufficiency of their personal faculties;

Noting that there continue to be other circumstances in which adults become incapacitated;

Having regard to relevant instruments of the Council of Europe, including the Convention for the Protection of Human Rights and Fundamental Freedoms (ETS No. 5, 1950), the Convention on Human Rights and Biomedicine (Oviedo Convention, ETS No. 164, 1997) and Recommendation $\operatorname{Rec}(2006) 5$ of the Committee of Ministers to member states on the Council of Europe Action Plan to promote the rights and full participation of people with disabilities in society: improving the quality of life of people with disabilities in Europe 2006-2015;

Having regard to the Hague Convention on the International Protection of Adults (2000) and the United Nations Convention on the Rights of Persons with Disabilities (2006);

Bearing in mind the relevant case law of the European Court of Human Rights;

Agreeing that Recommendation No. R (99) 4 of the Committee of Ministers to member states on principles concerning the legal protection of incapable adults is a valuable and up-to-date international instrument containing detailed guidance and general advice on legal rules dealing with measures of protection of such adults;

Noting that the above recommendation and the legislation of the member states concerning adults with incapacity strongly promotes self-determination and autonomy;

Considering that self-determination is essential in respecting the human rights and dignity of each human being;

Noting that in some member states continuing powers of attorney are a preferred alternative to court decisions on representation;

Noting that legislation on continuing powers of attorney and advance directives has recently been passed or proposed in some member states; 
Noting that in legal systems where continuing powers of attorney and advance directives are available, adults of all ages increasingly make use of them;

Recognising that there are considerable disparities between the legislation of member states as regards these issues;

Building upon the principles of subsidiarity and necessity contained in Recommendation No. $R$ (99) 4 and supplementing it with principles on self-determination,

Recommends that governments of member states promote self-determination for capable adults by introducing legislation on continuing powers of attorney and advance directives or by amending existing legislation with a view to implementing the principles contained in the appendix to this recommendation.

\section{Appendix to Recommendation CM/Rec(2009)11}

\section{Part I - Scope of application}

\section{Principle 1 - Promotion of self-determination}

1. States should promote self-determination for capable adults in the event of their future incapacity, by means of continuing powers of attorney and advance directives.

2. In accordance with the principles of self-determination and subsidiarity, states should consider giving those methods priority over other measures of protection.

\section{Principle 2 - Definition of terms used in the present recommendation}

1. A "continuing power of attorney" is a mandate given by a capable adult with the purpose that it shall remain in force, or enter into force, in the event of the granter's incapacity.

2. The "granter" is the person giving the continuing power of attorney. The person mandated to act on behalf of the granter is referred to as the "attorney".

3. "Advance directives" are instructions given or wishes made by a capable adult concerning issues that may arise in the event of his or her incapacity.

\section{Part II - Continuing powers of attorney}

\section{Principle 3 - Content}

States should consider whether it should be possible for a continuing power of attorney to cover economic and financial matters, as well as health, welfare and other personal matters, and whether some particular matters should be excluded.

\section{Principle 4 - Appointment of attorney}

1. The granter may appoint as attorney any person whom he or she considers to be appropriate.

2. The granter may appoint more than one attorney and may appoint them to act jointly, concurrently, separately, or as substitutes.

3. States may consider such restrictions as are deemed necessary for the protection of the granter.

\section{Principle 5 - Form}

1. A continuing power of attorney shall be in writing.

2. Except in states where such is the general rule, the document shall explicitly state that it shall enter into force or remain in force in the event of the granter's incapacity.

3. States should consider what other provisions and mechanisms may be required to ensure the validity of the document. 


\section{Principle 6 - Revocation}

A capable granter shall have the possibility to revoke the continuing power of attorney at any time. Principle 5, paragraph 3 , is applicable.

\section{Principle 7 - Entry into force}

1. States should regulate the manner of entry into force of the continuing power of attorney in the event of the granter's incapacity.

2. States should consider how incapacity should be determined and what evidence should be required.

\section{Principle 8 - Certification, registration and notification}

States should consider introducing systems of certification, registration and/or notification when the continuing power of attorney is granted, revoked, enters into force or terminates.

\section{Principle 9 - Preservation of capacity}

The entry into force of a continuing power of attorney shall not as such affect the legal capacity of the granter.

\section{Principle 10 - Role of the attorney}

1. The attorney acts in accordance with the continuing power of attorney and in the interests of the granter.

2. The attorney, as far as possible, informs and consults the granter on an ongoing basis. The attorney, as far as possible, ascertains and takes account of the past and present wishes and feelings of the granter and gives them due respect.

3. The granter's economic and financial matters are, as far as possible, kept separate from the attorney's own.

4. The attorney keeps sufficient records in order to demonstrate the proper exercise of his or her mandate.

\section{Principle 11 - Conflict of interest}

States should consider regulating conflicts of the granter's and the attorney's interests.

\section{Principle 12 - Supervision}

1. The granter may appoint a third party to supervise the attorney.

2. States should consider introducing a system of supervision under which a competent authority is empowered to investigate. When an attorney is not acting in accordance with the continuing power of attorney or in the interests of the granter, the competent authority should have the power to intervene. Such intervention might include terminating the continuing power of attorney in part or in whole. The competent authority should be able to act on request or on its own motion.

\section{Principle 13 - Termination}

1. States should consider under which circumstances a continuing power of attorney ceases to have effect.

2. When a continuing power of attorney ceases to have effect in part or in whole, the competent authority should consider which measures of protection might be taken.

\section{Part III - Advance directives}

\section{Principle 14 - Content}

Advance directives may apply to health, welfare and other personal matters, to economic and financial matters, and to the choice of a guardian, should one be appointed.

\section{Principle 15 - Effect}

1. States should decide to what extent advance directives should have binding effect. 
Advance directives which do not have binding effect should be treated as statements of wishes to be given due respect.

2. States should address the issue of situations that arise in the event of a substantial change in circumstances.

\section{Principle 16 - Form}

1. States should consider whether advance directives or certain types of advance directives should be made or recorded in writing if intended to have binding effect.

2. States should consider what other provisions and mechanisms may be required to ensure the validity and effectiveness of those advance directives.

\section{Principle 17 - Revocation}

An advance directive shall be revocable at any time and without any formalities. 


\section{Apéndice D}

Protecting human rights and dignity by taking into account previously expressed wishes of patients Resolution 1859 (2012). 



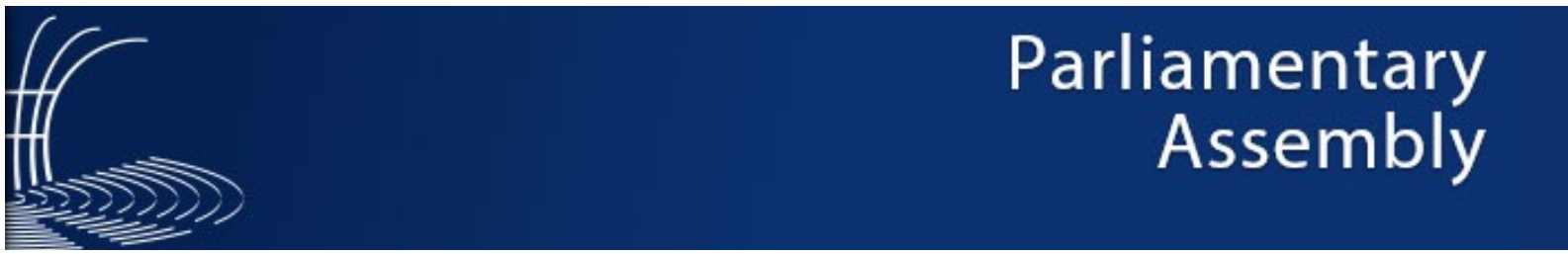

\section{Parliamentary Assembly Assemblée parlementaire}

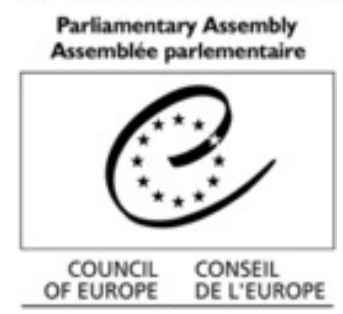

Provisional edition

\section{Protecting human rights and dignity by taking into account previously expressed wishes of patients \\ Resolution $1859(2012)^{1}$}

1. There is a general consensus based on Article 8 of the European Convention on Human Rights (ETS No. 5) on the right to privacy that there can be no intervention affecting a person without his or her consent. From this human right flow the principles of personal autonomy and the principle of consent. These principles hold that a capable adult patient must not be manipulated and that his or her will, when clearly expressed, must prevail even if it signifies refusal of treatment: no-one can be compelled to undergo a medical treatment against his or her will.

2. The Council of Europe has included this principle in the Convention for the protection of human rights and dignity of the human being with regard to the application of biology and medicine: Convention on human rights and biomedicine (Oviedo Convention, ETS No. 164), which legally binds the majority of member states. The convention also covers the situation in which a patient is no longer able to express his or her will, by stipulating that the previously expressed wishes relating to a medical intervention by a patient who is not, at the time of the intervention, in a state to express his or her wishes "shall be taken into account".

3. The ways in which these wishes can be formalised are advance directives, living wills or continuing powers of attorney. In Recommendation CM/ $\operatorname{Rec}(2009) 11$ on principles concerning continuing powers of attorney and advance directives for incapacity, the Committee of Ministers recommended that member states promote these, and laid down a number of principles to guide member states in regulating them.

4. However, on the ground, the situation in Europe is very diverse, ranging from no legislation whatsoever on advance directives, to specific legislation which 
confers binding effect on them. Even where specific legislation does exist, it is not always fully implemented. Thus, today, only a tiny minority of the Council of Europe's 800 million citizens actually have advance directives, living wills and/or continuing powers of attorney - making it difficult, if not impossible, to take their previously expressed wishes into account, and thus effectively protect their human rights and dignity.

5. This resolution is not intended to deal with the issues of euthanasia or assisted suicide. Euthanasia, in the sense of the intentional killing by act or omission of a dependent human being for his or her alleged benefit, must always be prohibited. This resolution thus limits itself to the question of advance directives, living wills and continuing powers of attorney.

6. The Parliamentary Assembly considers it essential that rapid progress be made in this area by member states to ensure that people's human rights and dignity are guaranteed across the whole continent. It thus recommends that member states:

6.1. sign, ratify and fully implement the Oviedo Convention, if they have not already done so;

6.2. apply Committee of Ministers Recommendation CM/Rec(2009) 11 on principles concerning continuing powers of attorney and advance directives for incapacity;

6.3. review, if need be, their relevant legislation with a view to possibly improving it:

6.3.1. for countries with no specific legislation on the matter - by putting into place a "road map" towards such legislation promoting advance directives, living wills and/or continuing powers of attorney, on the basis of the Oviedo Convention and Recommendation CM/ $\operatorname{Rec}(2009) 11$, involving consultation of all stakeholders before the adoption of legislation in parliament, and foreseeing an information and awareness-raising campaign for the general public, as well as for the medical and legal professions after its adoption;

6.3.2. for countries with specific legislation on the matter - by ensuring that the relevant Council of Europe standards are met by this legislation, and that the general public, as well as the medical and legal professions, are sufficiently aware of it and implement it in practice.

7. The Assembly, recalling its Recommendation 1418 (1999) on the protection of the human rights and dignity of the terminally ill and the dying, recommends that national parliaments, when legislating in this field, respect the following principles, in addition to those enshrined in the Oviedo Convention and Committee of Ministers Recommendation CM/Rec(2009)11:

7.1. self-determination for capable adults in the event of their future incapacity, by means of advance directives, living wills and/or continuing 
powers of attorney, should be promoted and given priority over other measures of protection;

7.2. advance directives, living wills and/or continuing powers of attorney should, in principle, be made in writing and be fully taken into account when properly validated and registered (ideally in state registries);

7.3. there should be an option to divide the function of representing the person between an attorney for property, and a separate person for health and welfare; provisions for the possibility of a public appointment should also be made in cases where the individual has made no appointment him or herself, where this is in the best interest of the individual;

7.4. prior instructions contained in advance directives and/or living wills which are against the law, or good practice, or those which do not correspond to the actual situation that the interested party anticipated at the time of signing the document, should not be applied;

7.5. advance directives, living wills and/or continuing powers of attorney should be accessible to all; thus, complicated forms or expensive formalities should be avoided;

7.6. capable adults should be encouraged to review at regular intervals (for example, once a year) the advance directives, living wills and/or continuing powers of attorney they have made, and should be able to revoke and/or change them at any time;

7.7. a system of supervision to fight abuse should be established under which a competent authority is empowered to investigate, and, if necessary, intervene, in particular in cases in which an attorney is not acting in accordance with the continuing power of attorney or in the interests of the granter;

7.8. surrogate decisions that rely on general value judgements present in society should not be admissible and, in case of doubt, the decision must always be pro-life and the prolongation of life.

${ }^{1}$ Assembly debate on 25 January 2012 (6th Sitting) (see Doc. 12804, report of the Committee on Social Affairs, Health and Sustainable Development, rapporteur: Mr Xuclà i Costa). Text adopted by the Assembly on 25 January 2012 (6th Sitting).

See also Recommendation 1993 (2012). 



\section{Apéndice E}

Protecting human rights and dignity by taking into account previously expressed wishes of patients Recommendation 1993 (2012). 



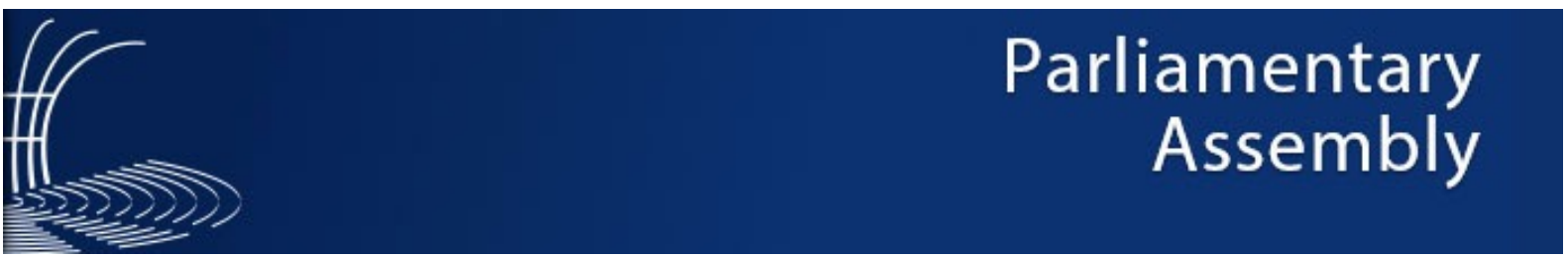

\section{Parliamentary Assembly \\ Assemblée parlementaire}

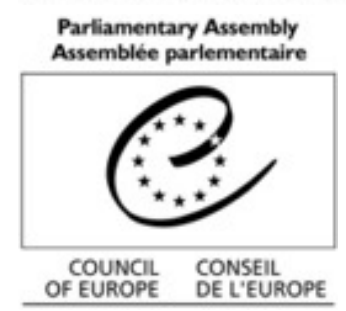

Provisional edition

\section{Protecting human rights and dignity by taking into account previously expressed wishes of patients}

Recommendation $1993(2012)^{1}$

1. The Parliamentary Assembly, referring to its Resolution 1859 (2012) on protecting human rights and dignity by taking into account previously expressed wishes of patients, commends the Committee of Ministers for its foresighted and timely adoption of both the Convention for the Protection of Human Rights and Dignity of the Human Being with regard to the Application of Biology and Medicine: Convention on Human Rights and Biomedicine (Oviedo Convention, ETS No. 164) and Recommendation CM/Rec(2009)11 on principles concerning continuing powers of attorney and advance directives for incapacity.

2. The Assembly believes it essential that rapid progress be made by member states in adhering to and implementing the standards enshrined in these texts. It thus recommends that the Committee of Ministers bring Parliamentary Assembly Resolution 1859 (2012) to the attention of member states, with a request for implementation.

3. The Assembly further believes that Council of Europe standards in this field should be developed further. It thus recommends that the Committee of Ministers instruct its relevant steering committees (in particular, the Steering Committee on Bioethics), to continue developing such standards and to promote and monitor their implementation based on the principles enshrined in Committee of Ministers Recommendation CM/Rec(2009)11 and those developed in paragraph 7 of Assembly Resolution 1859 (2012).

${ }^{1}$ Assembly debate on 25 January 2012 (6th Sitting) (see Doc. 12804, report of the Committee on Social Affairs, Health and Sustainable Development, rapporteur: Mr Xuclà i Costa). Text adopted by the Assembly on 25 January 2012 (6th Sitting). 




"Serán tomados en consideración los deseos expresados anteriormente con respecto a una intervención médica por un paciente que, en el momento de la intervención, no se encuentre en situación de expresar su voluntad" 